1 Host ecology regulates interspecies recombination in bacteria of the genus

\title{
2 Campylobacter
}

3

4 Evangelos Mourkas ${ }^{1}$, Koji Yahara ${ }^{2}$, Sion C. Bayliss ${ }^{1}$, Jessica K. Calland ${ }^{1}$, Håkan Johansson ${ }^{3}$, 5 Leonardos Mageiros ${ }^{1}$, Zilia Y. Muñoz-Ramirez ${ }^{4}$, Grant Futcher ${ }^{1}$, Guillaume Méric ${ }^{1 \#}$,

6 Matthew D. Hitchings ${ }^{5}$, Santiago Sandoval-Motta ${ }^{4}$, Javier Torres ${ }^{4}$, Keith A. Jolley ${ }^{6}$, Martin

7 C. J. Maiden ${ }^{6}$, Patrik Ellström ${ }^{7}$, Jonas Waldenström ${ }^{3}$, Ben Pascoe ${ }^{1}$, Samuel K. Sheppard ${ }^{1,6 * *}$ 8

$9{ }^{1}$ The Milner Centre for Evolution, Department of Biology and Biochemistry, University of Bath, Bath BA2

10 7AY, UK; ${ }^{2}$ Antimicrobial Resistance Research Center, National Institute of Infectious Diseases, Tokyo, 162-

11 8640, Japan; ${ }^{3}$ Centre for Ecology and Evolution in Microbial Model Systems, Linnaeus University, Kalmar, 391

12 82, Sweden; ${ }^{4}$ Unidad de Investigacion en Enfermedades Infecciosas, UMAE Pediatria, Instituto Mexicano del

13 Seguro Social; ${ }^{5}$ Swansea University Medical School, Swansea University, Singleton Park, Swansea, SA2 8PP,

14 UK; ${ }^{6}$ Department of Zoology, University of Oxford, South Parks Road, Oxford, OX1 3PS, UK; ${ }^{7}$ Department of 15 Medical Sciences, Zoonosis Science Centre, Uppsala University, Uppsala, Sweden;

*Corresponding authors: Samuel K. Sheppard; s.k.sheppard@bath.ac.uk

"Present address: Cambridge Baker Systems Genomics Initiative, Baker Heart and Diabetes Institute, 75 Commercial Rd, Melbourne 3004, Victoria, Australia; Department of Infectious Diseases, Central Clinical School, Monash University, Melbourne, Victoria 3004, Australia.

Keywords: Campylobacter, genus, species, niche, adaptation, host, evolution.

26 Running title: Comparative genomics of the Campylobacter genus 


\section{Abstract}

29 Horizontal gene transfer (HGT) can allow traits that have evolved in one bacterial species to 30 transfer to another. This has potential to rapidly promote new adaptive trajectories such as 31 zoonotic transfer or antimicrobial resistance. However, for this to occur requires gaps to align 32 in barriers to recombination within a given time frame. Chief among these barriers is the 33 physical separation of species with distinct ecologies in separate niches. Within the genus 34 Campylobacter there are species with divergent ecologies, from rarely isolated single host specialists to multi-host generalist species that are among the most common global causes of human bacterial gastroenteritis. Here, by characterising these contrasting ecologies, we can quantify HGT among sympatric and allopatric species in natural populations. Analysing recipient and donor population ancestry among genomes from 30 Campylobacter species we show that cohabitation in the same host can lead to a 6-fold increase in HGT between species.

40 This accounts for up to $30 \%$ of all SNPs within a given species and identifies highly 41 recombinogenic genes with functions including host adaptation and antimicrobial resistance. 42 As described in some animal and plant species, ecological factors are a major evolutionary 43 force for speciation in bacteria and changes to the host landscape can promote partial 44 convergence of distinct species through HGT. 


\section{Introduction}

It is well established that bacteria do not conform to a strict clonal model of reproduction but engage in regular horizontal gene transfer (HGT) [1]. This lateral exchange of DNA can confer new functionality on recipient genomes, potentially promoting novel adaptive trajectories such as colonization of a new host or the emergence of pathogenicity [2]. In some cases, gene flow can occur at such magnitude, even between different species $[3,4]$, that one may question why disparate lineages do not merge and why distinct bacterial species exist at all [5]. An answer to this lies in considering the successive processes that enable genes from one strain to establish in an entirely new genetic background.

The probability of HGT is governed by the interaction of multiple factors, including exposure to DNA, the susceptibility of the recipient genome to DNA uptake, and the impact of recombined DNA on the recipient strain. These factors can be broadly defined in three functional phases and HGT can only occur when gaps align in each successive ecological, mechanistic and adaptive barriers within a given time frame (Figure 1). In the first phase, the quantity of DNA available to recipient strains is determined by ecological factors such as the distribution, prevalence and interactions of donor and recipient bacteria, as well as the capacity for free DNA to be disseminated among species/strains. In the second phase, there are mechanistic barriers to HGT imposed by the homology dependence of recombination [6] or other factors promoting DNA specificity - such as restriction-modification, CRISPR interference or antiphage systems [7-11] - that can act as a defence against the uptake of foreign DNA (mechanistic barriers) $[12,13]$. Finally, the effect that HGT has on the fitness of the recipient cell in a given selective environment (adaptive barrier) will determine if the recombinant genotype survives for subsequent generations $[2,14]$.

Understanding how ecology maintains, and potentially confines, distinct strains and species has become increasingly important in the light of global challenges such as the emergence and spread of zoonotic pathogens [15]. A typical approach to investigating this is to consider spillover of particular strains or clones from one host to another (clonal transmission). This is an important phenomenon and may be influenced by anthropogenic change, such as habitat encroachment or agricultural intensification [16]. However, in many cases, important phenotypes, including antimicrobial resistance (AMR) [17-19], can be conferred by relatively few genes. In such cases, it may be important to consider how cohabiting strains and species can potentially draw genes from a common pangenome pool [20-23] and how 
genes, rather than clones, can transition between segregated populations (gene pool transmission). To investigate the impact of ecological segregation (ecological barriers) on this gene pool transmission, in natural populations, requires quantification of HGT among sympatric and allopatric bacteria.

Species within the genus Campylobacter are an ideal subject for considering how ecology influences the maintenance of genetically distinct species for several reasons. First, Campylobacter are a common component of the commensal gut microbiota of reptiles [24, 25], birds [26, 27] and mammals [28] but, being microaerophilic, do not survive well outside of the host. This creates island populations that have some degree of ecological isolation. Second, because at least 12 species have been identified as human pathogens [29] and $C$. jejuni and C. coli among the most common global causes of bacterial gastroenteritis [30], large numbers of isolate genomes have been sequenced from potential reservoir hosts as part of public health source tracking programs $[31,32]$. Third, within the genus there are species and strains that inhabit one or multiple hosts (ecological specialists and generalists $[16,26$, 33-37]). As a single host can simultaneously carry multiple lineages [38], possibly occupying different sub-niches within that host [39], there is potential to compare allopatric and sympatric populations. Finally, high magnitude interspecies admixture (introgression) between $C$. jejuni and $C$. coli isolated from agricultural animals suggests that host ecology plays a role in the maintenance of species [40-43].

Here, we quantify HGT among 600 genomes from 30 Campylobacter species using a 'chromosome painting' approach [44-46] to characterize shared ancestry among donor and recipient populations. Specifically, we investigate the role of ecological barriers to interspecies gene flow. By identifying recombining species pairs within the same and different hosts we can describe interactions where co-localization enhances gene flow, quantify the impact of ecological barriers in these populations and distinguish highly

108 recombinogenic genes that are found in multiple genetic backgrounds. This provides information about the evolutionary forces that gave rise to species and the extent to which ecological barriers maintain them as discrete entities.

\section{Results}

\section{Host restricted and host generalist Campylobacter species}


114 Isolate genomes were taken from publicly available databases to represent diversity within 115 the genus Campylobacter, including environmental isolates from the closely related 116 Arcobacter and Sulfurospirillum species to provide phylogenetic context within the 117 Campylobacteraceae family (Figure 2a-figure supplement 1). In total, there were 631 118 isolates from 30 different Campylobacter species (Figure 2a) and 64 different sources, 119 isolated from 31 different countries between 1964 and 2016 (Supplementary File 1). Among 120 the isolates, 361 were $C$. jejuni and $C$. coli and could be classified according to 31 Clonal 121 Complexes (CCs) based upon sharing four or more alleles at seven housekeeping genes defined by multi-locus sequence typing (MLST) (Supplementary File 1) [47] and were representative of known diversity in both species [16,33]. The obligate human commensal and pathogen $C$. concisus ( $\mathrm{n}=106$ isolates), comprised 2 genomospecies (GSI, $\mathrm{n}=32$ and GSII, n=74), as previously described [48] (Supplementary File 1). The collection also included more than 52 C. fetus isolate genomes, including 3 subspecies: C. fetus subsp. fetus $(\mathrm{n}=8), C$. fetus subsp. venerealis $(\mathrm{n}=23)$ and $C$. fetus subsps. testudinum $(\mathrm{n}=21)$ (Supplementary File 1) [49]. Two clades were observed in C. lari (Figure 2a-figure supplement 2) which could correspond to previously described subspecies based on $16 \mathrm{~S}$ rRNA sequencing [50].

A maximum-likelihood phylogeny of the Campylobacter genus was reconstructed on a geneby-gene concatenated sequence alignment of 820 gene families shared by $>95 \%$ of all isolates, with a core genome of 903,753 base pairs (Figure 2a). The phylogeny included species which appear to be restricted to one host or environment, including $C$. iguanorium [51] and C. geochelonis [52] (reptiles), C. lanienae [53] (pigs), C. hepaticus [54] (chicken liver), C. lari group [55] (marine birds and environment) and C. pinnipediorum [56] (seals) species, most of which were discovered recently (Figure 2a-figure supplement 3 ). There was no evidence that phylogeography was reflected in the observed population structure for

140 Campylobacter isolates from multiple hosts and countries. (Figure 2-figure supplement 4).

141 This is unsurprising as it is well known that host associated genetic variation transcends phylogeographic structuring in Campylobacter [35]. While some low-level local gene flow can be identified within a given country [57], this is vastly outweighed by recombination

144 within particular host niches [36], particularly in small isolate collections such as those for some of the species in this study. 
147 Host restricted species had lower diversity possibly linked to low sample numbers, with $C$.

148 hepaticus having the lowest diversity (Figure 2-figure supplement 2) with 8/10 genomes 149 associated with isolates from the same outbreak [54]. For other species there was evidence of 150 a broad host range (ecological generalists) (Figure 2b). For example, highly structured $C$.

151 jejuni and $C$. coli isolates were sampled from seven and six host sources respectively (Figure 152 2-figure supplements 2-3, Supplementary File 1). For C. fetus there was distinct separation 153 between mammal-associated $C$. fetus subsp fetus and $C$. fetus subsp venerealis and reptileassociated C. fetus subsp testudinum (Figure 2-figure supplement 2) as previously described [49]. Unsurprisingly, a large proportion of the isolates in this study were from humans, likely reflecting intensive sampling. $C$. jejuni $(27.52 \%$; $n=60 / 218)$, C. coli $(14.68 \% ; n=32 / 218)$ and

157 C. concisus (44.5\%; $\mathrm{n}=97 / 218)$ were all common among human clinical samples. However,

158 less common species were also present, with nearly half of all Campylobacter species $159(44.83 \%, \mathrm{n}=13 / 29)$ isolated from humans at least once (Figure 2b, Supplementary File 1). 160 Agricultural animals were also a common source accounting for more than $1 / 3$ of the isolates 161 (38.35\%; 242/631), with 10/30 Campylobacter species isolated from more than one source 162 (Figure 2b, Supplementary File 1).

164 Evidence of interspecies recombination in the core and accessory genome

165 Genome size varied between 1.40 and 2.51 Mb (Figure 3-figure supplement 1) (mean 1.73) 166 and the number of genes (per isolate) ranged from 1,293 to 2,170 (mean 1,675) (Figure 3a167 figure supplement 2). The pangenome for the genus comprised 15,649 unique genes, found in 168 at least one of the 631 isolates (Figure 3b-source data 1), with 820 genes $(5.24 \%$ of the 169 pangenome) shared by $>95 \%$ of all isolates (core genome), across 30 species (Figure $3 \mathrm{~b}-$ 170 source data 1). We excluded species with fewer than 3 isolates in subsequent analysis. For the 171 remaining 15 species the core genome ranged in size from 1,116 genes in C. lari to 1,700 in 172 C. geochelonis (Figure 3a right panel-source data 1). Differences were also noted in the size 173 of accessory genomes, with C. concisus (mean: 981 genes), C. hyointestinalis (mean: 946 174 genes), C. showae (mean: 1,160 genes), C. geochelonis (mean: 1,021 genes) and C. fetus 175 (mean: 912 genes) containing the highest average number of accessory genes (Figure 3a left 176 panel-source data 1). Functional annotation of all 14,829 accessory genes showed that $71 \%$ $177(10,561)$ encoded hypothetical proteins of unknown function due to the lack of homology 178 with well-characterized genes (Figure 3-figure supplement 3) [58]. Remaining genes were 179 related to metabolism, DNA modification, transporters, virulence, inner 
membrane/periplasmic, adhesion, regulators, metal transport and antimicrobial resistance (Figure 3-figure supplement 3).

183 To further understand genetic differentiation within and between species, we generated 184 genus-wide similarity matrices for the core and accessory genomes (Figure 3c-d-source data 185 1). For the core genome, pairwise average nucleotide identity (ANI) was calculated for 186 shared genes in all possible genome pairs (Figure 3c-source data 1) using FastANI [59]. On 187 average, isolates of the same species shared $>95 \%$ similarity (Figure 3c-source data 1), with decreasing genetic similarity (between $85 \%$ and $90 \%$ ) over greater phylogenetic distances. The number of core genome SNPs ranged from 983 to 230,264 for the 15 Campylobacter species with $\geq 3$ isolates in our dataset, with $C$. coli and $C$. concisus having the greatest mean SNP numbers (Figure 3-figure supplement 4a) indicating considerable diversity within these species. In contrast $C$. hepaticus and $C$. geochelonis had low mean SNP numbers with 986 and 4,310, respectively. This is likely related to low sample numbers with isolates either sampled in close proximity [52] or from a single outbreak [54].

The core genome similarity matrix provided initial evidence of interspecies gene flow (introgression). This can be observed as elevated nucleotide identity between $C$. jejuni and clade 1 C. coli (Figure 3c-source data 1), consistent with previous studies [40, 42, 43]. Further evidence of introgression came from pairwise ANI comparison of genus-wide core genes, in all isolates of the 15 major Campylobacter species, to the $C$. jejuni genome (Figure 3-figure supplement $4 \mathrm{~b}$ ). In the absence of gene flow, isolates from the two species should have an approximately unimodal ANI distribution reflecting accumulation of mutations throughout the genome. This was largely the case but for some species, low nucleotide divergence suggested recent recombination with $C$. jejuni. There was also evidence of interspecies accessory genome recombination. Presence/absence patterns in the accessory genome matrix show considerable accessory gene sharing among several species that was inconsistent with the phylogeny (Figure $3 \mathrm{~d}$-source data 1). This is well illustrated in $C$. lanienae where much of the accessory genome was shared with other Campylobacter species (Figure 3d-source data 1).

\section{Enhanced interspecies recombination among cohabiting species.}

212 For Campylobacter inhabiting different host species there is a physical barrier to HGT. 213 However, when there is niche overlap, interspecies recombination can occur, for example 
between $C$. jejuni and $C$. coli inhabiting livestock [33, 40, 42]. To understand the extent to which inhabiting different hosts impedes interspecies gene flow we quantified recombination among Campylobacter species where isolates originated from same host $\left(x_{1}, y\right)$ and different hosts $\left(x_{2}, y\right)$ (Figure 4a).

ChromoPainterV2 software was used to infer tracts of DNA donated from multiple donor groups, belonging to the same $\mathrm{CC}$ but isolated from different hosts to recipient groups (Materials and Methods). Among 27 combinations of multiple donor groups and recipient groups, overall, there were more recombining SNPs within hosts than between hosts (Figure 4b) and for 10/27 species pairs there was evidence of enhanced within species recombination $\left(x_{1} \rightarrow y>x_{2} \rightarrow y\right.$; Figure $\left.4 \mathrm{c}\right)$. To assess the robustness of the analysis we included the effect of randomization and repeated the analysis by assigning random hosts for every strain (Figure 4-figure supplement 1). In the 10 pair species comparisons where $x_{1} \rightarrow y>x_{2} \rightarrow y$, we detected 174,594 within-host recombining SNPs (mapped to 473 genes; $28.8 \%$ of NCTC11168 genes) and 109,564 between-host recombining SNPs (mapped to 395 genes; 24.05\% of NCTC11168 genes). From the 473 within-host recombining genes, 45 genes contained the highest number $\left(>95^{\text {th }}\right.$ percentile) of recombining SNPs (Figure 4-figure supplements 2-3, Supplementary File 2). These genes have diverse inferred functions including metabolism, cell wall biogenesis, DNA modification, transcription, and translation (Supplementary File 2).

Interspecies recombination was observed for isolates sampled from chickens between generalist lineages $\mathrm{CC} 21$ and $\mathrm{CC} 45$ (donors; $C$. jejuni) and generalist CC828 (recipient; $C$. coli). These lineages appear to have high recombination to mutation $(\mathrm{r} / \mathrm{m})$ ratio as inferred by

237 ClonalFrameML (Supplementary File 3). DNA from generalist C. jejuni CC45 was introduced into three Campylobacter species, including C. hepaticus (chicken), C. concisus GSI and GSII (clinical) and C. ureolyticus (clinical) (Figure 4c-figure supplement 2-3, Supplementary File 4). Clonal complex 45 had the highest $r / m$ ratio from all other lineages or species involved in the comparisons (Supplementary File 3). There was increased recombination in genomes sampled from cattle between $C$. jejuni CC61 (donor; $C$. jejuni) and C. fetus and C. hyointestinalis (recipients) with $71.75 \%$ of all within-host recombining SNPs from all 10 comparisons detected in these two pairs (Figure 4c-figure supplement 2-3, Supplementary File 4). Agricultural associated C. jejuni CC61 and C. fetus subsp. venerealis involved in these comparisons were among the lineages and subspecies with the highest $\mathrm{r} / \mathrm{m}$ ratios (Supplementary File 3). The cattle-associated CC61 has previously been described as 
highly recombinant, and has been associated with rapid clonal expansion and adaptation in cattle [16].

\section{The within-host mobilome}

252

Bacteria inhabiting the same niche may benefit from functionality conferred by similar gene combinations. Recombination can promote the dissemination of adaptive genetic elements among different bacterial species. Therefore, we postulated that the genes that recombine most among species $\left(>95^{\text {th }}\right.$ percentile) will include those that are potentially beneficial in multiple genetic backgrounds. To investigate this, we quantified mobility within the genome identifying recombining SNPs found in more than one species comparison (Figure 5a). These SNPs mapped to 337 genes (20.52\% of the NCTC11168 genes; $2.15 \%$ of the pangenome) (Figure 5a, Supplementary File 5). We found that 32 of those genes (9.49\%) have also been found on plasmids (Supplementary File 5). A total of 16 genes showed elevated within-host interspecies recombination in more than five species pairs (Figure 5c, Supplementary File 5). Genes included $c m e A$ and $c m e B$ which are part of the predominant efflux pump CmeABC system in Campylobacter. Sequence variation in the drug-binding pocket of the $c m e B$ gene has been linked to increased efflux function leading to resistance to multiple drugs [60]. Many of the same antimicrobial classes are used in human and veterinary medicine and this may be linked to selection for AMR Campylobacter, that are commonly isolated from livestock [61]. To investigate this further, we compared the genomes of all 631 isolates in our dataset to 8,762 known antibiotic resistance genes from the Comprehensive Antibiotic Resistance Database (CARD) [62], ResFinder [63] and the National Center for Biotechnology Information (NCBI) databases. Homology (>75\%) was found for 42 AMR determinants associated with multi-drug efflux pumps, aminoglycosides, tetracyclines and $\beta$ lactams (Figure 5b-figure supplement 1 -source data 1 ). Species that contained $>40 \%$ isolates from livestock, including $C$. jejuni, C. coli, C. lanienae, C. hepaticus, C. hyointestinalis and C. fetus contained far more AMR determinants (Figure 5d-figure supplement 1-source data 1). AMR genes are often collocated in the genome [64] and our analysis revealed several gene clusters (Figure 5-figure supplement 2) that have been described in previous studies $[64,65]$. These findings are consistent with HGT-mediated circulation of AMR genes among different Campylobacter species and support hypotheses that ecology drives gene pool transmission $[2,64]$. 
Campylobacter host transmission and virulence have been linked with biofilm formation and changes into surface polysaccharides [66, 67]. The carB gene showed elevated within-host interspecies recombination in eight species pair comparisons (Figure 5c, Supplementary File 5). This gene encodes a carbamoylphosphate synthase that has been associated with biosynthesis of substrates for many polysaccharides and is known to contain transposon insertion sites upstream of its genomic position [67]. Other genes with elevated within-host interspecies transfer ( $>7$ species pairs) included typA (Figure 5c, Supplementary File 5), a translator regulator for GTPase and gltX (Figure 5c), a glutamate-tRNA ligase, promoting survival under stress conditions [68, 69]. Other genes included gidA and hydB associated with virulence [70] and hydrogenase enzyme activity (respiratory pathway in C. concisus, 69), respectively. By considering genes that overcome barriers to interspecies recombination and establish in multiple new genetic backgrounds, it may be possible to infer important phenotypes that allow bacteria to adapt to different hosts and environments.

\section{Discussion}

Phylogenetic reconstruction of the genus Campylobacter revealed a highly structured population. Distinct core genome clustering largely supported known classification for species, subspecies (C. fetus, [49]), genomospecies (C. concisus, [48]) and clades (C. coli [42]). Also consistent with previous studies, certain species are principally associated with a specific host niche. For example, C. fetus subsp testudinum, C. iguanorium, C. geochelonis were only sampled from reptile species, and $C$. pinnipediorum was only sampled from seals. However, for several species there was clear evidence for host generalism, including $C$. jejuni, C. coli and C. lari, all of which were sampled from multiple hosts [26, 72]. It is clear that the hosts with the greatest diversity of Campylobacter species were agricultural animals (and humans) (Figure 2-figure supplement 3). While this undoubtedly reflects oversampling of these sources to some extent, the cohabitation of species in the same host niche potentially provides opportunities for interspecies HGT.

Initial evidence of interspecies gene flow came from comparison of average nucleotide identity (ANI) and the accessory genome gene presence/absence for all isolates. In each case, patterns of genetic similarity largely mirrored the phylogeny. However, consistent with

312 previous studies [40], there was clear evidence of elevated homologous and non-homologous 313 recombination between some species. For example, core genome ANI was higher between $C$.

314 jejuni and $C$. coli clade 1, compared to other $C$. coli clades (Figure 3c-source data 1). The 
evidence for non-homologous gene sharing was even more striking with accessory genome sharing across considerable genetic distances (Figure $3 \mathrm{~d}$-source data 1 ), exemplified by $C$. lanienae which shares accessory genes with most other Campylobacter species.

To quantify the extent to which ecological barriers influenced interspecies gene flow, it was necessary to focus on donor-recipient species pairs where there was evidence of elevated HGT in the same (sympatry) compared to different (allopatry) hosts. Perhaps unsurprisingly, this was not the case for all species comparisons. Interacting factors could lead to genetic isolation even when species inhabit the same host. First, rather than being a single niche, the host represents a collection of subniches with varying degrees of differentiation. For example, gut-associated bacteria in the same intestinal tract have been shown to occupy different microniches [73] and more striking segregation may be expected between $C$. hepaticus inhabits the liver in poultry [54] and gut-dwelling $C$. jejuni and $C$. coli in the same host. Second, there is potential for the resident microbiota to influence the colonization potential of different Campylobacter species and therefore the opportunity for genetic exchange, for example through succession [74] and inhibition of transient species by residents, as seen in some other bacteria [75-77] in humans.

Continued exposition of the microecology of subniches is important but for 10 species comparisons there was clear evidence of enhanced within-host gene flow allowing quantitative analysis of ecological barriers to gene flow. Specifically, there was on average a 3-fold increase in recombination among species pairs inhabiting the same host. In some cases, this was greater, with 5-6 times more recombination among cohabiting species $C$. jejuni and C. hointestinalis/C. fetus in cattle. In absolute terms, this equates to approximately $30 \%$ of all recorded SNPs in the recipient species being the result of introgression. To place this in context, if greater than half $(51 \%)$ of the recorded SNPs resulted from interspecies recombination then the forces of species convergence would be greater than those that maintain distinct species. If maintained over time, these relative rates could lead to progressive genetic convergence unless countered by strong genome-wide natural selection against introgressed DNA.

346 Quantitative SNP-based comparisons clearly ignore one very important factor. Specifically, 347 that recombined genes that do not reduce the fitness of the recipient genome (provide an adaptive advantage) will remain in the population while others will be purged through natural 
selection. Therefore, by identifying genomic hotspots of recombination and the putative function of genes that recombine between species it is possible to understand more about micro-niche segregation and the host adapted gene pool. Of the 35 genes with evidence of enhanced within host HGT in $\geq 5$ species pairs, several were linked to functions associated with proliferation in, and exploitation of, the host. For example, the carB gene, encoding the large subunit of carbamoylphosphatase associated with polysaccharide biosynthesis, recombined in eight cohabiting species pairs and is potentially linked to enhanced virulence and growth [67]. In addition, other highly mobile genes, including typA and gltX are associated with survival and proliferation in stress conditions [68, 69], and hydB is linked to $\mathrm{NiFe}$ hydrogenase and nickel uptake that is essential for the survival of $C$. jejuni in the gut of birds and mammals [78].

Some genes showed evidence of elevated recombination in a specific host species. For example, the glmS and napA genes in cohabiting Campylobacter species in cattle. In many bacteria, analogs of $g \operatorname{lm} S$ have multiple downstream integration specific sites (Tn7) [79] which may explain the mobility of this gene. Explaining the mobility of napA is less straight forward, but this gene is known to encode a nitrate reductase in Campylobacter [80] in microaerobic conditions which may be ecologically significant as the accumulation of nitrate in slurry, straw and drainage water can be potentially toxic to livestock mammals [81].

Factors such as host physiology, diet, and metabolism undoubtedly impose selection pressures upon resident bacteria and the horizontal acquisition of genes provides a possible vehicle for adaptation. However, the widespread use of antimicrobials by humans, pets and livestock production $[82,83]$, provides another major ecological barrier to niche colonization. We found that gyrA was among the most recombinogenic genes in Campylobacter in chickens. This is important as a single mutation in this gene is known to confer resistance to ciprofloxacin [84]. While the rising trend in fluoroquinolones resistance in Campylobacter from humans and livestock [85] may result from spontaneous independent mutations, it is likely that it is accelerated by HGT. However, there is currently no clear evidence for the transfer of resistant versions of gyrA. Interspecies recombination of AMR genes has been observed between $C$. jejuni and $C$. coli isolates from multiple sources including livestock, human and sewage [64]. Consistent with this, we found AMR genes present in strains from 12 Campylobacter species in multiple hosts (Figure 5-figure supplement 2). In some cases, strains from phylogenetically closely related species (C. fetus and C. hyointestinalis) isolated 
from cattle, shared the same AMR gene cluster (tet44 and ant(6)-Ib) described before in $C$.

384 fetus subsp. fetus [65], indicating the circulation of colocalized AMR genes among related species and host niche gene pools. Strikingly, the efflux pump genes cmeA and cmeB, associated with multidrug resistance (MDR) were highly mobile among Campylobacter species with evidence of elevated within host interspecies recombination in $>7$ species pairs. Furthermore, the gltX gene, which when phosphorylated by protein kinases promotes MDR [69], was also among the most introgressed genes. While a deeper understanding of gene interactions, epistasis and epigenetics would be needed to prove that the lateral acquisition of AMR genes promotes niche adaptation, these data do suggest that HGT may facilitate colonization of antimicrobial-rich host environments, potentially favouring the spread of genes into multiple genetic backgrounds.

In conclusion, we show that species within the genus Campylobacter include those that are host restricted as well as host generalists. When species cohabit in the same host, ecological barriers to recombination can be perforated leading to considerable introgression between species. While the magnitude of introgession varies, potentially reflecting microniche structure with the host, there is clear evidence that ecology is important in maintaining genetically distinct species. This parallels evolution in some interbreeding eukaryotes, such as Darwin's Finches, where fluctuating environmental conditions can change the selection pressures acting on species inhabiting distinct niches, potentially favouring hybrids [86, 87]. Consistent with this, the host landscape is changing for Campylobacter, with intensively reared livestock now constituting 60-70\% of bird and mammal biomass on earth respectively [88]. This creates opportunities for species to be brought together in new adaptive landscapes and for genes to be tested from multiple genetic backgrounds. By understanding the ecology of niche segregation and the genetics of bacterial adaptation we can hope to improve strategies and interventions to reduce the risk of zoonotic transmission and the spread of problematic genes among species.

\section{Materials \& Methods}

\section{Isolate genomes}

413 A total of 631 Campylobacter, 17 Arcobacter, seven Sulfurospirillum and five Helicobacter 414 genomes were assembled from previously published datasets (Supplementary File 1). Isolates 415 were sampled from clinical cases of campylobacteriosis and faeces of chickens, ruminants, 416 wild birds, wild mammals, pets and environmental sources. Genomes and related metadata 
were uploaded and archived in the BIGS database [89]. Quality control was performed based

418 on the genome size, number of contigs, N50 and N95 contig length using the integrated tools 419 in BIGS database. All assembled contigs were further screened for contamination and 420 completeness using CheckM [90] (Supplementary File 1). All assembled genomes can be 421 downloaded from FigShare (doi: 10.6084/m9.figshare.15061017). Comparative genomics 422 analyses focused on the Campylobacter genomes representing 30 species including: C. avium $423(\mathrm{n}=1) ;$ C. coli $(\mathrm{n}=143) ;$ C. concisus $(\mathrm{n}=106) ;$ C. corcagiensis $(\mathrm{n}=1) ;$ C. cuniculorum $(\mathrm{n}=2) ; C$. 424 curvus $(\mathrm{n}=2) ;$. fetus $(\mathrm{n}=52) ;$. geochelonis $(\mathrm{n}=3) ; C$. gracilis $(\mathrm{n}=2) ; C$. helveticus $(\mathrm{n}=1) ; C$. 425 hepaticus $(\mathrm{n}=10) ; C$. hominis $(\mathrm{n}=1) ; C$. hyointestinalis $(\mathrm{n}=16) ; C$. iguanorium $(\mathrm{n}=3) ; C$. 426 insulaenigrae $(\mathrm{n}=1) ;$ C. jejuni $(\mathrm{n}=218) ;$ C. lanienae $(\mathrm{n}=26) ;$ C. lari $(\mathrm{n}=13) ;$ C. mucosalis $427(\mathrm{n}=1) ;$ C. ornithocola $(\mathrm{n}=1) ;$. peloridis $(\mathrm{n}=1) ; C$. pinnipediorum $(\mathrm{n}=9) ; C$. rectus $(\mathrm{n}=1) ; C$. 428 showae $(\mathrm{n}=3) ; C$. sputorum $(\mathrm{n}=1) ; C$. subantarcticus $(\mathrm{n}=3) ; C$. upsaliensis $(\mathrm{n}=3) ; C$. 429 ureolyticus $(\mathrm{n}=4)$; C. volucris $(\mathrm{n}=2)$; Campylobacter $s p(\mathrm{n}=1)$ (Supplementary File 1). 430 Genomes belonging to $C$. jejuni and $C$. coli species were selected to represent a wide range of hosts, sequence types, and clonal complexes and reflect the known population structure for these two species. For other Campylobacter species, all genomes that were publicly available at the time of this study were included in the analysis. (Supplementary File 1).

\section{Pangenome characterization and phylogenetic analysis}

Sequence data were analysed using PIRATE, a fast and scalable pangenomics tool which allows for orthologue gene clustering in divergent bacterial species [91]. Genomes were annotated in Prokka [92], using a genus database comprising well annotated $C$. jejuni strains NCTC11168, 81116, 81-176 and M1, and plasmids pTet and pVir in addition to the already existing databases used by Prokka [92]. Briefly, annotated genomes were used as input for PIRATE. Non-redundant representative sequences were produced using CD-HIT and the longest sequence was used as a reference for sequence similarity interrogation using BLAST/DIAMOND. Gene orthologues were defined as "gene families" and were clustered in different MCL thresholds, from 10 to $98 \%$ sequence identity $(10,20,30,40,50,60,70$, 80, 90, 95, 98). Higher MCL thresholds were used to identify allelic variation within different loci. An inflation value of 4 was used to increase the granularity of MCL clustering between gene families. BLAST high-scoring pairs with a reciprocal minimum length of $90 \%$ of the query/subject sequence were excluded from MCL clustering to reduce the number of spurious associations between distantly related or conserved genes [93]. This information was used to generate gene presence/absence and allelic variation matrices. A core gene-by-gene multiple 
sequence alignment [89] was generated using MAFFT [94] comprising genes shared $>95 \%$ of isolates. Phylogenetic trees, based on core gene-by-gene alignments, were reconstructed using the maximum-likelihood algorithm implemented in RAxML v8.2.11 [95] with GTRGAMMA as substitution model.

\section{Quantifying core and accessory genome variation}

The degree of genetic differentiation between species was investigated gene-by-gene as in previous studies $[40,96]$ by calculating the average nucleotide identity (ANI) of all 631 Campylobacter genomes using FastANI v.1.0 [59]. The analysis generated a lower triangular matrix with the lowest ANI value at $75 \%$ (as computed by FastANI). A comparable gene presence/absence matrix was produced using PIRATE and was further used to generate a heatmap of accessory genome similarity based upon gene presence or absence. Subsequently, all Campylobacter genomes were screened for the presence of antimicrobial resistance genes against the CARD [62], ResFinder [63] and NCBI databases. All Campylobacter genomes were further screened for the presence of phage, conjugative elements and plasmid DNA using publicly available online databases to investigate the effect of other transfer mechanisms. First, we used the PHAge Search Tool Enhanced Release (PHASTER) [97] to identify and annotate prophage sequences within our genomes. A total of $86 \%$ (254/297) of the genomes used in chromosome painting were found to have DNA sequence of phage origin. Second, we used Iceberg 2.0 [98] for the detection of integrative and conjugative elements, identifying 32 ICEs in 19\% (56/297) of the genomes used in the chromosome painting analysis. Finally, we used MOB-suite software for clustering, reconstruction and typing of plasmids from draft assemblies [99, 100]. A positive hit was defined when a gene had $>75 \%$ nucleotide identity over $>50 \%$ of the sequence length showing that 32 genes identified in the recombination analysis have also been located on plasmids. A gene presence/absence matrix for every antimicrobial resistance gene was generated for every genome. Genomes carrying AMR genes were screened to characterize the location of adjacent genes using SnapGene software (GSL Biotech; available at snapgene.com), as previously described [64]. The number of core SNPs was identified using SNP-sites (v2.3.2) [101].

\section{Inference of recombination}

483 Each combination of a recipient group and multiple donor groups (belonging to the same CC 484 but isolated from different hosts) was selected to compare the extent of interspecies 
recombination into the recipient genomes. Each donor group consisted of 8 isolates to avoid the influence of difference in sample size on estimation of the extent of interspecies recombination. Each recipient group included at least 4 isolates. We excluded $C$. jejuni and C. coli clade 1 genomes isolated from seals and water, as these most likely represent spillover events and not true host segregated populations. Briefly, we conducted a pairwise genome alignment between reference genome NCTC11168 and one of the strains included in the donor-recipient analysis using progressiveMauve [102]. This enabled the construction of positional homology alignments for all genomes regardless gene content and genome rearrangements, which were then combined into a multiple whole-genome alignment, as previously described [103]. ChromoPainterV2 software was used to calculate the amount of DNA sequence that is donated from a donor to a recipient group [45]. Briefly, for each donorrecipient pair, SNPs in which $>90 \%$ recipient individuals had recombined with the donor group were considered in the analysis. These SNPs were mapped to genomic regions and specific genes were identified. A total of 258,444 (96.83\%) recombining SNPs mapped to 558 genes of the NCTC11168 reference strain with $>90 \%$ probability of copying from a donor to a recipient strain. Genes containing the highest number of recombining SNPs were considered for subsequent analyses $\left(>95^{\text {th }}\right.$ percentile) (Supplementary File 2). ClonalFrameML[104] was used to infer the relative number of substitutions introduced by recombination $(r)$ and mutation $(m)$ as the ratio $r / m$ as previously described [16].

\section{Data availability}

Genomes sequenced as part of other studies are archived on the Short Read Archive associated with BioProject accessions: PRJNA176480, PRJNA177352, PRJNA342755, PRJNA345429， PRJNA312235， PRJNA415188， PRJNA524300， PRJNA528879, PRJNA529798, PRJNA575343, PRJNA524315 and PRJNA689604. Additional genomes were also downloaded from NCBI [105] and pubMLST (http://pubmlst.org/campylobacter).

511 Contiguous assemblies of all genome sequences compared are available at the public data

512 repository Figshare (doi: 10.6084/m9.figshare.15061017) and individual project and accession numbers can be found in Supplementary File 1.

\section{References}

516 1. Smith JM, Dowson CG, Spratt BG. Localized sex in bacteria. Nature 1991; 349: 2931.

518 2. Sheppard SK, Guttman DS, Fitzgerald JR. Population genomics of bacterial host 

adaptation. Nat Rev Genet 2018; 19: 549-565.

3. Shapiro BJ, Leducq J-B, Mallet J. What Is Speciation? PLOS Genet 2016; 12 : e1005860.

4. Doolittle WF, Zhaxybayeva O. On the origin of prokaryotic species. Genome Res 2009; 19: 744-756.

524 5. Doolittle WF, Papke RT. Genomics and the bacterial species problem. Genome Biol 2006; 7: 116.

6. Fraser C, Hanage WP, Spratt BG. Recombination and the nature of bacterial speciation. Science 2007; 315: 476-80.

7. Budroni S, Siena E, Hotopp JCD, Seib KL, Serruto D, Nofroni C, et al. Neisseria meningitidis is structured in clades associated with restriction modification systems that modulate homologous recombination. Proc Natl Acad Sci 2011; 108: 4494-4499.

8. Oliveira PH, Touchon M, Rocha EPC. Regulation of genetic flux between bacteria by restriction-modification systems. Proc Natl Acad Sci 2016; 113: 5658-5663.

9. Doron S, Melamed S, Ofir G, Leavitt A, Lopatina A, Keren M, et al. Systematic discovery of antiphage defense systems in the microbial pangenome. Science (80- ) 2018; 359: eaar4120.

10. Nandi T, Holden MTG, Didelot X, Mehershahi K, Boddey JA, Beacham I, et al. Burkholderia pseudomallei sequencing identifies genomic clades with distinct recombination, accessory, and epigenetic profiles. Genome Res 2015; 25: 129-141.

11. Marraffini LA, Sontheimer EJ. CRISPR Interference Limits Horizontal Gene Transfer in Staphylococci by Targeting DNA. Science (80- ) 2008; 322: 1843-1845.

12. Thomas CM, Nielsen KM. Mechanisms of, and Barriers to, Horizontal Gene Transfer between Bacteria. Nat Rev Microbiol 2005; 3: 711-721.

13. Eggleston AK, Mitchell AH, West SC. In Vitro Reconstitution of the Late Steps of Genetic Recombination in E. coli. Cell 1997; 89: 607-617.

14. Zhu P, van der Ende A, Falush D, Brieske N, Morelli G, Linz B, et al. Fit genotypes and escape variants of subgroup III Neisseria meningitidis during three pandemics of epidemic meningitis. Proc Natl Acad Sci 2001; 98: 5234-5239.

15. Boni MF, Lemey P, Jiang X, Lam TT-Y, Perry BW, Castoe TA, et al. Evolutionary origins of the SARS-CoV-2 sarbecovirus lineage responsible for the COVID-19 pandemic. Nat Microbiol 2020; 5: 1408-1417.

16. Mourkas E, Taylor AJ, Méric G, Bayliss SC, Pascoe B, Mageiros L, et al. Agricultural intensification and the evolution of host specialism in the enteric pathogen 
17. Johnson AP, Woodford N. Global spread of antibiotic resistance: the example of New Delhi metallo- $\beta$-lactamase (NDM)-mediated carbapenem resistance. J Med Microbiol 2013; 62: 499-513.

18. Schwarz S, Johnson AP. Transferable resistance to colistin: a new but old threat. $J$ Antimicrob Chemother 2016; 71: 2066-70.

19. Baker KS, Dallman TJ, Field N, Childs T, Mitchell H, Day M, et al. Horizontal antimicrobial resistance transfer drives epidemics of multiple Shigella species. Nat Commun 2018; 9: 1462.

20. Young JPW. Bacteria Are Smartphones and Mobile Genes Are Apps. Trends Microbiol 2016; 24: 931-932.

21. McInerney JO, Whelan FJ, Domingo-Sananes MR, McNally A, O'Connell MJ. Pangenomes and Selection: The Public Goods Hypothesis. The Pangenome. 2020.

22. Vos M, Eyre-Walker A. Are pangenomes adaptive or not? Nat Microbiol 2017; 2: 1576.

23. Werren JH. Selfish genetic elements, genetic conflict, and evolutionary innovation. Proc Natl Acad Sci 2011; 108: 10863-10870.

24. Giacomelli M, Piccirillo A. Pet reptiles as potential reservoir of Campylobacter species with zoonotic potential: TABLE 1: Vet Rec 2014; 174: 479.2-479.

25. Fitzgerald C, Tu Z chao, Patrick M, Stiles T, Lawson AJ, Santovenia M, et al. Campylobacter fetus subsp. testudinum subsp. nov., isolated from humans and reptiles. Int J Syst Evol Microbiol 2014; 64: 2944-2948.

26. Griekspoor P, Colles FM, McCarthy ND, Hansbro PM, Ashhurst-Smith C, Olsen B, et al. Marked host specificity and lack of phylogeographic population structure of Campylobacter jejuni in wild birds. Mol Ecol 2013; 22: 1463-1472.

27. Atterby C, Mourkas E, Méric G, Pascoe B, Wang H, Waldenström J, et al. The Potential of Isolation Source to Predict Colonization in Avian Hosts: A Case Study in Campylobacter jejuni Strains From Three Bird Species. Front Microbiol 2018; 9.

28. Leatherbarrow AJH, Griffiths R, Hart CA, Kemp R, Williams NJ, Diggle PJ, et al. and water in an area of mixed dairy farmland in the United Kingdom. Environ Microbiol 2007; 9: 1772-1779.

29. Man SM. The clinical importance of emerging Campylobacter species. Nat Rev 
Gastroenterol Hepatol 2011; 8: 669-685.

30. Kaakoush NO, Castaño-Rodríguez N, Mitchell HM, Man SM. Global Epidemiology of Campylobacter Infection. Clin Microbiol Rev 2015; 28: 687-720.

31. Sheppard SK, Dallas JF, MacRae M, McCarthy ND, Sproston EL, Gormley FJ, et al. Campylobacter genotypes from food animals, environmental sources and clinical disease in Scotland 2005/6. Int J Food Microbiol 2009; 134: 96-103.

32. Sheppard SK, Dallas JF, Strachan NJC, MacRae M, McCarthy ND, Wilson DJ, et al.

33. Sheppard SK, Colles FM, McCarthy ND, Strachan NJC, Ogden ID, Forbes KJ, et al.

35. Sheppard SK, Colles F, Richardson J, Cody AJ, Elson R, Lawson A, et al. Host

37. Woodcock DJ, Krusche P, Strachan NJC, Forbes KJ, Cohan FM, Méric G, et al.

40. Sheppard SK, Didelot X, Jolley KA, Darling AE, Pascoe B, Meric G, et al. Progressive

34. Dearlove BL, Cody AJ, Pascoe B, Méric G, Wilson DJ, Sheppard SK. Rapid host switching in generalist Campylobacter strains erodes the signal for tracing human infections. ISME J 2016; 10: 721-729. Association of Campylobacter Genotypes Transcends Geographic Variation. Appl Environ Microbiol 2010; 76: 5269-5277.

36. Sheppard SK, Cheng L, Méric G, de Haan CPA, Llarena A-K, Marttinen P, et al. Cryptic ecology among host generalist Campylobacter jejuni in domestic animals. Mol Ecol 2014; 23: 2442-2451.

Genomic plasticity and rapid host switching can promote the evolution of generalism: a case study in the zoonotic pathogen Campylobacter. Sci Rep 2017; 7: 9650.

38. Colles FM, Dingle KE, Cody AJ, Maiden MCJ. Comparison of Campylobacter Populations in Wild Geese with Those in Starlings and Free-Range Poultry on the Same Farm. Appl Environ Microbiol 2008; 74: 3583-3590.

39. Colles FM, McCarthy ND, Bliss CM, Layton R, Maiden MCJ. The long-term dynamics of Campylobacter colonizing a free-range broiler breeder flock: an observational study. Environ Microbiol 2015; 17: 938-946.

genome-wide introgression in agricultural Campylobacter coli. Mol Ecol 2013; 22:

$$
1051-64 .
$$

41. Taylor AJ, Méric G, Yahara K, Pascoe B, Mageiros L, Mourkas E, et al. Cross-species 
evolutionary rewiring in the enteric bacterium Campylobacter; bioRxiv 2021; 2021.03.15.435406.

42. Sheppard SK, McCarthy ND, Falush D, Maiden MCJ. Convergence of Campylobacter Species: Implications for Bacterial Evolution. Science (80- ) 2008; 320: 237-239.

43. Sheppard SK, McCarthy ND, Jolley KA, Maiden MCJ. Introgression in the genus Campylobacter: generation and spread of mosaic alleles. Microbiology 2011; 157: 1066-1074.

44. Thorell K, Yahara K, Berthenet E, Lawson DJ, Mikhail J, Kato I, et al. Rapid evolution of distinct Helicobacter pylori subpopulations in the Americas. PLOS Genet 2017; 13: e1006730.

45. Lawson DJ, Hellenthal G, Myers S, Falush D. Inference of Population Structure using Dense Haplotype Data. PLoS Genet 2012; 8: e1002453.

46. Yahara K, Furuta Y, Oshima K, Yoshida M, Azuma T, Hattori M, et al. Chromosome Painting In Silico in a Bacterial Species Reveals Fine Population Structure. Mol Biol Evol 2013; 30: 1454-1464.

47. Dingle KE, Colles FM, Wareing DR, Ure R, Fox AJ, Bolton FE, et al. Multilocus sequence typing system for Campylobacter jejuni. J Clin Microbiol 2001; 39: 14-23.

48. Kirk KF, Méric G, Nielsen HL, Pascoe B, Sheppard SK, Thorlacius-Ussing O, et al. Molecular epidemiology and comparative genomics of Campylobacter concisus strains from saliva, faeces and gut mucosal biopsies in inflammatory bowel disease. Sci Rep 2018; 8: 1902.

49. Iraola G, Forster SC, Kumar N, Lehours P, Bekal S, García-Peña FJ, et al. Distinct Campylobacter fetus lineages adapted as livestock pathogens and human pathobionts in the intestinal microbiota. Nat Commun 2017; 8: 1367.

50. Debruyne L, On SLW, De Brandt E, Vandamme P. Novel Campylobacter lari-like bacteria from humans and molluscs: description of Campylobacter peloridis sp. nov., Campylobacter lari subsp. concheus subsp. nov. and Campylobacter lari subsp. lari subsp. nov. Int J Syst Evol Microbiol 2009; 59: 1126-32.

51. Gilbert MJ, Kik M, Miller WG, Duim B, Wagenaar JA. Campylobacter iguaniorum sp. nov., isolated from reptiles. Int J Syst Evol Microbiol 2015; 65: 975-982.

52. Piccirillo A, Niero G, Calleros L, Pérez R, Naya H, Iraola G. Campylobacter geochelonis sp. nov. isolated from the western Hermann's tortoise (Testudo hermanni hermanni). Int J Syst Evol Microbiol 2016; 66: 3468-3476.

53. Logan JMJ, Burnens A, Linton D, Lawson AJ, Stanley J. Campylobacter lanienae sp. 
nov., a new species isolated from workers in an abattoir. Int J Syst Evol Microbiol 2000; 50: $865-872$.

54. Van TTH, Elshagmani E, Gor MC, Scott PC, Moore RJ. Campylobacter hepaticus sp. nov., isolated from chickens with spotty liver disease. Int J Syst Evol Microbiol 2016; 66: $4518-4524$.

55. Miller WG, Yee E, Chapman MH, Smith TPL, Bono JL, Huynh S, et al. Comparative genomics of the Campylobacter lari group. Genome Biol Evol 2014; 6: 3252-66.

56. Gilbert MJ, Miller WG, Leger JS, Chapman MH, Timmerman AJ, Duim B, et al. Campylobacter pinnipediorum sp. nov., isolated from pinnipeds, comprising Campylobacter pinnipediorum subsp. pinnipediorum subsp. nov. and Campylobacter pinnipediorum subsp. caledonicus subsp. nov. Int J Syst Evol Microbiol 2017; 67: 1961-1968.

57. Pascoe B, Méric G, Yahara K, Wimalarathna H, Murray S, Hitchings MD, et al. Local genes for local bacteria: Evidence of allopatry in the genomes of transatlantic Campylobacter populations. Mol Ecol 2017; 26: 4497-4508.

58. Pascoe B, Williams LK, Calland JK, Meric G, Hitchings MD, Dyer M, et al. Domestication of Campylobacter jejuni NCTC 11168. Microb genomics 2019; 5.

59. Jain C, Rodriguez-R LM, Phillippy AM, Konstantinidis KT, Aluru S. High throughput ANI analysis of $90 \mathrm{~K}$ prokaryotic genomes reveals clear species boundaries. Nat Commun 2018; 9: 5114.

60. Yao H, Shen Z, Wang Y, Deng F, Liu D, Naren G, et al. Emergence of a Potent Multidrug Efflux Pump Variant That Enhances Campylobacter Resistance to Multiple Antibiotics. MBio 2016; 7: 1-11.

61. Livermore DM. Introduction: the challenge of multiresistance. Int J Antimicrob Agents 2007; 29: S1-S7.

62. Jia B, Raphenya AR, Alcock B, Waglechner N, Guo P, Tsang KK, et al. CARD 2017: expansion and model-centric curation of the comprehensive antibiotic resistance database. Nucleic Acids Res 2017; 45: D566-D573.

63. Zankari E, Hasman H, Cosentino S, Vestergaard M, Rasmussen S, Lund O, et al. Identification of acquired antimicrobial resistance genes. J Antimicrob Chemother 2012; 67: 2640-2644.

64. Mourkas E, Florez-Cuadrado D, Pascoe B, Calland JK, Bayliss SC, Mageiros L, et al. Gene pool transmission of multidrug resistance among Campylobacter from livestock, sewage and human disease. Environ Microbiol 2019; 21: 4597-4613. 
65. Abril C, Brodard I, Perreten V. Two Novel Antibiotic Resistance Genes, tet(44) and ant(6)-Ib, Are Located within a Transferable Pathogenicity Island in Campylobacter fetus subsp. fetus. Antimicrob Agents Chemother 2010; 54: 3052-3055.

66. Szymanski CM, Logan SM, Linton D, Wren BW. Campylobacter - a tale of two protein glycosylation systems. Trends Microbiol 2003; 11: 233-238.

67. McLennan MK, Ringoir DD, Frirdich E, Svensson SL, Wells DH, Jarrell H, et al. Campylobacter jejuni Biofilms Up-Regulated in the Absence of the Stringent Response Utilize a Calcofluor White-Reactive Polysaccharide. J Bacteriol 2008; 190: 1097-1107.

68. Margus T, Remm M, Tenson T. Phylogenetic distribution of translational GTPases in bacteria. BMC Genomics 2007; 8: 1-18.

69. Semanjski M, Germain E, Bratl K, Kiessling A, Gerdes K, Macek B. The kinases HipA and HipA7 phosphorylate different substrate pools in Escherichia coli to promote multidrug tolerance. Sci Signal 2018; 11.

70. Mikheil DM, Shippy DC, Eakley NM, Okwumabua OE, Fadl AA. Deletion of gene encoding methyltransferase ( $\mathrm{gid} B$ ) confers high-level antimicrobial resistance in Salmonella. J Antibiot (Tokyo) 2012; 65: 185-192.

71. Benoit SL, Maier RJ. Site-directed mutagenesis of Campylobacter concisus respiratory genes provides insight into the pathogen's growth requirements. Sci Rep 2018; 8: 14203.

72. Cody AJ, McCarthy ND, Bray JE, Wimalarathna HML, Colles FM, Jansen van Rensburg MJ, et al. Wild bird-associated Campylobacter jejuni isolates are a consistent source of human disease, in Oxfordshire, United Kingdom. Environ Microbiol Rep 2015; 7: 782-788.

73. Hayashi H, Takahashi R, Nishi T, Sakamoto M, Benno Y. Molecular analysis of jejunal, ileal, caecal and recto-sigmoidal human colonic microbiota using 16S rRNA gene libraries and terminal restriction fragment length polymorphism. J Med Microbiol 2005; 54: 1093-1101.

74. Lu J, Idris U, Harmon B, Hofacre C, Maurer JJ, Lee MD. Diversity and succession of the intestinal bacterial community of the maturing broiler chicken. Appl Environ Microbiol 2003; 69: 6816-24.

75. Stecher B, Chaffron S, Käppeli R, Hapfelmeier S, Freedrich S, Weber TC, et al. Like will to like: abundances of closely related species can predict susceptibility to intestinal colonization by pathogenic and commensal bacteria. PLoS Pathog 2010; 6: 
e1000711.

76. van Elsas JD, Chiurazzi M, Mallon CA, Elhottova D, Kristufek V, Salles JF. Microbial diversity determines the invasion of soil by a bacterial pathogen. Proc Natl Acad Sci U S A 2012; 109: 1159-64.

77. Nowrouzian FL, Wold AE, Adlerberth I. Escherichia coli strains belonging to phylogenetic group B2 have superior capacity to persist in the intestinal microflora of infants. J Infect Dis 2005; 191: 1078-83.

78. Howlett RM, Hughes BM, Hitchcock A, Kelly DJ. Hydrogenase activity in the foodborne pathogen Campylobacter jejuni depends upon a novel ABC-type nickel transporter (NikZYXWV) and is SlyD-independent. Microbiology 2012; 158: 16451655.

79. Choi K-H. Applications of Transposon-Based Gene Delivery System in Bacteria. $J$ Microbiol Biotechnol 2009; 19: 217-28.

80. Pittman MS, Elvers KT, Lee L, Jones MA, Poole RK, Park SF, et al. Growth of Campylobacter jejuni on nitrate and nitrite: electron transport to NapA and NrfA via $\mathrm{NrfH}$ and distinct roles for $\mathrm{NrfA}$ and the globin $\mathrm{Cgb}$ in protection against nitrosative stress. Mol Microbiol 2007; 63: 575-590.

81. Alexander J, Benford D, Cockburn A, Cravedi J, Dogliotti E, Domenico A Di, et al. Nitrite as undesirable substances in animal feed - Scientific Opinion of the Panel on Contaminants in the Food Chain. EFSA J 2009; 7: 1-47.

82. Teuber M. Veterinary use and antibiotic resistance. Curr Opin Microbiol 2001; 4: 493-499.

83. Price LB, Koch BJ, Hungate BA. Ominous projections for global antibiotic use in food-animal production. Proc Natl Acad Sci U S A 2015; 112: 5554-5.

84. Luo N, Sahin O, Lin J, Michel LO, Zhang Q. In Vivo Selection of Campylobacter Isolates with High Levels of Fluoroquinolone Resistance Associated with gyrA Mutations and the Function of the CmeABC Efflux Pump. Antimicrob Agents Chemother 2003; 47: 390-394.

85. Sproston EL, Wimalarathna HML, Sheppard SK. Trends in fluoroquinolone resistance in Campylobacter. Microb Genomics 2018; 4: 1-8.

86. Mallet J. Hybrid speciation. Nature 2007; 446: 279-283.

87. Grant PR, Grant BR. Hybridization of Bird Species. Science (80- ) 1992; 256: 193197.

88. Bar-On YM, Phillips R, Milo R. The biomass distribution on Earth. Proc Natl Acad 
Sci 2018; 115: 6506-6511.

89. Sheppard SK, Jolley KA, Maiden MCJ. A Gene-By-Gene Approach to Bacterial Population Genomics: Whole Genome MLST of Campylobacter. Genes (Basel) 2012; 3: $261-277$.

90. Parks DH, Imelfort M, Skennerton CT, Hugenholtz P, Tyson GW. CheckM: assessing the quality of microbial genomes recovered from isolates, single cells, and metagenomes. Genome Res 2015; 25: 1043-1055.

91. Bayliss SC, Thorpe HA, Coyle NM, Sheppard SK, Feil EJ. PIRATE: A fast and scalable pangenomics toolbox for clustering diverged orthologues in bacteria. Gigascience 2019; 8: 1-9.

92. Seemann T. Prokka: rapid prokaryotic genome annotation. Bioinformatics 2014; 30: 2068-2069.

93. Sahl JW, Caporaso JG, Rasko DA, Keim P. The large-scale blast score ratio (LS-BSR) pipeline: a method to rapidly compare genetic content between bacterial genomes. PeerJ 2014; 2: e332.

94. Katoh K. MAFFT: a novel method for rapid multiple sequence alignment based on fast Fourier transform. Nucleic Acids Res 2002; 30: 3059-3066.

95. Stamatakis A. RAxML version 8: a tool for phylogenetic analysis and post-analysis of large phylogenies. Bioinformatics 2014; 30: 1312-1313.

96. Didelot X, Achtman M, Parkhill J, Thomson NR, Falush D. A bimodal pattern of relatedness between the Salmonella Paratyphi A and Typhi genomes: convergence or divergence by homologous recombination? Genome Res 2007; 17: 61-8.

97. Arndt D, Grant JR, Marcu A, Sajed T, Pon A, Liang Y, et al. PHASTER: a better, faster version of the PHAST phage search tool. Nucleic Acids Res 2016; 44: W16W21.

98. Liu M, Li X, Xie Y, Bi D, Sun J, Li J, et al. ICEberg 2.0: an updated database of bacterial integrative and conjugative elements. Nucleic Acids Res 2019; 47: D660D665.

99. Robertson J, Nash JHE. MOB-suite: software tools for clustering, reconstruction and typing of plasmids from draft assemblies. Microb genomics 2018; 4.

100. Robertson J, Bessonov K, Schonfeld J, Nash JHE. Universal whole-sequence-based plasmid typing and its utility to prediction of host range and epidemiological surveillance. Microb Genomics 2020; 6: 1-12.

101. Page AJ, Taylor B, Delaney AJ, Soares J, Seemann T, Keane JA, et al. SNP-sites: 
rapid efficient extraction of SNPs from multi-FASTA alignments. Microb Genomics 2016; 2: e000056.

102. Darling AE, Mau B, Perna NT. progressiveMauve: Multiple Genome Alignment with Gene Gain, Loss and Rearrangement. PLoS One 2010; 5: e11147.

103. Yahara K, Nakayama S, Shimuta K, Lee K, Morita M, Kawahata T, et al. Genomic surveillance of Neisseria gonorrhoeae to investigate the distribution and evolution of antimicrobial-resistance determinants and lineages. Microb Genomics 2018; 4: 1-3.

104. Didelot X, Wilson DJ. ClonalFrameML: Efficient Inference of Recombination in Whole Bacterial Genomes. PLOS Comput Biol 2015; 11: e1004041.

105. NCBI Resource Coordinators. Database resources of the National Center for Biotechnology Information. Nucleic Acids Res 2016; 44: D7-D19.

Acknowledgements

This work was supported by Wellcome Trust grants 088786/C/09/Z and Medical Research Council (MRC) grants MR/M501608/1 and MR/L015080/1 awarded to S.K.S.

\section{Competing interests}

808 The authors declare no competing interests.

\section{Figure legends}

811 Figure 1. Barriers to horizontal gene transfer in bacteria. A series of barriers must be surmounted for DNA to transmit from one species to another. These are broadly defined in 813 three categories. At a given time, alignment of holes in successive barriers is necessary for 814 HGT to occur. Here we focus on ecological barriers that are influenced by multiple factors 815 that reflect the physical isolation of bacteria in separate niches.

817 Figure 2. Population structure and host ecology in the genus Campylobacter. a,

818 Phylogenetic tree of 631 Campylobacter isolates from 30 species reconstructed using a gene819 by-gene concatenated alignment of 820 core genes (shared by $>95 \%$ of isolates) and an approximation of the maximum-likelihood algorithm (ML) implemented in RAxML. The species name is indicated adjacent to the associated sequence cluster. The scale bar indicates the estimated number of substitutions per site. b. Isolation source of Campylobacter species with $\mathrm{n} \geq 3$ isolates. 

distribution of the total number of accessory genes (left) and core genes (right) per isolate for each Campylobacter species (where $\mathrm{n} \geq 3$ isolates). The number of accessory genes is shown as boxplots (min to max). b, Venn diagram of pangenomes among different Campylobacter species $(n \geq 9)$. The number of core genes shared by all species is illustrated in the center. $\mathbf{c}$, Pairwise average nucleotide identity comparison calculated for all 631 Campylobacter isolates based upon 820 core genes shared by $>95 \%$ of isolates. ANI values $<75 \%$ are not calculated by FastANI [59]. d, Pairwise accessory genome similarity based upon gene presence or absence at 2,168 non-core loci. The heatmaps coloring ranges from yellow (minimum) to red (maximum). The matrices are ordered according to the phylogenetic tree presented in figure 2a. Different colours correspond to Campylobacter species with $\geq 3$ isolates.

Figure 4. Elevated within-host interspecies recombination and donor-recipient comparisons. a, A hypothesis depicting the relationships between Campylobacter species, $C$. jejuni $\left(x_{1}, x_{2}\right)$ and $C$. coli $(y)$, when found in the same or in different hosts. b, Number of recombining SNPs within and between host as inferred by chromosome painting analysis for all donor recipient species comparisons. The error bar represents the standard error of the mean (SEM). c, The figure shows the number of donated SNPs in 10 donor-recipient pair species comparisons. The proportion (\%) of recombining SNPs with $>90 \%$ probability of copying from a donor to a recipient genome is illustrated in the $y$ axis. All donor groups are shows in the $x$ axis. All coloured boxes correspond to comparison where donors and recipients are found in the same host.

Figure 5. The mobilome of the Campylobacter genus. a, The graph illustrates the proportion of recombining genes in 10 different species comparisons. The number of species pairs in which the gene was found to recombine is shown on the $x$ axis and the number of genes in each category is given on the $y$ axis and. The exact number of genes found in each group comparison is shown on the top of each box. b, Number of Campylobacter species harbouring AMR genes that belong to efflux pumps and four different antibiotic classes which are shown on the $x$ axis. c, The circos plot indicates the 16 genes involved in recombination in $>5$ donor-recipient pair species comparisons. Gene matches are indicated by joining lines, coloured differently for each gene. Gene names are shown around the perimeter for each Campylobacter species. d, The circos plot indicates the sharing of AMR genes 
associated with efflux pumps and four antibiotic classes among Campylobacter species.

860 Presence of at least one gene (not necessarily the same gene) conferring resistance to a 861 specific antibiotic class is indicated by joining lines, coloured differently for each drug class.

862 Efflux pumps (i), $\beta$-lactams (ii), tetracyclines (iii), aminoglycosides (iv) and lincosamides (v) 863 are shown around the perimeter for each Campylobacter species.

Figure 2-figure supplement 1. Population structure of the Campylobacteraceae family. Phylogenetic tree of 506 isolates that belong to the Campylobacteraceae family with Helicobacter pylori used as an outgroup. Different colors correspond to main species with number of isolates greater than three. The Tree was reconstructed using a gene-by-gene concatenated alignment of 799 core genes shared by $>95 \%$ by all isolates and an approximation of the maximum-likelihood algorithm (ML) implemented in RAxML. The scale bar indicates the estimated number of substitutions per site.

873 Figure 2-figure supplement 2. Core genome species trees. Single-species trees for nine 874 Campylobacter species with $>4$ isolates demonstrating the diversity for among species. The scale bars indicate the estimated number of substitutions per site. $(*)$ The scale for the tree corresponding to $C$. hepaticus is 10 times smaller than the rest.

Figure 2-figure supplement 3. Overview of host-associations of Campylobacter species. Abundance and diversity of 631 Campylobacter isolates in each host and environment. Different colours correspond to main species with number of isolates $\geq$ three. The number of isolates is shown on the $y$ axis while the various isolation sources on the $x$ axis.

882

883 Figure 2-figure supplement 4. Core genome species trees. Single-species trees for C. jejuni,

884 C. coli and C. fetus species which contain isolates from multiple hosts and countries. The scale bars indicate the estimated number of substitutions per site.

Figure 3-figure supplement 1. Genome size variation of the Campylobacter genus. The frequency distribution of the genome size of all Campylobacter genomes used in this study is shown as a histogram. The number of genomes is shown on the $y$ axis while the genome size

$890 \quad$ (in bp) on the $x$ axis. 

distribution of the total number of genes per isolate for each Campylobacter species (where $\mathrm{n} \geq 3$ isolates). The number of genes is shown as boxplots ( $\min$ to max).

Figure 3-figure supplement 3. Accessory gene function in all main Campylobacter species. The different gene functions are depicted on the $y$ axis, while the number of shared accessory genes on the $x$ axis. Different colours corresponding to different Campylobacter species.

900

Figure 3-figure supplement 4. Core genome allelic variation and the effect of recombination. a, Number of SNPs per genome of the main Campylobacter species (where $\mathrm{n} \geq 3$ isolates) in the core genome alignment. The horizontal line in each plot represents the mean value while the upper and lower lines the standard deviation. b, Average nucleotide identity for pairwise comparisons of 820 core genes for 605 genomes of 15 main Campylobacter species. Different colours corresponding to different Campylobacter species.

907

Figure 4-figure supplement 1. Probability of the recipient genomes sharing DNA with each donor groups is illustrated as box whiskers (white) for every donor-recipient comparison for all 10 pairs that supported our hypothesis. The analysis where the host data were randomized across all isolates is illustrated as box whiskers (red). The probability of copying DNA from a donor to a recipient genome is shown on the $y$ axis. The midline in the box whiskers indicates the mean and the error bars the standard deviation.

914

915 Figure 4-figure supplement 2. Genome position of genes containing recombining SNPs.

916 Genes and their corresponding number of recombining SNPs, inferred by Chromosome

917 Painting analysis for all 10 species comparisons, and mapped to the NCTC11168 reference

918 genome. Genes from within-host (red) and between-host (white) pair comparisons are shown

919 for each comparison. Donors are isolates from chicken (triangle), cattle (square), wild bird 920 (cross), pig (star), clinical (circle) and water (snowflake) samples. The dashed line indicates the $95^{\text {th }}$ percentile for every individual group comparison.

923 Figure 4-figure supplement 3. Genes ranked in ascending order of the number of 924 recombining SNPs they contain as inferred by Chromosome Painting analysis for all ten 925 species comparisons. Genes from within-host (red) and between-host (white) are shown for 
each comparison. Donors are isolates from chicken (triangle), cattle (square), wild bird (cross), pig (star), clinical (circle) and water (snowflake) samples.

928

Figure 5-figure supplement 1. Presence of antimicrobial resistance genes in the

930 Campylobacter genus. The phylogenetic tree was reconstructed using a gene-by-gene

931 concatenated alignment of 820 core and soft-core genes and an approximation of the

932 maximum-likelihood algorithm (ML) implemented in RAxML. The designated colour

933 scheme was used for each species in the first column. The second column indicates whether

934 the strain is isolated from an agricultural animal (grey). Remaining columns indicate presence

935 of AMR genes (black). The scale represents the number of substitutions per site.

936

937 Figure 5-figure supplement 2. Genetic organization of AMR genes in Campylobacter.

938 The presence of each AMR gene, highlighted in different colours, is shown for representative

939 genomes from C. jejuni, C. coli, C. lanienae, C. hyointestinalis and C. fetus subspecies fetus

940 sampled from different agricultural animals. The number of isolate genomes containing each

941 genomic arrangement is indicated in parenthesis.

942

943 Supplementary File 1. Isolate information about the genomes used in this study.

945 Supplementary File 2. Within-host highly $\left(>95^{\text {th }}\right.$ percentile) recombining genes.

Supplementary File 3. Recombination parameters as calculated by ClonalFrameML.

Supplementary File 4. Quantifying recombination between co-habiting species using

Supplementary File 5. Genes involved in interspecies recombination in 10 species comparisons.

Figure 3-source data 1. This file contains the numerical values on which the graphs in

958 Figure 5-source data 1. This file contains the numerical values on which the graphs in 959 Figure 5b-d are based. 
1 Host ecology regulates interspecies recombination in bacteria of the genus

\section{Campylobacter}

3

4 Evangelos Mourkas ${ }^{1}$, Koji Yahara ${ }^{2}$, Sion C. Bayliss ${ }^{1}$, Jessica K. Calland ${ }^{1}$, Håkan Johansson ${ }^{3}$, 5 Leonardos Mageiros ${ }^{1}$, Zilia Y. Muñoz-Ramirez ${ }^{4}$, Grant Futcher ${ }^{1}$, Guillaume Méric ${ }^{1 \#}$, 6 Matthew D. Hitchings ${ }^{5}$, Santiago Sandoval-Motta ${ }^{4}$, Javier Torres ${ }^{4}$, Keith A. Jolley ${ }^{6}$, Martin 7 C. J. Maiden ${ }^{6}$, Patrik Ellström ${ }^{7}$, Jonas Waldenström ${ }^{3}$, Ben Pascoe ${ }^{1,8}$, Samuel K. Sheppard ${ }^{1,6 *}$ 8

$9{ }^{1}$ The Milner Centre for Evolution, Department of Biology and Biochemistry, University of Bath, Bath BA2 10 7AY, UK; ${ }^{2}$ Antimicrobial Resistance Research Center, National Institute of Infectious Diseases, Tokyo, 16211 8640, Japan; ${ }^{3}$ Centre for Ecology and Evolution in Microbial Model Systems, Linnaeus University, Kalmar, 391 12 82, Sweden; ${ }^{4}$ Unidad de Investigacion en Enfermedades Infecciosas, UMAE Pediatria, Instituto Mexicano del 13 Seguro Social; ${ }^{5}$ Swansea University Medical School, Swansea University, Singleton Park, Swansea, SA2 8PP, 14 UK; ${ }^{6}$ Department of Zoology, University of Oxford, South Parks Road, Oxford, OX1 3PS, UK; ${ }^{7}$ Department of 15 Medical Sciences, Zoonosis Science Centre, Uppsala University, Uppsala, Sweden; ${ }^{8}$ Faculty of Veterinary 16 Medicine, Chiang Mai University, Chiang Mai 50100, Thailand

*Corresponding authors: Samuel K. Sheppard; s.k.sheppard@bath.ac.uk

"Present address: Cambridge Baker Systems Genomics Initiative, Baker Heart and Diabetes Institute, 75

Keywords: Campylobacter, genus, species, niche, adaptation, host, evolution. 


\section{Abstract}

30 Horizontal gene transfer (HGT) can allow traits that have evolved in one bacterial species to 31 transfer to another. This has potential to rapidly promote new adaptive trajectories such as 32 zoonotic transfer or antimicrobial resistance. However, for this to occur requires gaps to align 33 in barriers to recombination within a given time frame. Chief among these barriers is the 34 physical separation of species with distinct ecologies in separate niches. Within the genus 35 Campylobacter there are species with divergent ecologies, from rarely isolated single host specialists to multi-host generalist species that are among the most common global causes of human bacterial gastroenteritis. Here, by characterising these contrasting ecologies, we can quantify HGT among sympatric and allopatric species in natural populations. Analysing recipient and donor population ancestry among genomes from 30 Campylobacter species we

40 show that cohabitation in the same host can lead to a 6-fold increase in HGT between species. 41 This accounts for up to $30 \%$ of all SNPs within a given species and identifies highly 42 recombinogenic genes with functions including host adaptation and antimicrobial resistance. 43 As described in some animal and plant species, ecological factors are a major evolutionary 44 force for speciation in bacteria and changes to the host landscape can promote partial convergence of distinct species through HGT. 


\section{Introduction}

It is well established that bacteria do not conform to a strict clonal model of reproduction but engage in regular horizontal gene transfer (HGT) [1]. This lateral exchange of DNA can confer new functionality on recipient genomes, potentially promoting novel adaptive trajectories such as colonization of a new host or the emergence of pathogenicity [2]. In some cases, gene flow can occur at such magnitude, even between different species [3,4], that one may question why disparate lineages do not merge and why distinct bacterial species exist at all [5]. An answer to this lies in considering the successive processes that enable genes from one strain to establish in an entirely new genetic background.

The probability of HGT is governed by the interaction of multiple factors, including exposure to DNA, the susceptibility of the recipient genome to DNA uptake, and the impact of recombined DNA on the recipient strain. These factors can be broadly defined in three functional phases and HGT can only occur when gaps align in each successive ecological, mechanistic and adaptive barriers within a given time frame (Figure 1). In the first phase, the quantity of DNA available to recipient strains is determined by ecological factors such as the distribution, prevalence and interactions of donor and recipient bacteria, as well as the capacity for free DNA to be disseminated among species/strains. In the second phase, there are mechanistic barriers to HGT imposed by the homology dependence of recombination [6] or other factors promoting DNA specificity - such as restriction-modification, CRISPR interference or antiphage systems [7-11] - that can act as a defence against the uptake of foreign DNA (mechanistic barriers) [12, 13]. Finally, the effect that HGT has on the fitness of the recipient cell in a given selective environment (adaptive barrier) will determine if the recombinant genotype survives for subsequent generations [2, 14].

Understanding how ecology maintains, and potentially confines, distinct strains and species has become increasingly important in the light of global challenges such as the emergence and spread of zoonotic pathogens [15]. A typical approach to investigating this is to consider spillover of particular strains or clones from one host to another (clonal transmission). This is an important phenomenon and may be influenced by anthropogenic change, such as habitat encroachment or agricultural intensification [16]. However, in many cases, important phenotypes, including antimicrobial resistance (AMR) [17-19], can be conferred by relatively few genes. In such cases, it may be important to consider how cohabiting strains 
genes, rather than clones, can transition between segregated populations (gene pool transmission). To investigate the impact of ecological segregation (ecological barriers) on this gene pool transmission, in natural populations, requires quantification of HGT among sympatric and allopatric bacteria.

Species within the genus Campylobacter are an ideal subject for considering how ecology influences the maintenance of genetically distinct species for several reasons. First, Campylobacter are a common component of the commensal gut microbiota of reptiles [24, 25], birds [26, 27] and mammals [28] but, being microaerophilic, do not survive well outside of the host. This creates island populations that have some degree of ecological isolation. Second, because at least 12 species have been identified as human pathogens [29] and $C$. jejuni and C. coli among the most common global causes of bacterial gastroenteritis [30], large numbers of isolate genomes have been sequenced from potential reservoir hosts as part of public health source tracking programs $[31,32]$. Third, within the genus there are species and strains that inhabit one or multiple hosts (ecological specialists and generalists $[16,26$, 33-37]). As a single host can simultaneously carry multiple lineages [38], possibly occupying different sub-niches within that host [39], there is potential to compare allopatric and sympatric populations. Finally, high magnitude interspecies admixture (introgression) between $C$. jejuni and $C$. coli isolated from agricultural animals suggests that host ecology plays a role in the maintenance of species [40-43].

103 Here, we quantify HGT among 600 genomes from 30 Campylobacter species using a 'chromosome painting' approach [44-46] to characterize shared ancestry among donor and recipient populations. Specifically, we investigate the role of ecological barriers to interspecies gene flow. By identifying recombining species pairs within the same and different hosts we can describe interactions where co-localization enhances gene flow, quantify the impact of ecological barriers in these populations and distinguish highly recombinogenic genes that are found in multiple genetic backgrounds. This provides

110 information about the evolutionary forces that gave rise to species and the extent to which

111 ecological barriers maintain them as discrete entities.

\section{Results}

\section{Host restricted and host generalist Campylobacter species}


115 Isolate genomes were taken from publicly available databases to represent diversity within 116 the genus Campylobacter, including environmental isolates from the closely related 117 Arcobacter and Sulfurospirillum species to provide phylogenetic context within the 118 Campylobacteraceae family (Figure 2a-figure supplement 1). In total, there were 631 119 isolates from 30 different Campylobacter species (Figure 2a) and 64 different sources, 120 isolated from 31 different countries between 1964 and 2016 (Supplementary File 1). Among 121 the isolates, 361 were $C$. jejuni and $C$. coli and could be classified according to 31 Clonal 122 Complexes (CCs) based upon sharing four or more alleles at seven housekeeping genes defined by multi-locus sequence typing (MLST) (Supplementary File 1) [47] and were representative of known diversity in both species [16,33]. The obligate human commensal and pathogen $C$. concisus ( $\mathrm{n}=106$ isolates), comprised 2 genomospecies (GSI, $\mathrm{n}=32$ and GSII, n=74), as previously described [48] (Supplementary File 1). The collection also included 52 C. fetus isolate genomes, including 3 subspecies: C. fetus subsp. fetus (n=8), C. fetus subsp. venerealis $(\mathrm{n}=23)$ and $C$. fetus subsps. testudinum $(\mathrm{n}=21)($ Supplementary File 1) [49]. Two clades were observed in C. lari (Figure 2a-figure supplement 2) which could correspond to previously described subspecies based on 16S rRNA sequencing [50].

A maximum-likelihood phylogeny of the Campylobacter genus was reconstructed on a geneby-gene concatenated sequence alignment of 820 gene families shared by $>95 \%$ of all isolates, with a core genome of 903,753 base pairs (Figure 2a). The phylogeny included species which appear to be restricted to one host or environment, including $C$. iguanorium [51] and C. geochelonis [52] (reptiles), C. lanienae [53] (pigs), C. hepaticus [54] (chicken liver), C. lari group [55] (marine birds and environment) and C. pinnipediorum [56] (seals) species, most of which were discovered recently (Figure 2a-figure supplement 3 ). There was no evidence that phylogeography was reflected in the observed population structure for

140 Campylobacter isolates from multiple hosts and countries. (Figure 2-figure supplement 4).

141 This is unsurprising as it is well known that host associated genetic variation transcends phylogeographic structuring in Campylobacter [35]. While some low-level local gene flow can be identified within a given country [57], this is vastly outweighed by recombination within particular host niches [36], particularly in small isolate collections such as those for some of the species in this study.

147 Host restricted species had lower diversity possibly linked to low sample numbers, with $C$. 148 hepaticus having the lowest diversity (Figure 2-figure supplement 2) with 8/10 genomes 
associated with isolates from the same outbreak [54]. For other species there was evidence of

150 a broad host range (ecological generalists) (Figure 2b). For example, highly structured $C$.

151 jejuni and $C$. coli isolates were sampled from seven and six host sources respectively (Figure

152 2-figure supplements 2-3, Supplementary File 1). For C. fetus there was distinct separation

153 between mammal-associated $C$. fetus subsp fetus and $C$. fetus subsp venerealis and reptile-

154 associated $C$. fetus subsp testudinum (Figure 2-figure supplement 2) as previously described

155 [49]. Unsurprisingly, a large proportion of the isolates in this study were from humans, likely

156 reflecting intensive sampling. $C$. jejuni $(27.52 \% ; n=60 / 218)$, C. coli $(14.68 \% ; n=32 / 218)$ and

157 C. concisus $(44.5 \% ; \mathrm{n}=97 / 218)$ were all common among human clinical samples. However,

158 less common species were also present, with nearly half of all Campylobacter species

$159(44.83 \%, \mathrm{n}=13 / 29)$ isolated from humans at least once (Figure 2b, Supplementary File 1).

160 Agricultural animals were also a common source accounting for more than $1 / 3$ of the isolates

161 (38.35\%; 242/631), with 10/30 Campylobacter species isolated from more than one source

162 (Figure 2b, Supplementary File 1).

163

164 Evidence of interspecies recombination in the core and accessory genome

165 Genome size varied between 1.40 and 2.51 Mb (Figure 3-figure supplement 1) (mean 1.73)

166 and the number of genes (per isolate) ranged from 1,293 to 2,170 (mean 1,675) (Figure 3a-

167 figure supplement 2). The pangenome for the genus comprised 15,649 unique genes, found in

168 at least one of the 631 isolates (Figure 3b-source data 1), with 820 genes $(5.24 \%$ of the

169 pangenome) shared by $>95 \%$ of all isolates (core genome), across 30 species (Figure $3 \mathrm{~b}-$

170 source data 1). We excluded species with fewer than 3 isolates in subsequent analysis. For the

171 remaining 15 species the core genome ranged in size from 1,116 genes in C. lari to 1,700 in

172 C. geochelonis (Figure 3a right panel-source data 1). Differences were also noted in the size

173 of accessory genomes, with C. concisus (mean: 981 genes), C. hyointestinalis (mean: 946

174 genes), C. showae (mean: 1,160 genes), C. geochelonis (mean: 1,021 genes) and C. fetus

175 (mean: 912 genes) containing the highest average number of accessory genes (Figure 3a left

176 panel-source data 1). Functional annotation of all 14,829 accessory genes showed that $71 \%$

$177(10,561)$ encoded hypothetical proteins of unknown function due to the lack of homology

178 with well-characterized genes (Figure 3-figure supplement 3) [58]. Remaining genes were

179 related to metabolism, DNA modification, transporters, virulence, inner

180 membrane/periplasmic, adhesion, regulators, metal transport and antimicrobial resistance

181 (Figure 3-figure supplement 3). 
183 To further understand genetic differentiation within and between species, we generated 184 genus-wide similarity matrices for the core and accessory genomes (Figure 3c-d-source data 185 1). For the core genome, pairwise average nucleotide identity (ANI) was calculated for 186 shared genes in all possible genome pairs (Figure 3c-source data 1) using FastANI [59]. On 187 average, isolates of the same species shared $>95 \%$ similarity (Figure 3c-source data 1), with 188 decreasing genetic similarity (between $85 \%$ and 90\%) over greater phylogenetic distances.

189 The number of core genome SNPs ranged from 983 to 230,264 for the 15 Campylobacter 190 species with $\geq 3$ isolates in our dataset, with $C$. coli and $C$. concisus having the greatest mean 191 SNP numbers (Figure 3-figure supplement 4a) indicating considerable diversity within these species. In contrast $C$. hepaticus and $C$. geochelonis had low mean SNP numbers with 986

193 and 4,310, respectively. This is likely related to low sample numbers with isolates either 194 sampled in close proximity [52] or from a single outbreak [54].

196 The core genome similarity matrix provided initial evidence of interspecies gene flow 197 (introgression). This can be observed as elevated nucleotide identity between $C$. jejuni and 198 clade 1 C. coli (Figure 3c-source data 1), consistent with previous studies [40, 42, 43]. 199 Further evidence of introgression came from pairwise ANI comparison of genus-wide core 200 genes, in all isolates of the 15 major Campylobacter species, to the C. jejuni genome (Figure 201 3-figure supplement 4b). In the absence of gene flow, isolates from the two species should 202 have an approximately unimodal ANI distribution reflecting accumulation of mutations 203 throughout the genome. This was largely the case but for some species, low nucleotide divergence suggested recent recombination with $C$. jejuni. There was also evidence of interspecies accessory genome recombination. Presence/absence patterns in the accessory genome matrix show considerable accessory gene sharing among several species that was inconsistent with the phylogeny (Figure $3 \mathrm{~d}$-source data 1). This is well illustrated in $C$. lanienae where much of the accessory genome was shared with other Campylobacter species (Figure 3d-source data 1).

\section{Enhanced interspecies recombination among cohabiting species.}

212 For Campylobacter inhabiting different host species there is a physical barrier to HGT. 213 However, when there is niche overlap, interspecies recombination can occur, for example

214 between $C$. jejuni and $C$. coli inhabiting livestock [33, 40, 42]. To understand the extent to 215 which inhabiting different hosts impedes interspecies gene flow we quantified recombination 
among Campylobacter species where isolates originated from same host $\left(x_{1, y)}\right.$ and different hosts $\left(x_{2}, y\right)$ (Figure $\left.4 \mathrm{a}\right)$.

219 ChromoPainterV2 software was used to infer tracts of DNA donated from multiple donor 220 groups, belonging to the same CC but isolated from different hosts to recipient groups (Materials and Methods). Among 27 combinations of multiple donor groups and recipient groups, overall, there were more recombining SNPs within hosts than between hosts (Figure 4b) and for 10/27 species pairs there was evidence of enhanced within species recombination $\left(x_{1} \rightarrow y>x_{2} \rightarrow y\right.$; Figure $\left.4 \mathrm{c}\right)$. To assess the robustness of the analysis we included the effect of randomization and repeated the analysis by assigning random hosts for every strain (Figure 4-figure supplement 1). In the 10 pair species comparisons where $x_{1} \rightarrow y>x_{2} \rightarrow y$, we detected 174,594 within-host recombining SNPs (mapped to 473 genes; $28.8 \%$ of NCTC11168 genes) and 109,564 between-host recombining SNPs (mapped to 395 genes; 24.05\% of NCTC11168 genes). From the 473 within-host recombining genes, 45 genes contained the highest number $\left(>95^{\text {th }}\right.$ percentile) of recombining SNPs (Figure 4-figure supplements 2-3, Supplementary File 2). These genes have diverse inferred functions including metabolism, cell wall biogenesis, DNA modification, transcription, and translation (Supplementary File 2).

233

Interspecies recombination was observed for isolates sampled from chickens between generalist lineages CC21 and CC45 (donors; $C$. jejuni) and generalist CC828 (recipient; $C$. coli). These lineages appear to have high recombination to mutation $(\mathrm{r} / \mathrm{m})$ ratio as inferred by ClonalFrameML (Supplementary File 3). DNA from generalist $C$. jejuni CC45 was introduced into three Campylobacter species, including C. hepaticus (chicken), C. concisus GSI and GSII (clinical) and C. ureolyticus (clinical) (Figure 4c-figure supplement 2-3, Supplementary File 4). Clonal complex 45 had the highest $r / m$ ratio from all other lineages or species involved in the comparisons (Supplementary File 3). There was increased recombination in genomes sampled from cattle between $C$. jejuni CC61 (donor; $C$. jejuni) and C. fetus and C. hyointestinalis (recipients) with $71.75 \%$ of all within-host recombining SNPs from all 10 comparisons detected in these two pairs (Figure 4c-figure supplement 2-3, Supplementary File 4). Agricultural associated C. jejuni CC61 and C. fetus subsp. venerealis involved in these comparisons were among the lineages and subspecies with the highest $\mathrm{r} / \mathrm{m}$ ratios (Supplementary File 3). The cattle-associated CC61 has previously been described as highly recombinant, and has been associated with rapid clonal expansion and adaptation in cattle [16]. 


\section{The within-host mobilome}

252

253

254

255

256

257

258

259

260

261

262

263

264

265

266

267

268

269

270

271

272

273

274

275

276

277

278

279

280

281

282

283

Bacteria inhabiting the same niche may benefit from functionality conferred by similar gene combinations. Recombination can promote the dissemination of adaptive genetic elements among different bacterial species. Therefore, we postulated that the genes that recombine most among species $\left(>95^{\text {th }}\right.$ percentile) will include those that are potentially beneficial in multiple genetic backgrounds. To investigate this, we quantified mobility within the genome identifying recombining SNPs found in more than one species comparison (Figure 5a). These SNPs mapped to 337 genes (20.52\% of the NCTC11168 genes; $2.15 \%$ of the pangenome) (Figure 5a, Supplementary File 5). We found that 32 of those genes $(9.49 \%)$ have also been found on plasmids (Supplementary File 5). A total of 16 genes showed elevated within-host interspecies recombination in more than five species pairs (Figure 5c, Supplementary File 5). Genes included $c m e A$ and $c m e B$ which are part of the predominant efflux pump CmeABC system in Campylobacter. Sequence variation in the drug-binding pocket of the cmeB gene has been linked to increased efflux function leading to resistance to multiple drugs [60]. Many of the same antimicrobial classes are used in human and veterinary medicine and this may be linked to selection for AMR Campylobacter, that are commonly isolated from livestock [61]. To investigate this further, we compared the genomes of all 631 isolates in our dataset to 8,762 known antibiotic resistance genes from the Comprehensive Antibiotic Resistance Database (CARD) [62], ResFinder [63] and the National Center for Biotechnology Information (NCBI) databases. Homology (>75\%) was found for 42 AMR determinants associated with multi-drug efflux pumps, aminoglycosides, tetracyclines and $\beta$ lactams (Figure 5b-figure supplement 1 -source data 1 ). Species that contained $>40 \%$ isolates from livestock, including C. jejuni, C. coli, C. lanienae, C. hepaticus, C. hyointestinalis and C. fetus contained far more AMR determinants (Figure 5d-figure supplement 1-source data 1). AMR genes are often collocated in the genome [64] and our analysis revealed several gene clusters (Figure 5-figure supplement 2) that have been described in previous studies $[64,65]$. These findings are consistent with HGT-mediated circulation of AMR genes among different Campylobacter species and support hypotheses that ecology drives gene pool transmission $[2,64]$.

Campylobacter host transmission and virulence have been linked with biofilm formation and changes into surface polysaccharides [66, 67]. The carB gene showed elevated within-host interspecies recombination in eight species pair comparisons (Figure 5c, Supplementary File 
284 5). This gene encodes a carbamoylphosphate synthase that has been associated with 285 biosynthesis of substrates for many polysaccharides and is known to contain transposon 286 insertion sites upstream of its genomic position [67]. Other genes with elevated within-host 287 interspecies transfer (>7 species pairs) included typA (Figure 5c, Supplementary File 5), a 288 translator regulator for GTPase and gltX (Figure 5c), a glutamate-tRNA ligase, promoting 289 survival under stress conditions [68, 69]. Other genes included gidA and hydB associated with 290 virulence [70] and hydrogenase enzyme activity (respiratory pathway in C. concisus, 69), respectively. By considering genes that overcome barriers to interspecies recombination and establish in multiple new genetic backgrounds, it may be possible to infer important phenotypes that allow bacteria to adapt to different hosts and environments.

\section{Discussion}

296 Phylogenetic reconstruction of the genus Campylobacter revealed a highly structured 297 population. Distinct core genome clustering largely supported known classification for species, subspecies (C. fetus, [49]), genomospecies (C. concisus, [48]) and clades (C. coli [42]). Also consistent with previous studies, certain species are principally associated with a specific host niche. For example, C. fetus subsp testudinum, C. iguanorium, C. geochelonis were only sampled from reptile species, and C. pinnipediorum was only sampled from seals. However, for several species there was clear evidence for host generalism, including $C$. jejuni, C. coli and C. lari, all of which were sampled from multiple hosts [26, 72]. It is clear that the hosts with the greatest diversity of Campylobacter species were agricultural animals (and humans) (Figure 2-figure supplement 3). While this undoubtedly reflects oversampling of these sources to some extent, the cohabitation of species in the same host niche potentially provides opportunities for interspecies HGT.

Initial evidence of interspecies gene flow came from comparison of average nucleotide identity (ANI) and the accessory genome gene presence/absence for all isolates. In each case, patterns of genetic similarity largely mirrored the phylogeny. However, consistent with previous studies [40], there was clear evidence of elevated homologous and non-homologous recombination between some species. For example, core genome ANI was higher between $C$.

314 jejuni and $C$. coli clade 1, compared to other $C$. coli clades (Figure 3c-source data 1). The 315 evidence for non-homologous gene sharing was even more striking with accessory genome 316 sharing across considerable genetic distances (Figure 3d-source data 1), exemplified by $C$. 317 lanienae which shares accessory genes with most other Campylobacter species. 
319 To quantify the extent to which ecological barriers influenced interspecies gene flow, it was necessary to focus on donor-recipient species pairs where there was evidence of elevated HGT in the same (sympatry) compared to different (allopatry) hosts. Perhaps unsurprisingly, this was not the case for all species comparisons. Interacting factors could lead to genetic isolation even when species inhabit the same host. First, rather than being a single niche, the host represents a collection of subniches with varying degrees of differentiation. For example, gut-associated bacteria in the same intestinal tract have been shown to occupy different microniches [73] and more striking segregation may be expected between $C$. hepaticus inhabits the liver in poultry [54] and gut-dwelling $C$. jejuni and $C$. coli in the same host.

328 Second, there is potential for the resident microbiota to influence the colonization potential of different Campylobacter species and therefore the opportunity for genetic exchange, for example through succession [74] and inhibition of transient species by residents, as seen in some other bacteria [75-77] in humans.

333 Continued exposition of the microecology of subniches is important but for 10 species comparisons there was clear evidence of enhanced within-host gene flow allowing quantitative analysis of ecological barriers to gene flow. Specifically, there was on average a 3-fold increase in recombination among species pairs inhabiting the same host. In some cases, this was greater, with 5-6 times more recombination among cohabiting species $C$. jejuni and $C$. hyointestinalis/C. fetus in cattle. In absolute terms, this equates to approximately $30 \%$ of all recorded SNPs in the recipient species being the result of introgression. To place this in context, if greater than half (51\%) of the recorded SNPs resulted from interspecies recombination then the forces of species convergence would be greater than those that maintain distinct species. If maintained over time, these relative rates could lead to progressive genetic convergence unless countered by strong genome-wide natural selection against introgressed DNA.

346 Quantitative SNP-based comparisons clearly ignore one very important factor. Specifically, that recombined genes that do not reduce the fitness of the recipient genome (provide an adaptive advantage) will remain in the population while others will be purged through natural selection. Therefore, by identifying genomic hotspots of recombination and the putative function of genes that recombine between species it is possible to understand more about micro-niche segregation and the host adapted gene pool. Of the 35 genes with evidence of 
enhanced within host HGT in $\geq 5$ species pairs, several were linked to functions associated with proliferation in, and exploitation of, the host. For example, the carB gene, encoding the large subunit of carbamoylphosphatase associated with polysaccharide biosynthesis, recombined in eight cohabiting species pairs and is potentially linked to enhanced virulence and growth [67]. In addition, other highly mobile genes, including typA and gltX are associated with survival and proliferation in stress conditions $[68,69]$, and hydB is linked to $\mathrm{NiFe}$ hydrogenase and nickel uptake that is essential for the survival of $C$. jejuni in the gut of birds and mammals [78].

Some genes showed evidence of elevated recombination in a specific host species. For example, the glmS and napA genes in cohabiting Campylobacter species in cattle. In many bacteria, analogs of $g \operatorname{lm} S$ have multiple downstream integration specific sites ( $\operatorname{Tn} 7)$ [79] which may explain the mobility of this gene. Explaining the mobility of napA is less straight forward, but this gene is known to encode a nitrate reductase in Campylobacter [80] in microaerobic conditions which may be ecologically significant as the accumulation of nitrate in slurry, straw and drainage water can be potentially toxic to livestock mammals [81].

Factors such as host physiology, diet, and metabolism undoubtedly impose selection pressures upon resident bacteria and the horizontal acquisition of genes provides a possible vehicle for adaptation. However, the widespread use of antimicrobials by humans, pets and livestock production $[82,83]$, provides another major ecological barrier to niche colonization. We found that gyrA was among the most recombinogenic genes in Campylobacter in chickens. This is important as a single mutation in this gene is known to confer resistance to ciprofloxacin [84]. While the rising trend in fluoroquinolones resistance in Campylobacter from humans and livestock [85] may result from spontaneous independent mutations, it is likely that it is accelerated by HGT. However, there is currently no clear evidence for the transfer of resistant versions of gyrA. Interspecies recombination of AMR genes has been observed between $C$. jejuni and $C$. coli isolates from multiple sources including livestock, human and sewage [64]. Consistent with this, we found AMR genes present in strains from 12 Campylobacter species in multiple hosts (Figure 5-figure supplement 2). In some cases, strains from phylogenetically closely related species (C. fetus and C. hyointestinalis) isolated from cattle, shared the same AMR gene cluster (tet44 and ant(6)-Ib) described before in $C$. fetus subsp. fetus [65], indicating the circulation of colocalized AMR genes among related species and host niche gene pools. Strikingly, the efflux pump genes $c m e A$ and $c m e B$, 
associated with multidrug resistance (MDR) were highly mobile among Campylobacter species with evidence of elevated within host interspecies recombination in $>7$ species pairs.

388 Furthermore, the gltX gene, which when phosphorylated by protein kinases promotes MDR 389 [69], was also among the most introgressed genes. While a deeper understanding of gene 390 interactions, epistasis and epigenetics would be needed to prove that the lateral acquisition of 391 AMR genes promotes niche adaptation, these data do suggest that HGT may facilitate 392 colonization of antimicrobial-rich host environments, potentially favouring the spread of genes into multiple genetic backgrounds.

In conclusion, we show that species within the genus Campylobacter include those that are host restricted as well as host generalists. When species cohabit in the same host, ecological barriers to recombination can be perforated leading to considerable introgression between species. While the magnitude of introgession varies, potentially reflecting microniche structure with the host, there is clear evidence that ecology is important in maintaining genetically distinct species. This parallels evolution in some interbreeding eukaryotes, such as Darwin's Finches, where fluctuating environmental conditions can change the selection pressures acting on species inhabiting distinct niches, potentially favouring hybrids [86, 87]. Consistent with this, the host landscape is changing for Campylobacter, with intensively reared livestock now constituting $60-70 \%$ of bird and mammal biomass on earth respectively [88]. This creates opportunities for species to be brought together in new adaptive landscapes and for genes to be tested from multiple genetic backgrounds. By understanding the ecology of niche segregation and the genetics of bacterial adaptation we can hope to improve strategies and interventions to reduce the risk of zoonotic transmission and the spread of problematic genes among species.

410

Materials \& Methods

412 Isolate genomes

413 A total of 631 Campylobacter, 17 Arcobacter, seven Sulfurospirillum and five Helicobacter 414 genomes were assembled from previously published datasets (Supplementary File 1). Isolates 415 were sampled from clinical cases of campylobacteriosis and faeces of chickens, ruminants, 416 wild birds, wild mammals, pets and environmental sources. Genomes and related metadata 417 were uploaded and archived in the BIGS database [89]. Quality control was performed based 418 on the genome size, number of contigs, N50 and N95 contig length using the integrated tools 419 in BIGS database. All assembled contigs were further screened for contamination and 
completeness using CheckM [90] (Supplementary File 1). All assembled genomes can be downloaded from FigShare (doi: 10.6084/m9.figshare.15061017). Comparative genomics analyses focused on the Campylobacter genomes representing 30 species including: $C$. avium $(\mathrm{n}=1) ; C$. coli $(\mathrm{n}=143) ; C$. concisus $(\mathrm{n}=106) ;$. corcagiensis $(\mathrm{n}=1) ;$. cuniculorum $(\mathrm{n}=2) ; C$. curvus $(\mathrm{n}=2) ; C$. fetus $(\mathrm{n}=52) ; C$. geochelonis $(\mathrm{n}=3) ;$. gracilis $(\mathrm{n}=2) ; C$. helveticus $(\mathrm{n}=1) ; C$. hepaticus $(\mathrm{n}=10) ; C$. hominis $(\mathrm{n}=1) ; C$. hyointestinalis $(\mathrm{n}=16) ; C$. iguanorium $(\mathrm{n}=3) ; C$. insulaenigrae $(\mathrm{n}=1) ;$ C. jejuni $(\mathrm{n}=218) ;$ C. lanienae $(\mathrm{n}=26) ;$ C. lari $(\mathrm{n}=13) ;$. mucosalis $(\mathrm{n}=1) ; C$. ornithocola $(\mathrm{n}=1) ; C$. peloridis $(\mathrm{n}=1) ; C$. pinnipediorum $(\mathrm{n}=9) ; C$. rectus $(\mathrm{n}=1) ; C$. showae $(\mathrm{n}=3) ; C$. sputorum $(\mathrm{n}=1) ; C$. subantarcticus $(\mathrm{n}=3) ; C$. upsaliensis $(\mathrm{n}=3) ; C$. ureolyticus $(\mathrm{n}=4)$; C. volucris $(\mathrm{n}=2)$; Campylobacter $s p(\mathrm{n}=1)$ (Supplementary File 1). Genomes belonging to $C$. jejuni and $C$. coli species were selected to represent a wide range of hosts, sequence types, and clonal complexes and reflect the known population structure for these two species. For other Campylobacter species, all genomes that were publicly available at the time of this study were included in the analysis. (Supplementary File 1).

\section{Pangenome characterization and phylogenetic analysis}

Sequence data were analysed using PIRATE, a fast and scalable pangenomics tool which allows for orthologue gene clustering in divergent bacterial species [91]. Genomes were annotated in Prokka [92], using a genus database comprising well annotated $C$. jejuni strains NCTC11168, 81116, 81-176 and M1, and plasmids pTet and pVir in addition to the already existing databases used by Prokka [92]. Briefly, annotated genomes were used as input for PIRATE. Non-redundant representative sequences were produced using CD-HIT and the longest sequence was used as a reference for sequence similarity interrogation using BLAST/DIAMOND. Gene orthologues were defined as "gene families" and were clustered in different MCL thresholds, from 10 to $98 \%$ sequence identity $(10,20,30,40,50,60,70$, 80, 90, 95, 98). Higher MCL thresholds were used to identify allelic variation within different loci. An inflation value of 4 was used to increase the granularity of MCL clustering between gene families. BLAST high-scoring pairs with a reciprocal minimum length of $90 \%$ of the query/subject sequence were excluded from MCL clustering to reduce the number of spurious associations between distantly related or conserved genes [93]. This information was used to generate gene presence/absence and allelic variation matrices. A core gene-by-gene multiple sequence alignment [89] was generated using MAFFT [94] comprising genes shared $>95 \%$ of isolates. Phylogenetic trees, based on core gene-by-gene alignments, were reconstructed 
using the maximum-likelihood algorithm implemented in RAxML v8.2.11 [95] with GTRGAMMA as substitution model.

\section{Quantifying core and accessory genome variation}

457 The degree of genetic differentiation between species was investigated gene-by-gene as in 458 previous studies $[40,96]$ by calculating the average nucleotide identity (ANI) of all 631 459 Campylobacter genomes using FastANI v.1.0 [59]. The analysis generated a lower triangular 460 matrix with the lowest ANI value at $75 \%$ (as computed by FastANI). A comparable gene presence/absence matrix was produced using PIRATE and was further used to generate a heatmap of accessory genome similarity based upon gene presence or absence. Subsequently, all Campylobacter genomes were screened for the presence of antimicrobial resistance genes against the CARD [62], ResFinder [63] and NCBI databases. All Campylobacter genomes were further screened for the presence of phage, conjugative elements and plasmid DNA using publicly available online databases to investigate the effect of other transfer mechanisms. First, we used the PHAge Search Tool Enhanced Release (PHASTER) [97] to identify and annotate prophage sequences within our genomes. A total of $86 \%$ (254/297) of the genomes used in chromosome painting were found to have DNA sequence of phage origin. Second, we used Iceberg 2.0 [98] for the detection of integrative and conjugative elements, identifying 32 ICEs in 19\% (56/297) of the genomes used in the chromosome painting analysis. Finally, we used MOB-suite software for clustering, reconstruction and typing of plasmids from draft assemblies [99, 100]. A positive hit was defined when a gene had $>75 \%$ nucleotide identity over $>50 \%$ of the sequence length showing that 32 genes identified in the recombination analysis have also been located on plasmids. A gene presence/absence matrix for every antimicrobial resistance gene was generated for every genome. Genomes carrying AMR genes were screened to characterize the location of adjacent genes using SnapGene software (GSL Biotech; available at snapgene.com), as previously described [64]. The number of core SNPs was identified using SNP-sites (v2.3.2)

\section{Inference of recombination}

483 Each combination of a recipient group and multiple donor groups (belonging to the same CC but isolated from different hosts) was selected to compare the extent of interspecies recombination into the recipient genomes. Each donor group consisted of 8 isolates to avoid the influence of difference in sample size on estimation of the extent of interspecies 
recombination. Each recipient group included at least 4 isolates. We excluded $C$. jejuni and C. coli clade 1 genomes isolated from seals and water, as these most likely represent spillover events and not true host segregated populations. Briefly, we conducted a pairwise genome alignment between reference genome NCTC11168 and one of the strains included in the donor-recipient analysis using progressiveMauve [102]. This enabled the construction of positional homology alignments for all genomes regardless gene content and genome rearrangements, which were then combined into a multiple whole-genome alignment, as previously described [103]. ChromoPainterV2 software was used to calculate the amount of DNA sequence that is donated from a donor to a recipient group [45]. Briefly, for each donorrecipient pair, SNPs in which $>90 \%$ recipient individuals had recombined with the donor group were considered in the analysis. These SNPs were mapped to genomic regions and specific genes were identified. A total of 258,444 (96.83\%) recombining SNPs mapped to 558 genes of the NCTC11168 reference strain with $>90 \%$ probability of copying from a donor to a recipient strain. Genes containing the highest number of recombining SNPs were considered for subsequent analyses $\left(>95^{\text {th }}\right.$ percentile) (Supplementary File 2). ClonalFrameML[104] was used to infer the relative number of substitutions introduced by recombination $(r)$ and mutation $(m)$ as the ratio $r / m$ as previously described [16].

\section{Data availability}

506 Genomes sequenced as part of other studies are archived on the Short Read Archive associated with BioProject accessions: PRJNA176480, PRJNA177352, PRJNA342755, PRJNA345429， PRJNA312235， PRJNA415188， PRJNA524300， PRJNA528879, PRJNA529798, PRJNA575343, PRJNA524315 and PRJNA689604. Additional genomes were also downloaded from NCBI [105] and pubMLST (http://pubmlst.org/campylobacter).

511 Contiguous assemblies of all genome sequences compared are available at the public data

512 repository Figshare (doi: 10.6084/m9.figshare.15061017) and individual project and accession numbers can be found in Supplementary File 1.

\section{References}

516 1. Smith JM, Dowson CG, Spratt BG. Localized sex in bacteria. Nature 1991; 349: 29$517 \quad 31$.

518 2. Sheppard SK, Guttman DS, Fitzgerald JR. Population genomics of bacterial host 519 adaptation. Nat Rev Genet 2018; 19: 549-565.

520 3. Shapiro BJ, Leducq J-B, Mallet J. What Is Speciation? PLOS Genet 2016; 12: 
e1005860.

4. Doolittle WF, Zhaxybayeva O. On the origin of prokaryotic species. Genome Res 2009; 19: 744-756.

524 5. Doolittle WF, Papke RT. Genomics and the bacterial species problem. Genome Biol 2006; 7: 116.

526 6. Fraser C, Hanage WP, Spratt BG. Recombination and the nature of bacterial speciation. Science 2007; 315: 476-80.

528 7. Budroni S, Siena E, Hotopp JCD, Seib KL, Serruto D, Nofroni C, et al. Neisseria meningitidis is structured in clades associated with restriction modification systems that modulate homologous recombination. Proc Natl Acad Sci 2011; 108: 4494-4499.

8. Oliveira PH, Touchon M, Rocha EPC. Regulation of genetic flux between bacteria by restriction-modification systems. Proc Natl Acad Sci 2016; 113: 5658-5663.

9. Doron S, Melamed S, Ofir G, Leavitt A, Lopatina A, Keren M, et al. Systematic discovery of antiphage defense systems in the microbial pangenome. Science (80- ) 2018; 359: eaar4120.

10. Nandi T, Holden MTG, Didelot X, Mehershahi K, Boddey JA, Beacham I, et al. Burkholderia pseudomallei sequencing identifies genomic clades with distinct recombination, accessory, and epigenetic profiles. Genome Res 2015; 25: 129-141.

11. Marraffini LA, Sontheimer EJ. CRISPR Interference Limits Horizontal Gene Transfer in Staphylococci by Targeting DNA. Science (80- ) 2008; 322: 1843-1845.

12. Thomas CM, Nielsen KM. Mechanisms of, and Barriers to, Horizontal Gene Transfer between Bacteria. Nat Rev Microbiol 2005; 3: 711-721.

13. Eggleston AK, Mitchell AH, West SC. In Vitro Reconstitution of the Late Steps of Genetic Recombination in E. coli. Cell 1997; 89: 607-617.

14. Zhu P, van der Ende A, Falush D, Brieske N, Morelli G, Linz B, et al. Fit genotypes and escape variants of subgroup III Neisseria meningitidis during three pandemics of epidemic meningitis. Proc Natl Acad Sci 2001; 98: 5234-5239.

15. Boni MF, Lemey P, Jiang X, Lam TT-Y, Perry BW, Castoe TA, et al. Evolutionary origins of the SARS-CoV-2 sarbecovirus lineage responsible for the COVID-19 pandemic. Nat Microbiol 2020; 5: 1408-1417.

16. Mourkas E, Taylor AJ, Méric G, Bayliss SC, Pascoe B, Mageiros L, et al. Agricultural intensification and the evolution of host specialism in the enteric pathogen Campylobacter jejuni. Proc Natl Acad Sci 2020; 117: 11018-11028.

17. Johnson AP, Woodford N. Global spread of antibiotic resistance: the example of New 
Delhi metallo- $\beta$-lactamase (NDM)-mediated carbapenem resistance. J Med Microbiol 2013; 62: 499-513.

18. Schwarz S, Johnson AP. Transferable resistance to colistin: a new but old threat. $J$ Antimicrob Chemother 2016; 71: 2066-70.

19. Baker KS, Dallman TJ, Field N, Childs T, Mitchell H, Day M, et al. Horizontal antimicrobial resistance transfer drives epidemics of multiple Shigella species. Nat Commun 2018; 9: 1462.

20. Young JPW. Bacteria Are Smartphones and Mobile Genes Are Apps. Trends Microbiol 2016; 24: 931-932.

21. McInerney JO, Whelan FJ, Domingo-Sananes MR, McNally A, O'Connell MJ. Pangenomes and Selection: The Public Goods Hypothesis. The Pangenome. 2020. Springer International Publishing, Cham, pp 151-167.

22. Vos M, Eyre-Walker A. Are pangenomes adaptive or not? Nat Microbiol 2017; 2: 1576.

23. Werren JH. Selfish genetic elements, genetic conflict, and evolutionary innovation. Proc Natl Acad Sci 2011; 108: 10863-10870.

24. Giacomelli M, Piccirillo A. Pet reptiles as potential reservoir of Campylobacter species with zoonotic potential: TABLE 1: Vet Rec 2014; 174: 479.2-479.

25. Fitzgerald C, Tu Z chao, Patrick M, Stiles T, Lawson AJ, Santovenia M, et al. Campylobacter fetus subsp. testudinum subsp. nov., isolated from humans and reptiles. Int J Syst Evol Microbiol 2014; 64: 2944-2948.

26. Griekspoor P, Colles FM, McCarthy ND, Hansbro PM, Ashhurst-Smith C, Olsen B, et al. Marked host specificity and lack of phylogeographic population structure of Campylobacter jejuni in wild birds. Mol Ecol 2013; 22: 1463-1472.

27. Atterby C, Mourkas E, Méric G, Pascoe B, Wang H, Waldenström J, et al. The Potential of Isolation Source to Predict Colonization in Avian Hosts: A Case Study in Campylobacter jejuni Strains From Three Bird Species. Front Microbiol 2018; 9.

28. Leatherbarrow AJH, Griffiths R, Hart CA, Kemp R, Williams NJ, Diggle PJ, et al. Campylobacter lari: genotype and antibiotic resistance of isolates from cattle, wildlife and water in an area of mixed dairy farmland in the United Kingdom. Environ Microbiol 2007; 9: 1772-1779.

29. Man SM. The clinical importance of emerging Campylobacter species. Nat Rev Gastroenterol Hepatol 2011; 8: 669-685.

30. Kaakoush NO, Castaño-Rodríguez N, Mitchell HM, Man SM. Global Epidemiology of 
31. Sheppard SK, Dallas JF, MacRae M, McCarthy ND, Sproston EL, Gormley FJ, et al. Campylobacter genotypes from food animals, environmental sources and clinical disease in Scotland 2005/6. Int J Food Microbiol 2009; 134: 96-103.

32. Sheppard SK, Dallas JF, Strachan NJC, MacRae M, McCarthy ND, Wilson DJ, et al. Campylobacter genotyping to determine the source of human infection. Clin Infect Dis

33. Sheppard SK, Colles FM, McCarthy ND, Strachan NJC, Ogden ID, Forbes KJ, et al. Niche segregation and genetic structure of Campylobacter jejuni populations from wild and agricultural host species. Mol Ecol 2011; 20: 3484-90.

34. Dearlove BL, Cody AJ, Pascoe B, Méric G, Wilson DJ, Sheppard SK. Rapid host switching in generalist Campylobacter strains erodes the signal for tracing human infections. ISME J 2016; 10: 721-729.

35. Sheppard SK, Colles F, Richardson J, Cody AJ, Elson R, Lawson A, et al. Host Association of Campylobacter Genotypes Transcends Geographic Variation. Appl Environ Microbiol 2010; 76: 5269-5277.

38. Colles FM, Dingle KE, Cody AJ, Maiden MCJ. Comparison of Campylobacter Populations in Wild Geese with Those in Starlings and Free-Range Poultry on the Same Farm. Appl Environ Microbiol 2008; 74: 3583-3590.

39. Colles FM, McCarthy ND, Bliss CM, Layton R, Maiden MCJ. The long-term dynamics of Campylobacter colonizing a free-range broiler breeder flock: an observational study. Environ Microbiol 2015; 17: 938-946.

40. Sheppard SK, Didelot X, Jolley KA, Darling AE, Pascoe B, Meric G, et al. Progressive genome-wide introgression in agricultural Campylobacter coli. Mol Ecol 2013; 22: 1051-64.

41. Taylor AJ, Méric G, Yahara K, Pascoe B, Mageiros L, Mourkas E, et al. Cross-species evolutionary rewiring in the enteric bacterium Campylobacter; bioRxiv 2021; 2021.03.15.435406. 
42. Sheppard SK, McCarthy ND, Falush D, Maiden MCJ. Convergence of Campylobacter Species: Implications for Bacterial Evolution. Science (80- ) 2008; 320: 237-239.

43. Sheppard SK, McCarthy ND, Jolley KA, Maiden MCJ. Introgression in the genus Campylobacter: generation and spread of mosaic alleles. Microbiology 2011; 157: 1066-1074.

44. Thorell K, Yahara K, Berthenet E, Lawson DJ, Mikhail J, Kato I, et al. Rapid evolution of distinct Helicobacter pylori subpopulations in the Americas. PLOS Genet 2017; 13: e1006730.

45. Lawson DJ, Hellenthal G, Myers S, Falush D. Inference of Population Structure using Dense Haplotype Data. PLoS Genet 2012; 8: e1002453.

46. Yahara K, Furuta Y, Oshima K, Yoshida M, Azuma T, Hattori M, et al. Chromosome Painting In Silico in a Bacterial Species Reveals Fine Population Structure. Mol Biol Evol 2013; 30: 1454-1464.

47. Dingle KE, Colles FM, Wareing DR, Ure R, Fox AJ, Bolton FE, et al. Multilocus sequence typing system for Campylobacter jejuni. J Clin Microbiol 2001; 39: 14-23.

48. Kirk KF, Méric G, Nielsen HL, Pascoe B, Sheppard SK, Thorlacius-Ussing O, et al. Molecular epidemiology and comparative genomics of Campylobacter concisus strains from saliva, faeces and gut mucosal biopsies in inflammatory bowel disease. Sci Rep 2018; 8: 1902.

49. Iraola G, Forster SC, Kumar N, Lehours P, Bekal S, García-Peña FJ, et al. Distinct Campylobacter fetus lineages adapted as livestock pathogens and human pathobionts in the intestinal microbiota. Nat Commun 2017; 8: 1367.

50. Debruyne L, On SLW, De Brandt E, Vandamme P. Novel Campylobacter lari-like bacteria from humans and molluscs: description of Campylobacter peloridis sp. nov., Campylobacter lari subsp. concheus subsp. nov. and Campylobacter lari subsp. lari subsp. nov. Int J Syst Evol Microbiol 2009; 59: 1126-32.

51. Gilbert MJ, Kik M, Miller WG, Duim B, Wagenaar JA. Campylobacter iguaniorum sp. nov., isolated from reptiles. Int J Syst Evol Microbiol 2015; 65: 975-982.

52. Piccirillo A, Niero G, Calleros L, Pérez R, Naya H, Iraola G. Campylobacter geochelonis sp. nov. isolated from the western Hermann's tortoise (Testudo hermanni hermanni). Int J Syst Evol Microbiol 2016; 66: 3468-3476.

53. Logan JMJ, Burnens A, Linton D, Lawson AJ, Stanley J. Campylobacter lanienae sp. nov., a new species isolated from workers in an abattoir. Int J Syst Evol Microbiol 2000; 50: 865-872. 
54. Van TTH, Elshagmani E, Gor MC, Scott PC, Moore RJ. Campylobacter hepaticus sp. nov., isolated from chickens with spotty liver disease. Int J Syst Evol Microbiol 2016; 66: $4518-4524$.

55. Miller WG, Yee E, Chapman MH, Smith TPL, Bono JL, Huynh S, et al. Comparative genomics of the Campylobacter lari group. Genome Biol Evol 2014; 6: 3252-66.

56. Gilbert MJ, Miller WG, Leger JS, Chapman MH, Timmerman AJ, Duim B, et al. Campylobacter pinnipediorum sp. nov., isolated from pinnipeds, comprising Campylobacter pinnipediorum subsp. pinnipediorum subsp. nov. and Campylobacter pinnipediorum subsp. caledonicus subsp. nov. Int J Syst Evol Microbiol 2017; 67: 1961-1968.

57. Pascoe B, Méric G, Yahara K, Wimalarathna H, Murray S, Hitchings MD, et al. Local genes for local bacteria: Evidence of allopatry in the genomes of transatlantic Campylobacter populations. Mol Ecol 2017; 26: 4497-4508.

58. Pascoe B, Williams LK, Calland JK, Meric G, Hitchings MD, Dyer M, et al. Domestication of Campylobacter jejuni NCTC 11168. Microb genomics 2019; 5.

59. Jain C, Rodriguez-R LM, Phillippy AM, Konstantinidis KT, Aluru S. High throughput ANI analysis of $90 \mathrm{~K}$ prokaryotic genomes reveals clear species boundaries. Nat Commun 2018; 9: 5114.

60. Yao H, Shen Z, Wang Y, Deng F, Liu D, Naren G, et al. Emergence of a Potent Multidrug Efflux Pump Variant That Enhances Campylobacter Resistance to Multiple Antibiotics. MBio 2016; 7: 1-11.

61. Livermore DM. Introduction: the challenge of multiresistance. Int J Antimicrob Agents 2007; 29: S1-S7.

62. Jia B, Raphenya AR, Alcock B, Waglechner N, Guo P, Tsang KK, et al. CARD 2017: expansion and model-centric curation of the comprehensive antibiotic resistance database. Nucleic Acids Res 2017; 45: D566-D573.

63. Zankari E, Hasman H, Cosentino S, Vestergaard M, Rasmussen S, Lund O, et al. Identification of acquired antimicrobial resistance genes. J Antimicrob Chemother 2012; 67: 2640-2644.

64. Mourkas E, Florez-Cuadrado D, Pascoe B, Calland JK, Bayliss SC, Mageiros L, et al. Gene pool transmission of multidrug resistance among Campylobacter from livestock, sewage and human disease. Environ Microbiol 2019; 21: 4597-4613.

65. Abril C, Brodard I, Perreten V. Two Novel Antibiotic Resistance Genes, tet(44) and ant(6)-Ib, Are Located within a Transferable Pathogenicity Island in Campylobacter 
fetus subsp. fetus. Antimicrob Agents Chemother 2010; 54: 3052-3055.

66. Szymanski CM, Logan SM, Linton D, Wren BW. Campylobacter - a tale of two protein glycosylation systems. Trends Microbiol 2003; 11: 233-238.

67. McLennan MK, Ringoir DD, Frirdich E, Svensson SL, Wells DH, Jarrell H, et al. Campylobacter jejuni Biofilms Up-Regulated in the Absence of the Stringent Response Utilize a Calcofluor White-Reactive Polysaccharide. J Bacteriol 2008; 190: $1097-1107$.

68. Margus T, Remm M, Tenson T. Phylogenetic distribution of translational GTPases in bacteria. BMC Genomics 2007; 8: 1-18.

69. Semanjski M, Germain E, Bratl K, Kiessling A, Gerdes K, Macek B. The kinases HipA and HipA7 phosphorylate different substrate pools in Escherichia coli to promote multidrug tolerance. Sci Signal 2018; 11.

70. Mikheil DM, Shippy DC, Eakley NM, Okwumabua OE, Fadl AA. Deletion of gene encoding methyltransferase ( $g i d B$ ) confers high-level antimicrobial resistance in Salmonella. J Antibiot (Tokyo) 2012; 65: 185-192.

71. Benoit SL, Maier RJ. Site-directed mutagenesis of Campylobacter concisus respiratory genes provides insight into the pathogen's growth requirements. Sci Rep 2018; 8: 14203.

72. Cody AJ, McCarthy ND, Bray JE, Wimalarathna HML, Colles FM, Jansen van Rensburg MJ, et al. Wild bird-associated Campylobacter jejuni isolates are a consistent source of human disease, in Oxfordshire, United Kingdom. Environ Microbiol Rep 2015; 7: 782-788.

73. Hayashi H, Takahashi R, Nishi T, Sakamoto M, Benno Y. Molecular analysis of jejunal, ileal, caecal and recto-sigmoidal human colonic microbiota using 16S rRNA gene libraries and terminal restriction fragment length polymorphism. J Med Microbiol 2005; 54: 1093-1101.

74. Lu J, Idris U, Harmon B, Hofacre C, Maurer JJ, Lee MD. Diversity and succession of the intestinal bacterial community of the maturing broiler chicken. Appl Environ Microbiol 2003; 69: 6816-24.

75. Stecher B, Chaffron S, Käppeli R, Hapfelmeier S, Freedrich S, Weber TC, et al. Like will to like: abundances of closely related species can predict susceptibility to intestinal colonization by pathogenic and commensal bacteria. PLoS Pathog 2010; 6: e1000711.

76. van Elsas JD, Chiurazzi M, Mallon CA, Elhottova D, Kristufek V, Salles JF. Microbial 
diversity determines the invasion of soil by a bacterial pathogen. Proc Natl Acad Sci U S A 2012; 109: 1159-64.

77. Nowrouzian FL, Wold AE, Adlerberth I. Escherichia coli strains belonging to phylogenetic group B2 have superior capacity to persist in the intestinal microflora of infants. J Infect Dis 2005; 191: 1078-83.

78. Howlett RM, Hughes BM, Hitchcock A, Kelly DJ. Hydrogenase activity in the foodborne pathogen Campylobacter jejuni depends upon a novel ABC-type nickel transporter (NikZYXWV) and is SlyD-independent. Microbiology 2012; 158: 16451655.

79. Choi K-H. Applications of Transposon-Based Gene Delivery System in Bacteria. $J$ Microbiol Biotechnol 2009; 19: 217-28.

80. Pittman MS, Elvers KT, Lee L, Jones MA, Poole RK, Park SF, et al. Growth of Campylobacter jejuni on nitrate and nitrite: electron transport to NapA and NrfA via $\mathrm{NrfH}$ and distinct roles for $\mathrm{NrfA}$ and the globin $\mathrm{Cgb}$ in protection against nitrosative stress. Mol Microbiol 2007; 63: 575-590.

81. Alexander J, Benford D, Cockburn A, Cravedi J, Dogliotti E, Domenico A Di, et al. Nitrite as undesirable substances in animal feed - Scientific Opinion of the Panel on Contaminants in the Food Chain. EFSA J 2009; 7: 1-47.

82. Teuber M. Veterinary use and antibiotic resistance. Curr Opin Microbiol 2001; 4: 493-499.

83. Price LB, Koch BJ, Hungate BA. Ominous projections for global antibiotic use in food-animal production. Proc Natl Acad Sci U S A 2015; 112: 5554-5.

84. Luo N, Sahin O, Lin J, Michel LO, Zhang Q. In Vivo Selection of Campylobacter Isolates with High Levels of Fluoroquinolone Resistance Associated with gyrA Mutations and the Function of the CmeABC Efflux Pump. Antimicrob Agents Chemother 2003; 47: 390-394.

85. Sproston EL, Wimalarathna HML, Sheppard SK. Trends in fluoroquinolone resistance in Campylobacter. Microb Genomics 2018; 4: 1-8.

86. Mallet J. Hybrid speciation. Nature 2007; 446: 279-283.

87. Grant PR, Grant BR. Hybridization of Bird Species. Science (80- ) 1992; 256: $193-$ 197.

88. Bar-On YM, Phillips R, Milo R. The biomass distribution on Earth. Proc Natl Acad Sci 2018; 115: 6506-6511.

89. Sheppard SK, Jolley KA, Maiden MCJ. A Gene-By-Gene Approach to Bacterial 

3: $261-277$.

90. Parks DH, Imelfort M, Skennerton CT, Hugenholtz P, Tyson GW. CheckM: assessing the quality of microbial genomes recovered from isolates, single cells, and metagenomes. Genome Res 2015; 25: 1043-1055.

91. Bayliss SC, Thorpe HA, Coyle NM, Sheppard SK, Feil EJ. PIRATE: A fast and scalable pangenomics toolbox for clustering diverged orthologues in bacteria. Gigascience 2019; 8: 1-9.

92. Seemann T. Prokka: rapid prokaryotic genome annotation. Bioinformatics 2014; 30: 2068-2069.

93. Sahl JW, Caporaso JG, Rasko DA, Keim P. The large-scale blast score ratio (LS-BSR) pipeline: a method to rapidly compare genetic content between bacterial genomes. PeerJ 2014; 2: e332.

94. Katoh K. MAFFT: a novel method for rapid multiple sequence alignment based on fast Fourier transform. Nucleic Acids Res 2002; 30: 3059-3066.

95. Stamatakis A. RAxML version 8: a tool for phylogenetic analysis and post-analysis of large phylogenies. Bioinformatics 2014; 30: 1312-1313.

96. Didelot X, Achtman M, Parkhill J, Thomson NR, Falush D. A bimodal pattern of relatedness between the Salmonella Paratyphi A and Typhi genomes: convergence or divergence by homologous recombination? Genome Res 2007; 17: 61-8.

98. Liu M, Li X, Xie Y, Bi D, Sun J, Li J, et al. ICEberg 2.0: an updated database of bacterial integrative and conjugative elements. Nucleic Acids Res 2019; 47: D660D665.

99. Robertson J, Nash JHE. MOB-suite: software tools for clustering, reconstruction and typing of plasmids from draft assemblies. Microb genomics 2018; 4.

100. Robertson J, Bessonov K, Schonfeld J, Nash JHE. Universal whole-sequence-based plasmid typing and its utility to prediction of host range and epidemiological surveillance. Microb Genomics 2020; 6: 1-12.

101. Page AJ, Taylor B, Delaney AJ, Soares J, Seemann T, Keane JA, et al. SNP-sites: rapid efficient extraction of SNPs from multi-FASTA alignments. Microb Genomics 2016; 2: e000056. 
102. Darling AE, Mau B, Perna NT. progressiveMauve: Multiple Genome Alignment with Gene Gain, Loss and Rearrangement. PLoS One 2010; 5: e11147.

103. Yahara K, Nakayama S, Shimuta K, Lee K, Morita M, Kawahata T, et al. Genomic surveillance of Neisseria gonorrhoeae to investigate the distribution and evolution of antimicrobial-resistance determinants and lineages. Microb Genomics 2018; 4: 1-3.

104. Didelot X, Wilson DJ. ClonalFrameML: Efficient Inference of Recombination in Whole Bacterial Genomes. PLOS Comput Biol 2015; 11: e1004041.

105. NCBI Resource Coordinators. Database resources of the National Center for Biotechnology Information. Nucleic Acids Res 2016; 44: D7-D19.

\section{Acknowledgements}

This work was supported by Wellcome Trust grants 088786/C/09/Z and Medical Research Council (MRC) grants MR/M501608/1 and MR/L015080/1 awarded to S.K.S. The computational calculations were performed at the Human Genome Center at the Institute of Medical Science (University of Tokyo) and at the National Institute of Genetics.

\section{Competing interests}

The authors declare no competing interests.

\section{Figure legends}

Figure 1. Barriers to horizontal gene transfer in bacteria. A series of barriers must be surmounted for DNA to transmit from one species to another. These are broadly defined in three categories. At a given time, alignment of holes in successive barriers is necessary for HGT to occur. Here we focus on ecological barriers that are influenced by multiple factors that reflect the physical isolation of bacteria in separate niches.

\section{Figure 2. Population structure and host ecology in the genus Campylobacter. a,} Phylogenetic tree of 631 Campylobacter isolates from 30 species reconstructed using a geneby-gene concatenated alignment of 820 core genes (shared by $>95 \%$ of isolates) and an approximation of the maximum-likelihood algorithm (ML) implemented in RAxML. The species name is indicated adjacent to the associated sequence cluster. The scale bar indicates the estimated number of substitutions per site. b, Isolation source of Campylobacter species with $\mathrm{n} \geq 3$ isolates. 

distribution of the total number of accessory genes (left) and core genes (right) per isolate for each Campylobacter species (where $\mathrm{n} \geq 3$ isolates). The number of accessory genes is shown as boxplots (min to max). b, Venn diagram of pangenomes among different Campylobacter species $(n \geq 9)$. The number of core genes shared by all species is illustrated in the center. $\mathbf{c}$,

832 Pairwise average nucleotide identity comparison calculated for all 631 Campylobacter 833 isolates based upon 820 core genes shared by $>95 \%$ of isolates. ANI values $<75 \%$ are not calculated by FastANI [59]. d, Pairwise accessory genome similarity based upon gene presence or absence at 2,168 non-core loci. The heatmaps coloring ranges from yellow (minimum) to red (maximum). The matrices are ordered according to the phylogenetic tree presented in figure 2a. Different colours correspond to Campylobacter species with $\geq 3$ isolates.

Figure 4. Elevated within-host interspecies recombination and donor-recipient comparisons. a, A hypothesis depicting the relationships between Campylobacter species, $C$. jejuni $\left(x_{1}, x_{2}\right)$ and $C$. coli $(y)$, when found in the same or in different hosts. b, Number of recombining SNPs within and between host as inferred by chromosome painting analysis for all donor recipient species comparisons. The error bar represents the standard error of the mean (SEM). c, The figure shows the number of donated SNPs in 10 donor-recipient pair species comparisons. The proportion $(\%)$ of recombining SNPs with $>90 \%$ probability of copying from a donor to a recipient genome is illustrated in the $y$ axis. All donor groups are shows in the $x$ axis. All coloured boxes correspond to comparison where donors and recipients are found in the same host.

Figure 5. The mobilome of the Campylobacter genus. a, The graph illustrates the proportion of recombining genes in 10 different species comparisons. The number of species pairs in which the gene was found to recombine is shown on the $x$ axis and the number of genes in each category is given on the $y$ axis and. The exact number of genes found in each group comparison is shown on the top of each box. b, Number of Campylobacter species harbouring AMR genes that belong to efflux pumps and four different antibiotic classes which are shown on the $x$ axis. c, The circos plot indicates the 16 genes involved in recombination in $>5$ donor-recipient pair species comparisons. Gene matches are indicated by joining lines, coloured differently for each gene. Gene names are shown around the perimeter

860 for each Campylobacter species. d, The circos plot indicates the sharing of AMR genes 
861

862

863

864

865

866

867

868

869

870

871

872

873

874

875

876

877

878

879

880

881

882

883

884

885

886

887

888

889

890

891

892

893

associated with efflux pumps and four antibiotic classes among Campylobacter species. Presence of at least one gene (not necessarily the same gene) conferring resistance to a specific antibiotic class is indicated by joining lines, coloured differently for each drug class. Efflux pumps (i), $\beta$-lactams (ii), tetracyclines (iii), aminoglycosides (iv) and lincosamides (v) are shown around the perimeter for each Campylobacter species.

\section{Figure 2-figure supplement 1. Population structure of the Campylobacteraceae family.} Phylogenetic tree of 506 isolates that belong to the Campylobacteraceae family with Helicobacter pylori used as an outgroup. Different colors correspond to main species with number of isolates greater than three. The Tree was reconstructed using a gene-by-gene concatenated alignment of 799 core genes shared by $>95 \%$ by all isolates and an approximation of the maximum-likelihood algorithm (ML) implemented in RAxML. The scale bar indicates the estimated number of substitutions per site.

Figure 2-figure supplement 2. Core genome species trees. Single-species trees for nine Campylobacter species with $>4$ isolates demonstrating the diversity for among species. The scale bars indicate the estimated number of substitutions per site. $(*)$ The scale for the tree corresponding to $C$. hepaticus is 10 times smaller than the rest.

\section{Figure 2-figure supplement 3. Overview of host-associations of Campylobacter species.} Abundance and diversity of 631 Campylobacter isolates in each host and environment. Different colours correspond to main species with number of isolates $\geq$ three. The number of isolates is shown on the $y$ axis while the various isolation sources on the $x$ axis.

Figure 2-figure supplement 4. Core genome species trees. Single-species trees for C. jejuni, C. coli and C. fetus species which contain isolates from multiple hosts and countries. The scale bars indicate the estimated number of substitutions per site.

Figure 3-figure supplement 1. Genome size variation of the Campylobacter genus. The frequency distribution of the genome size of all Campylobacter genomes used in this study is shown as a histogram. The number of genomes is shown on the $y$ axis while the genome size (in $b p$ ) on the $x$ axis. 

distribution of the total number of genes per isolate for each Campylobacter species (where $\mathrm{n} \geq 3$ isolates). The number of genes is shown as boxplots ( $\min$ to max).

Figure 3-figure supplement 3. Accessory gene function in all main Campylobacter species. The different gene functions are depicted on the $y$ axis, while the number of shared accessory genes on the $x$ axis. Different colours corresponding to different Campylobacter species.

902

Figure 3-figure supplement 4. Core genome allelic variation and the effect of recombination. a, Number of SNPs per genome of the main Campylobacter species (where $\mathrm{n} \geq 3$ isolates) in the core genome alignment. The horizontal line in each plot represents the mean value while the upper and lower lines the standard deviation. b, Average nucleotide identity for pairwise comparisons of 820 core genes for 605 genomes of 15 main Campylobacter species. Different colours corresponding to different Campylobacter species.

Figure 4-figure supplement 1. Probability of the recipient genomes sharing DNA with each donor groups is illustrated as box whiskers (white) for every donor-recipient comparison for all 10 pairs that supported our hypothesis. The analysis where the host data were randomized across all isolates is illustrated as box whiskers (red). The probability of copying DNA from a donor to a recipient genome is shown on the $y$ axis. The midline in the box whiskers indicates the mean and the error bars the standard deviation.

916

917 Figure 4-figure supplement 2. Genome position of genes containing recombining SNPs.

918 Genes and their corresponding number of recombining SNPs, inferred by Chromosome

919 Painting analysis for all 10 species comparisons, and mapped to the NCTC11168 reference genome. Genes from within-host (red) and between-host (white) pair comparisons are shown for each comparison. Donors are isolates from chicken (triangle), cattle (square), wild bird (cross), pig (star), clinical (circle) and water (snowflake) samples. The dashed line indicates the $95^{\text {th }}$ percentile for every individual group comparison.

Figure 4-figure supplement 3. Genes ranked in ascending order of the number of recombining SNPs they contain as inferred by Chromosome Painting analysis for all ten 
928

929

930

931

932

933

934

935

936

937

938

939

940

941

942

943

944

945

946

947

948

949

950

951

952

953

954

955

956

957

958

959

960

961

each comparison. Donors are isolates from chicken (triangle), cattle (square), wild bird (cross), pig (star), clinical (circle) and water (snowflake) samples.

Figure 5-figure supplement 1. Presence of antimicrobial resistance genes in the Campylobacter genus. The phylogenetic tree was reconstructed using a gene-by-gene concatenated alignment of 820 core and soft-core genes and an approximation of the maximum-likelihood algorithm (ML) implemented in RAxML. The designated colour scheme was used for each species in the first column. The second column indicates whether the strain is isolated from an agricultural animal (grey). Remaining columns indicate presence of AMR genes (black). The scale represents the number of substitutions per site.

Figure 5-figure supplement 2. Genetic organization of AMR genes in Campylobacter. The presence of each AMR gene, highlighted in different colours, is shown for representative genomes from C. jejuni, C. coli, C. lanienae, C. hyointestinalis and C. fetus subspecies fetus sampled from different agricultural animals. The number of isolate genomes containing each genomic arrangement is indicated in parenthesis.

Supplementary File 1. Isolate information about the genomes used in this study.

Supplementary File 2 . Within-host highly $\left(>95^{\text {th }}\right.$ percentile $)$ recombining genes.

Supplementary File 3. Recombination parameters as calculated by ClonalFrameML.

Supplementary File 4. Quantifying recombination between co-habiting species using ChromoPainter.

Supplementary File 5. Genes involved in interspecies recombination in 10 species comparisons.

Figure 3-source data 1. This file contains the numerical values on which the graphs in Figure 3 are based.

Figure 5-source data 1. This file contains the numerical values on which the graphs in Figure 5b-d are based. 


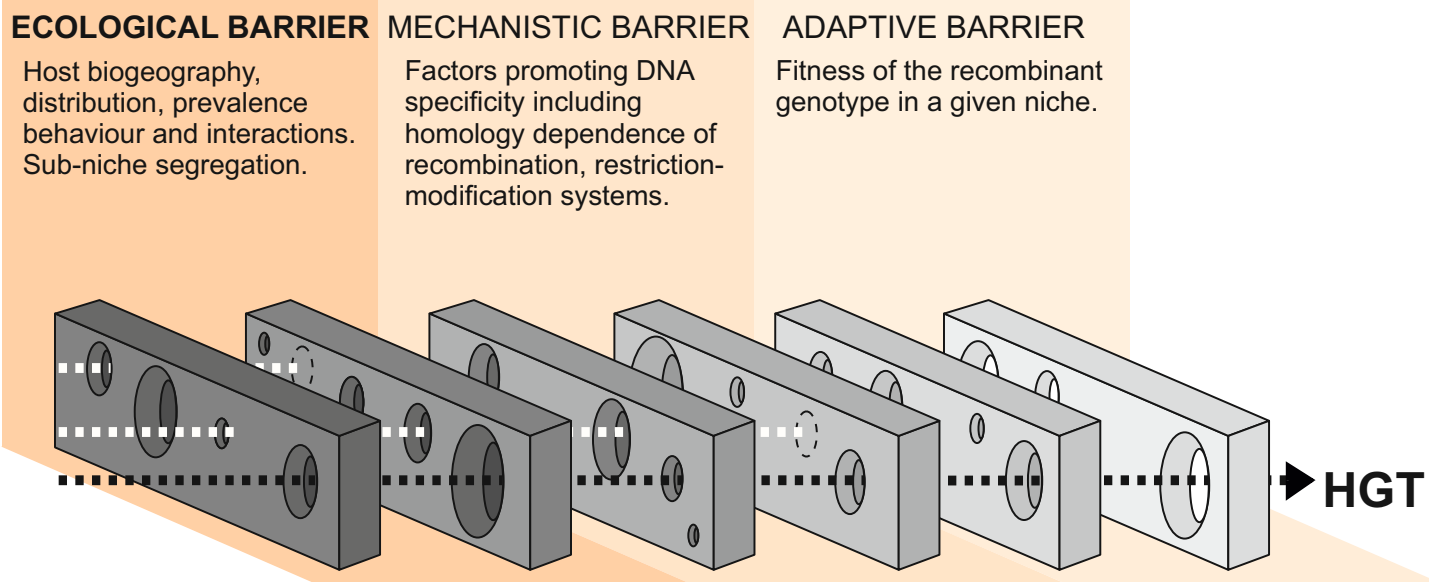


a
c. hepaticus

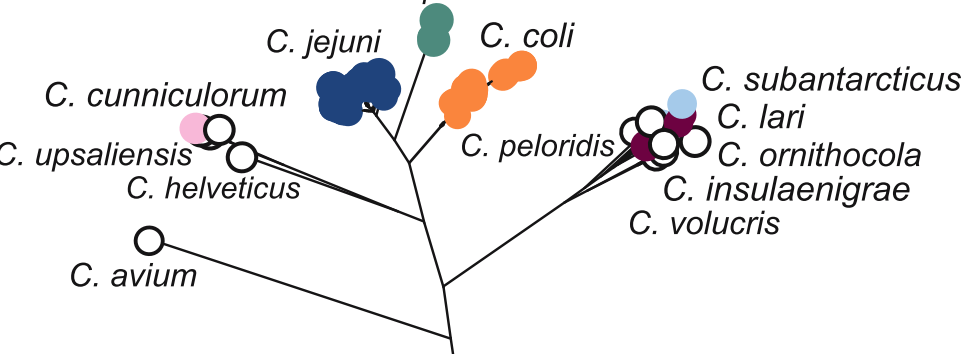
C. coli clade $1(n=103)$
C. coli clade $2(n=19)$
C. pinnipediorum $(\mathrm{n}=9)$
C. coli clade $3(n=18)$
C. jejuni $(n=218)$
C. concisus $(n=106)$
C. lari $(n=13)$
C. fetus $(n=52)$
C. lanienae $(n=26)$
C. hepaticus $(\mathrm{n}=10)$
C. hyointestinalis $(n=16)$
C. geochelonis $(n=3)$
C. ureolyticus $(n=4)$
C. upsaliensis $(\mathrm{n}=3)$
C. showae $(\mathrm{n}=3)$
C. subantarcticus $(n=3)$
C. iguanorium $(\mathrm{n}=3)$
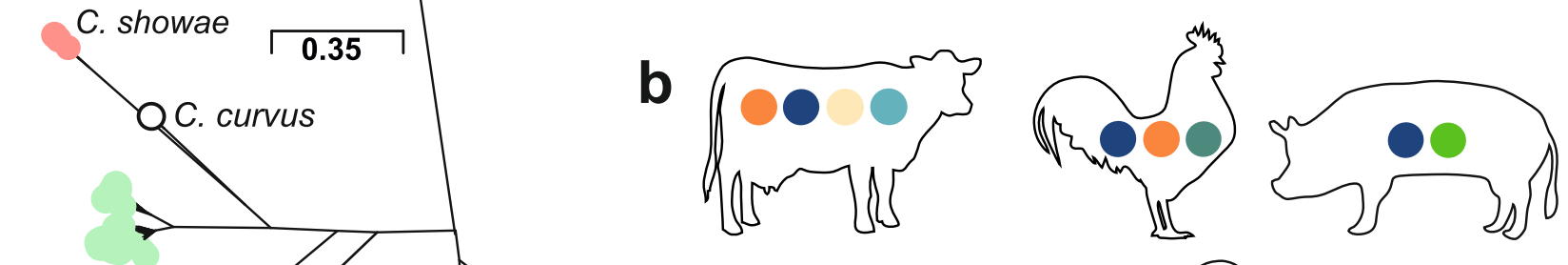

C. concisus

C. mucosalis

C. pinnipediorum

C. iguanorium C. fetus
subs testudinum C. fetus subs fetus
C. fetus subs venerealis
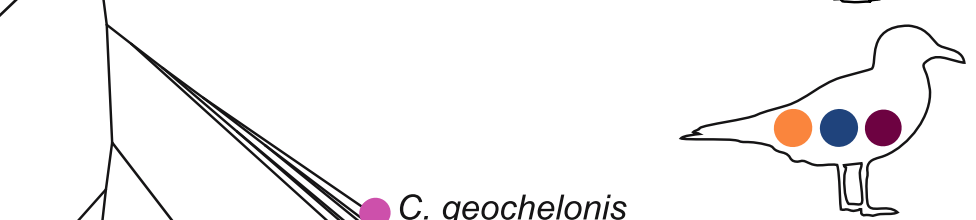

C. geochelonis

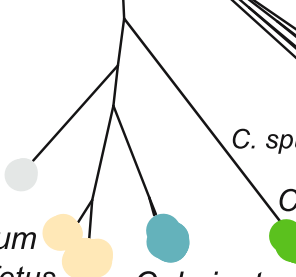

C. hyiontestinalis

C. ureolyticus

C. corcagiensis
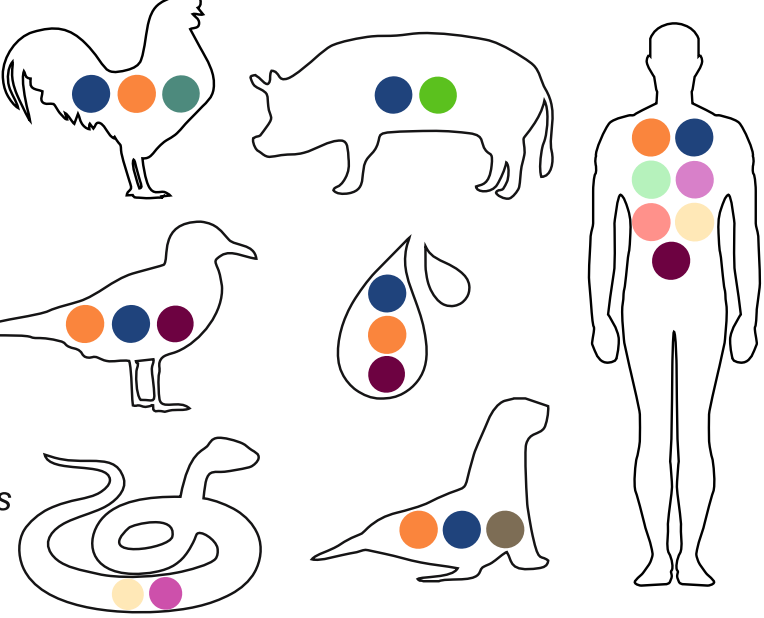

c. gracilis 
a

b
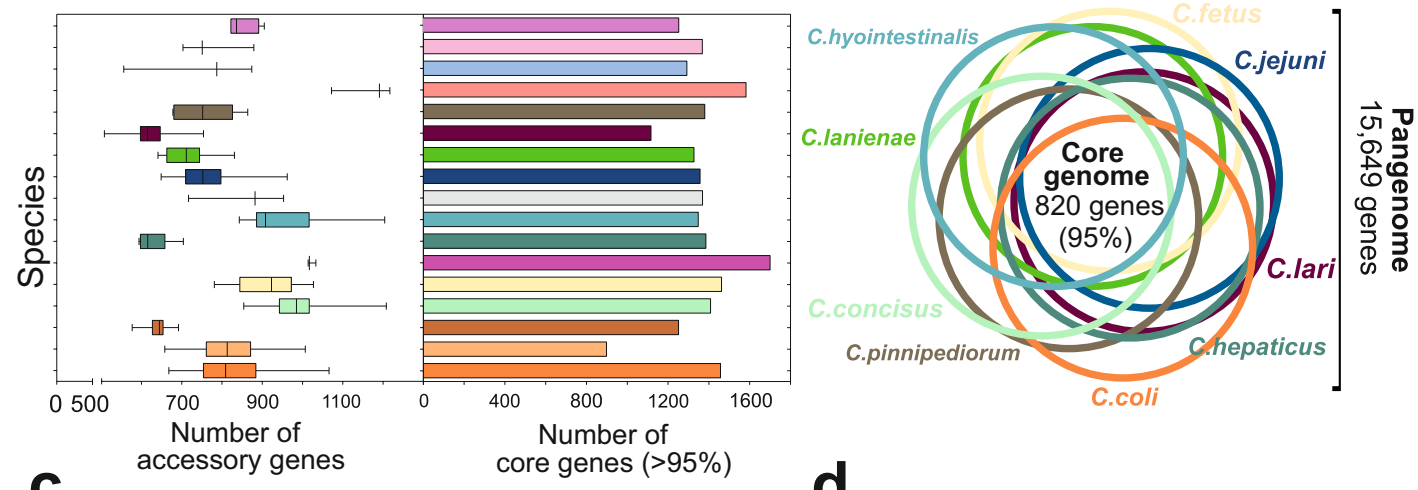

C

Core genome

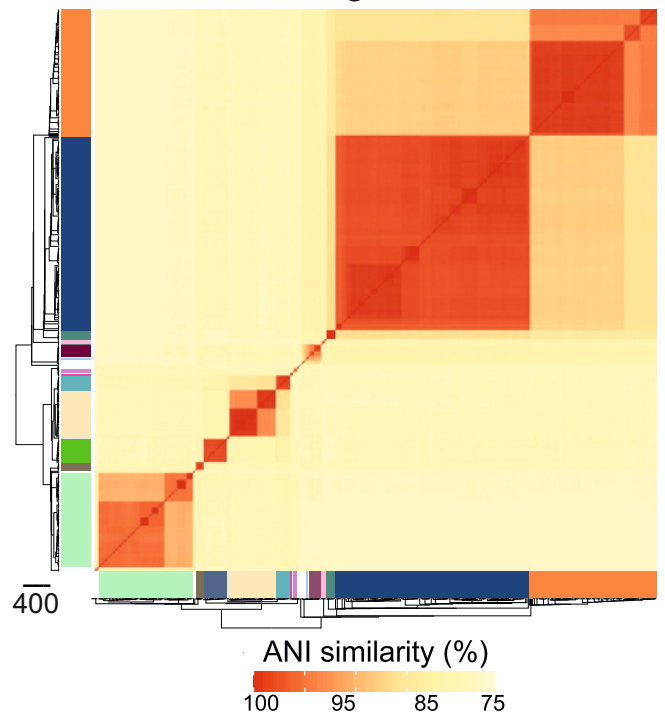

d
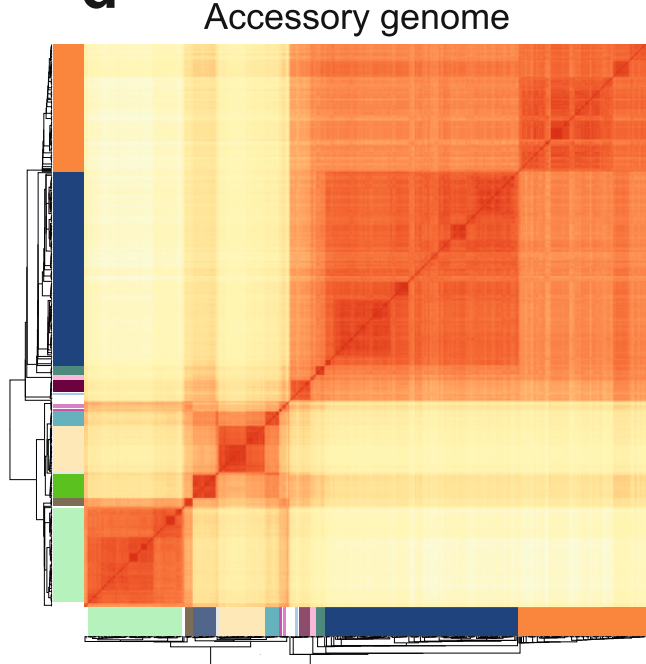

Shared presence matrix similarity

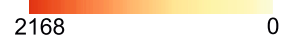

C. coli clade $1(n=103) \square$ C. lanienae $(n=26)$

C. coli clade $2(n=19)$

C. hepaticus $(\mathrm{n}=10)$

C. ureolyticus $(n=4)$

C. coli clade $3(n=18)$

C. jejuni $(\mathrm{n}=218)$

C. concisus $(\mathrm{n}=106)$

C. hyointestinalis $(n=16)$
C. pinnipediorum $(n=9)$

C. upsaliensis $(\mathrm{n}=3)$

C. showae $(n=3)$

C. Iari $(n=13)$

C. geochelonis $(n=3)$

C. subantarcticus $(\mathrm{n}=3)$

C. fetus $(\mathrm{n}=52)$

C. iguanorium $(\mathrm{n}=3)$ 
a

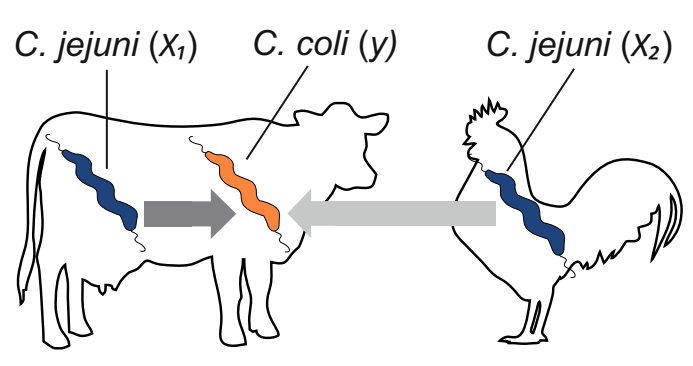

b

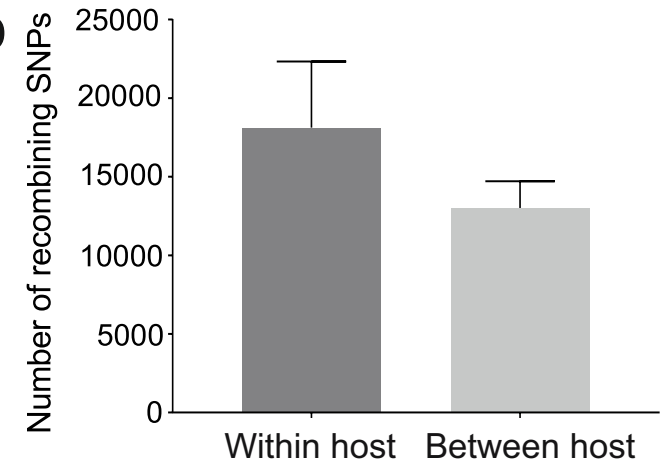

C

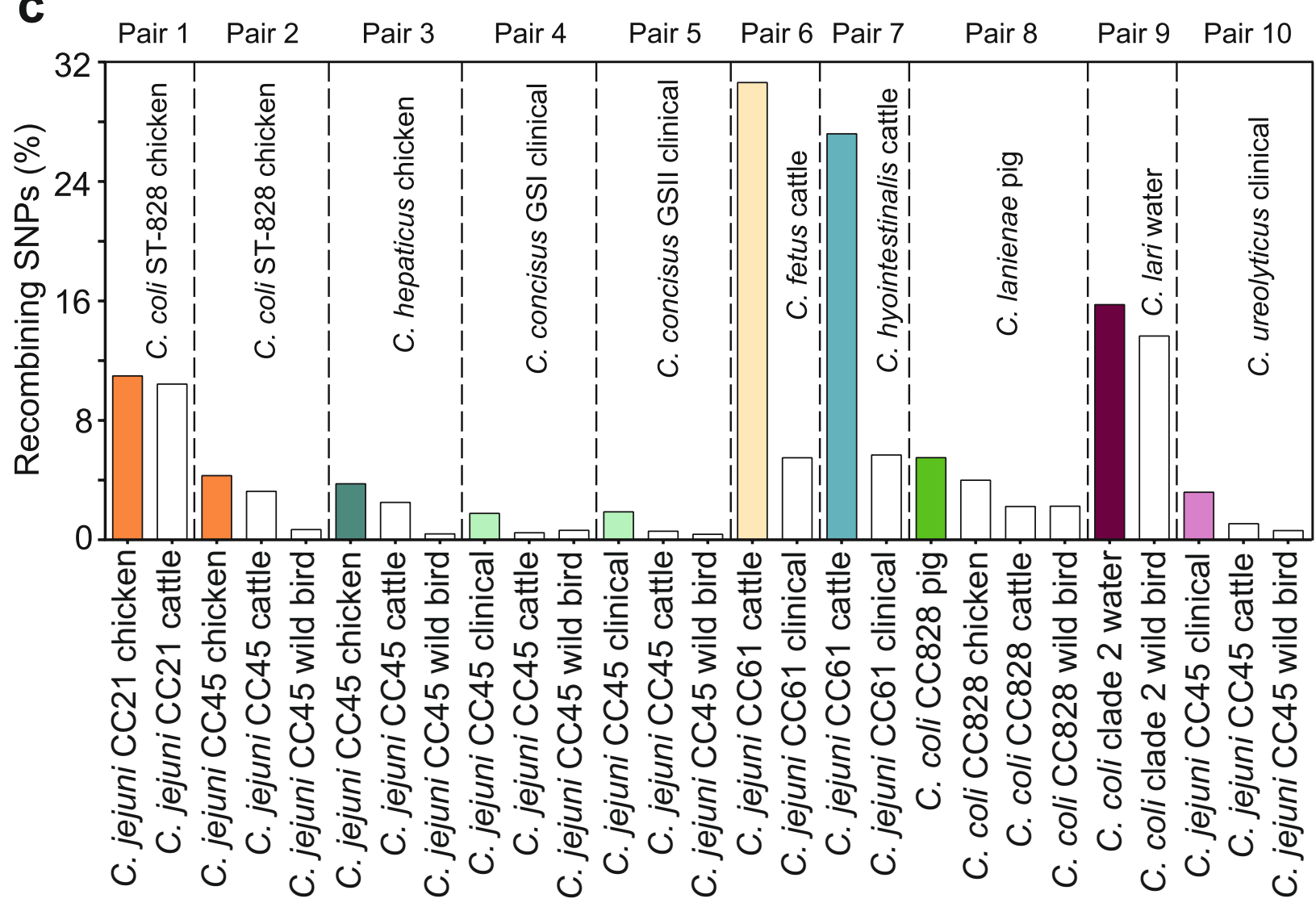


a

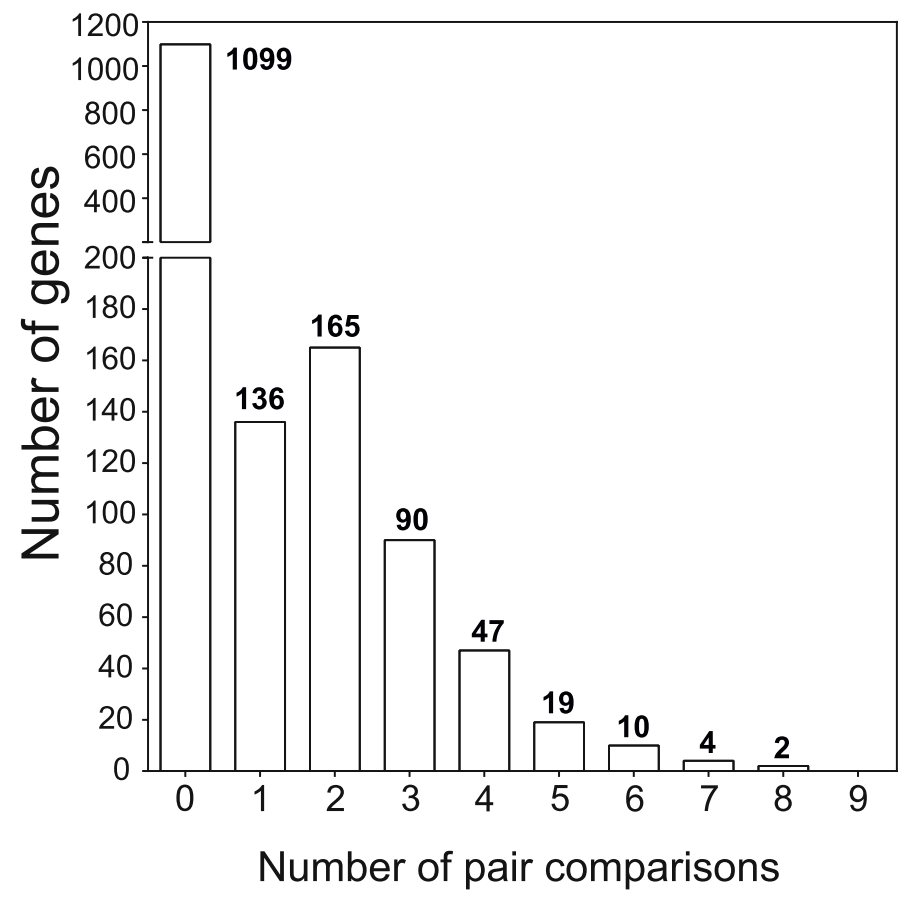

C

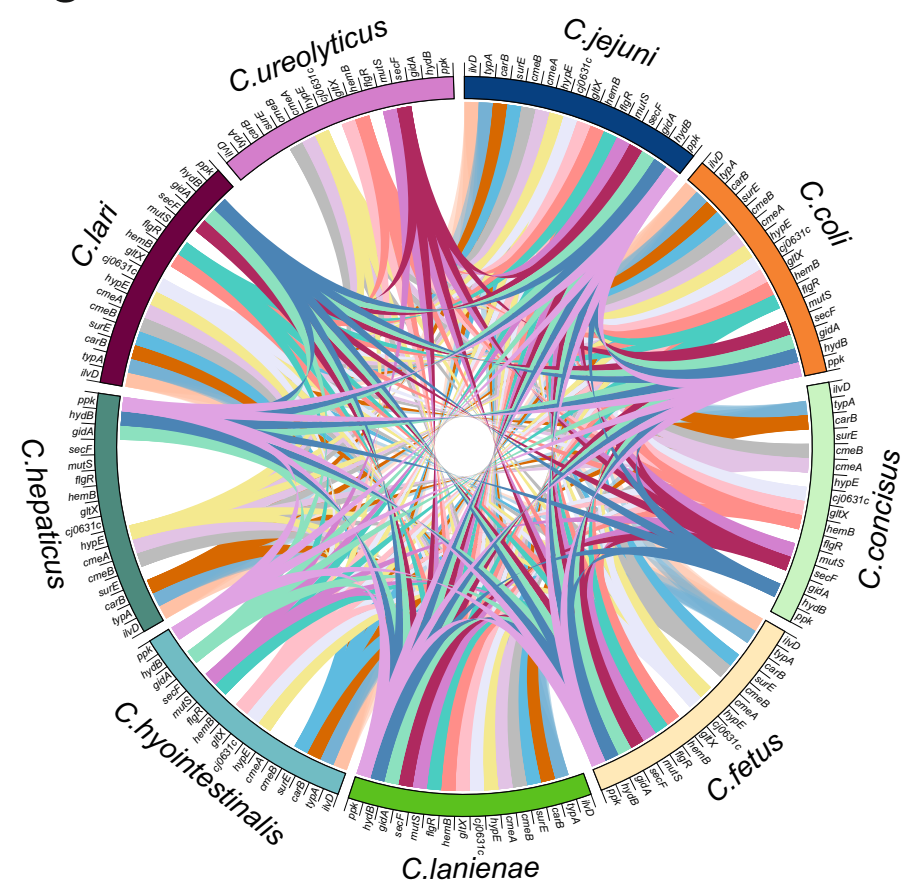

b

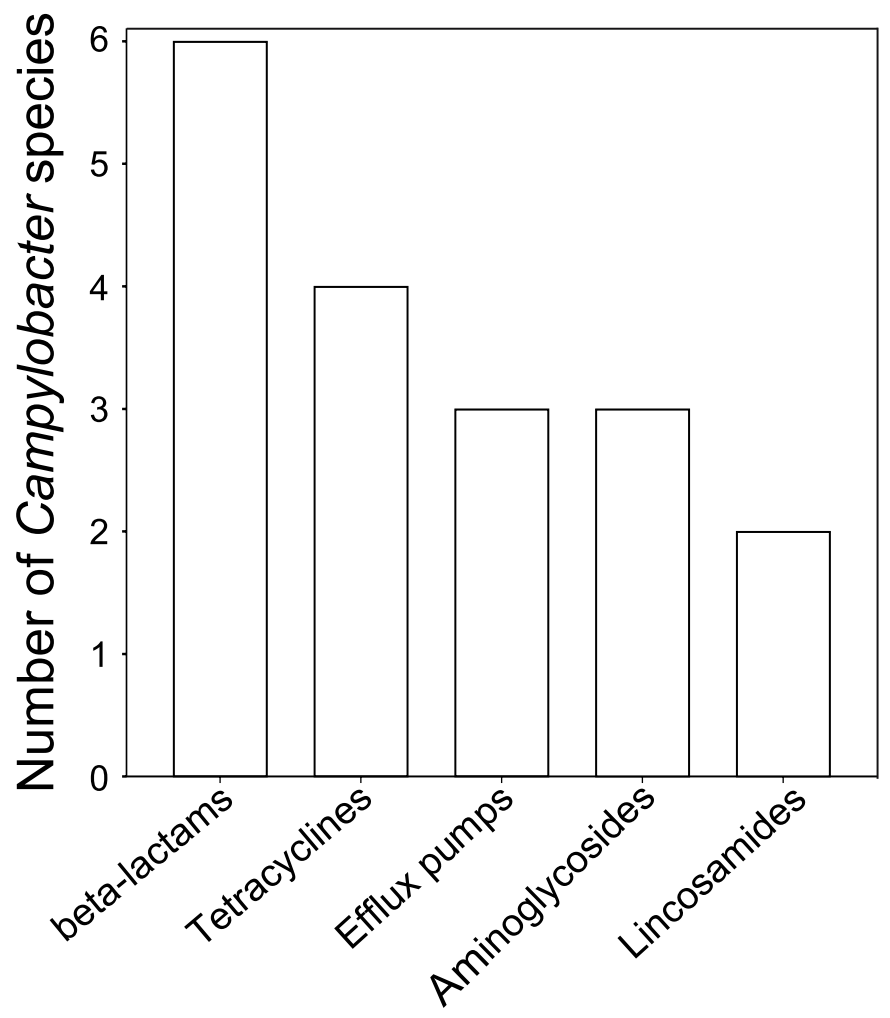

d

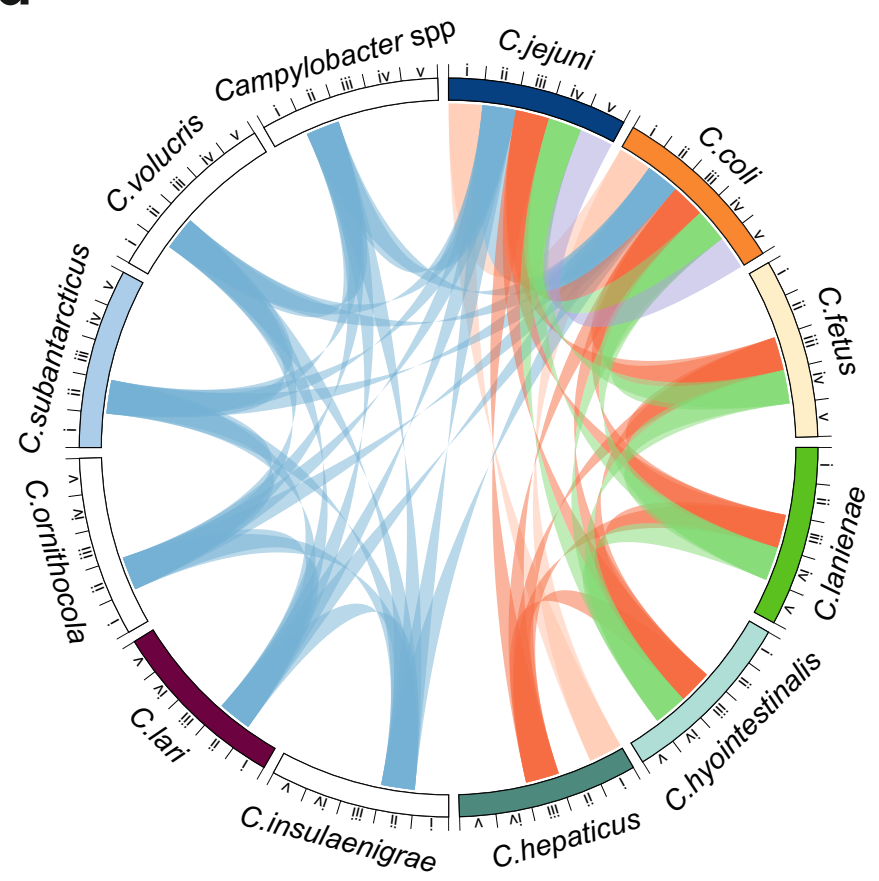


Helicobacter spp

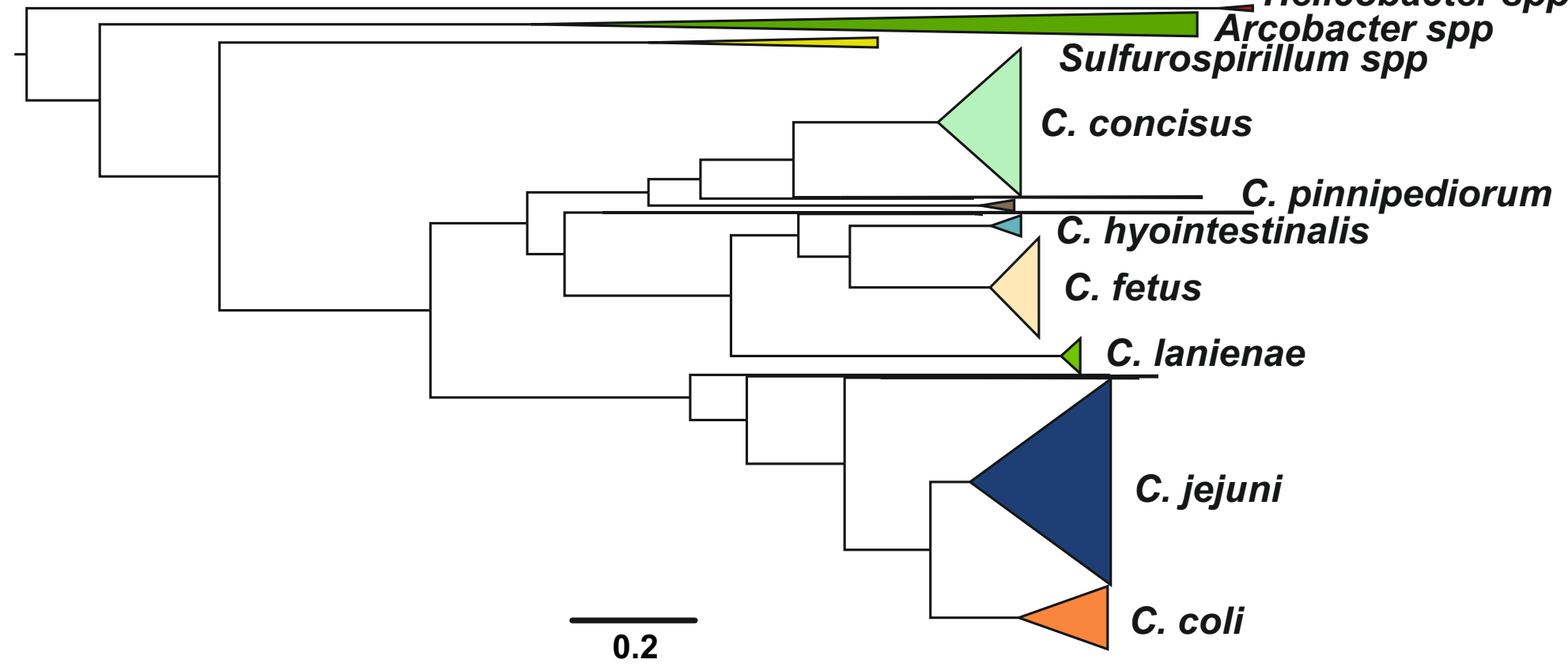


C. jejuni $(\mathrm{n}=218)$

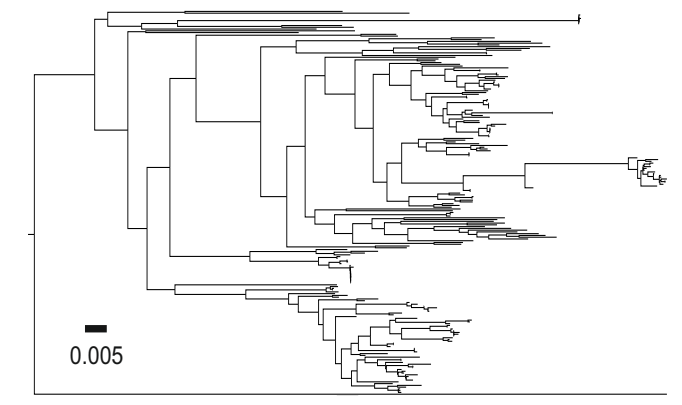

C. coli $(n=143)$

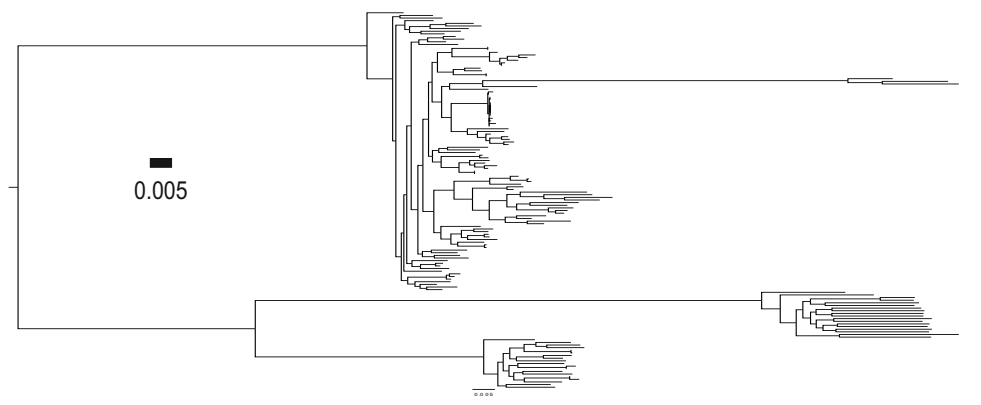

C. fetus $(n=52)$

C. lanienae $(\mathrm{n}=26)$

C. concisus $(\mathrm{n}=106)$
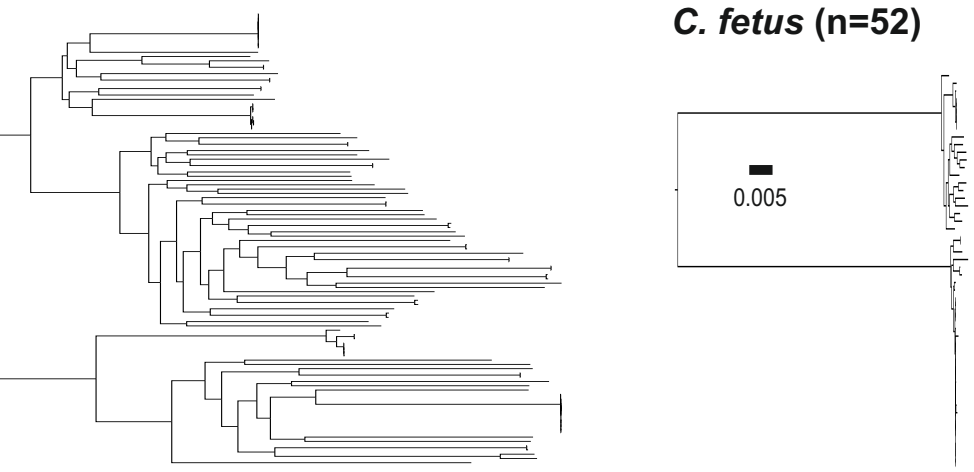

C. hyointestinalis $(n=16)$

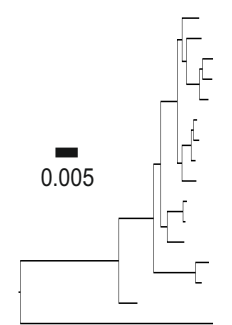

C. Iari $(n=13)$

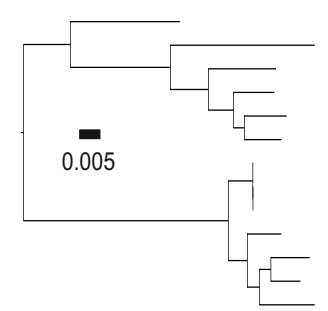

C. hepaticus $(\mathrm{n}=10)^{*}$

C. pinnipediorum $(n=9)$

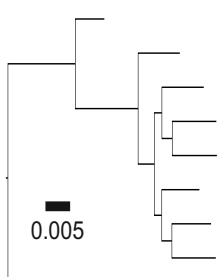




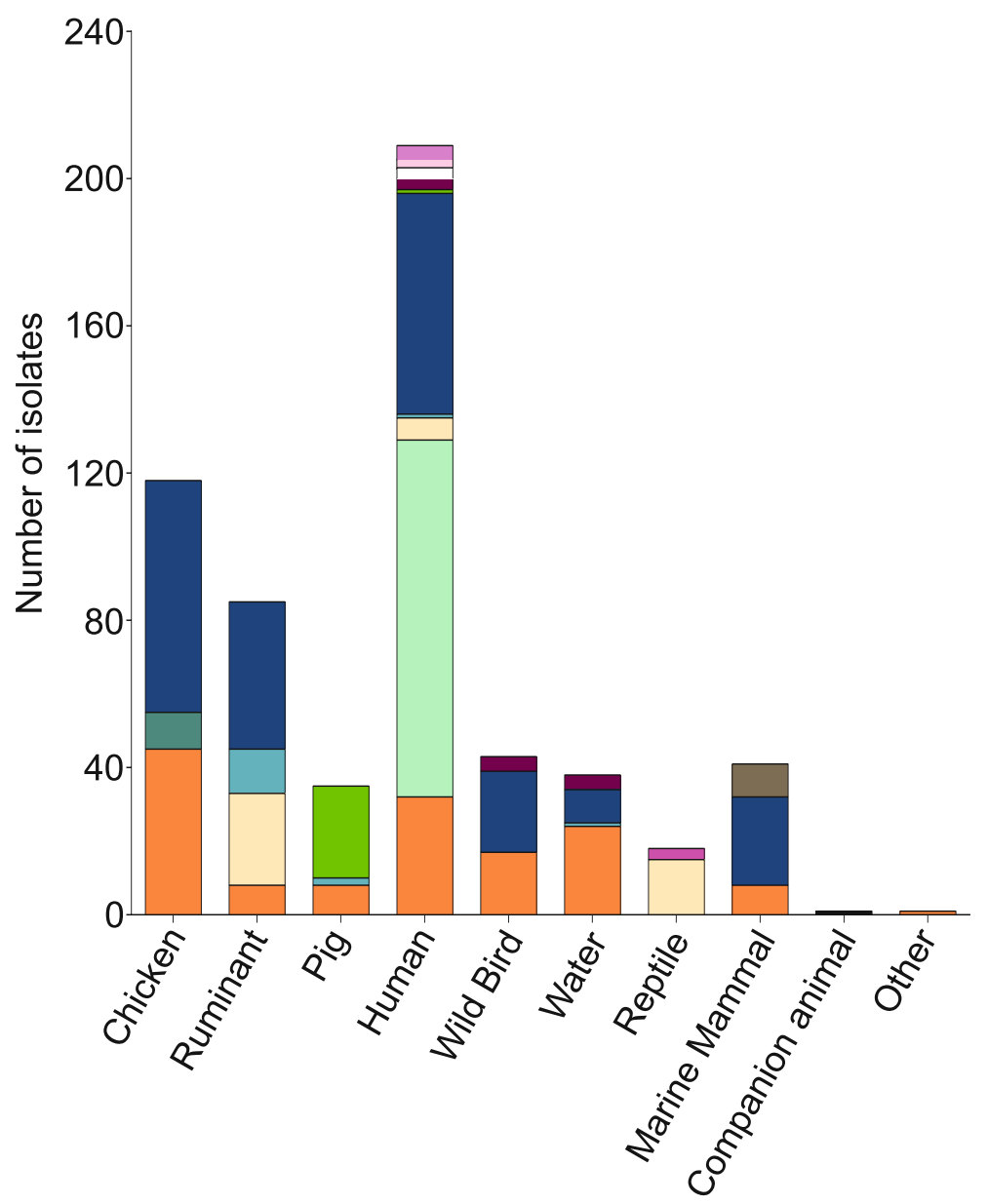

$$
\begin{aligned}
& \text { C. coli clade } 1(n=103) \\
& \text { C. coli clade } 2(n=19) \\
& \text { C. coli clade } 3(n=18) \\
& \text { C. jejuni }(n=218) \\
& \text { C. concisus }(n=106) \\
& \text { C. fetus }(n=52) \\
& \text { C. Ianienae }(n=26) \\
& \text { C. hepaticus }(n=10) \\
& \text { C. hyointestinalis }(n=16) \\
& \text { C. pinnipediorum }(n=9) \\
& \text { C. Iari }(n=13) \\
& \text { C. geochelonis }(n=3) \\
& \text { C. ureolyticus }(n=4) \\
& \text { C. upsaliensis }(n=3) \\
& \text { C. showae }(n=3) \\
& \text { C. subantarcticus }(n=3) \\
& \text { C. iguanorium }(n=3)
\end{aligned}
$$


C. jejuni

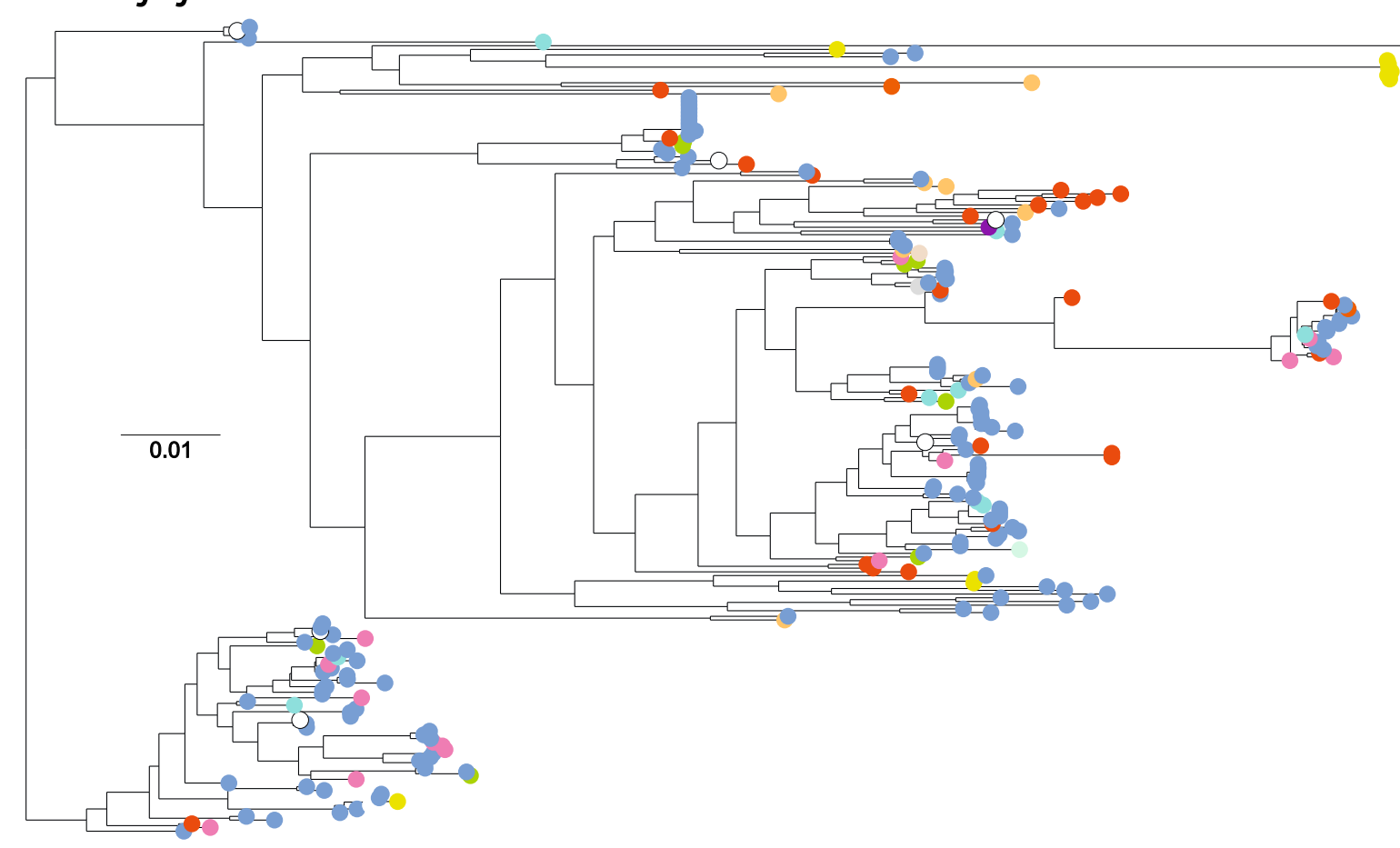

C. coli

C. fetus

0.011
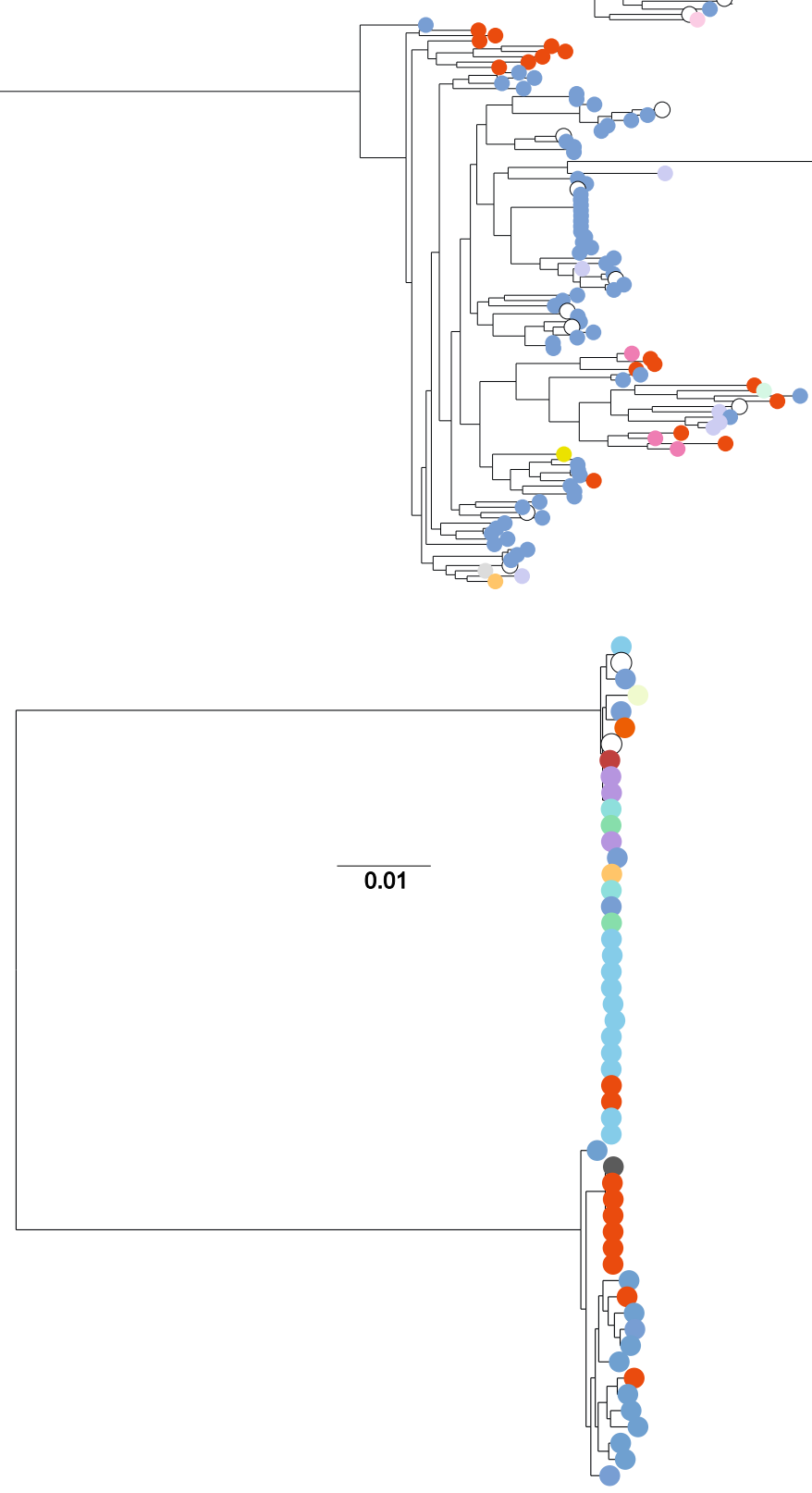

$\begin{array}{ll}\square \text { Argentina } & \square \text { Slovenia } \\ \square \text { Australia } & \square \text { South Africa } \\ \square \text { Belgium } & \text { South America } \\ \square \text { Bosnia } & \square \text { Spain } \\ \square \text { Canada } & \square \text { Sweden } \\ \square \text { Denmark } & \square \text { Switzerland } \\ \square \text { Finland } & \square \text { Taiwan } \\ \square \text { France } & \square \text { UK } \\ \square \text { India } & \square \text { Uruguay } \\ \square \text { Netherlands } & \square \text { USA } \\ \square \text { New Zealand } & \square \text { Unknown } \\ \square \text { Poland } & \end{array}$




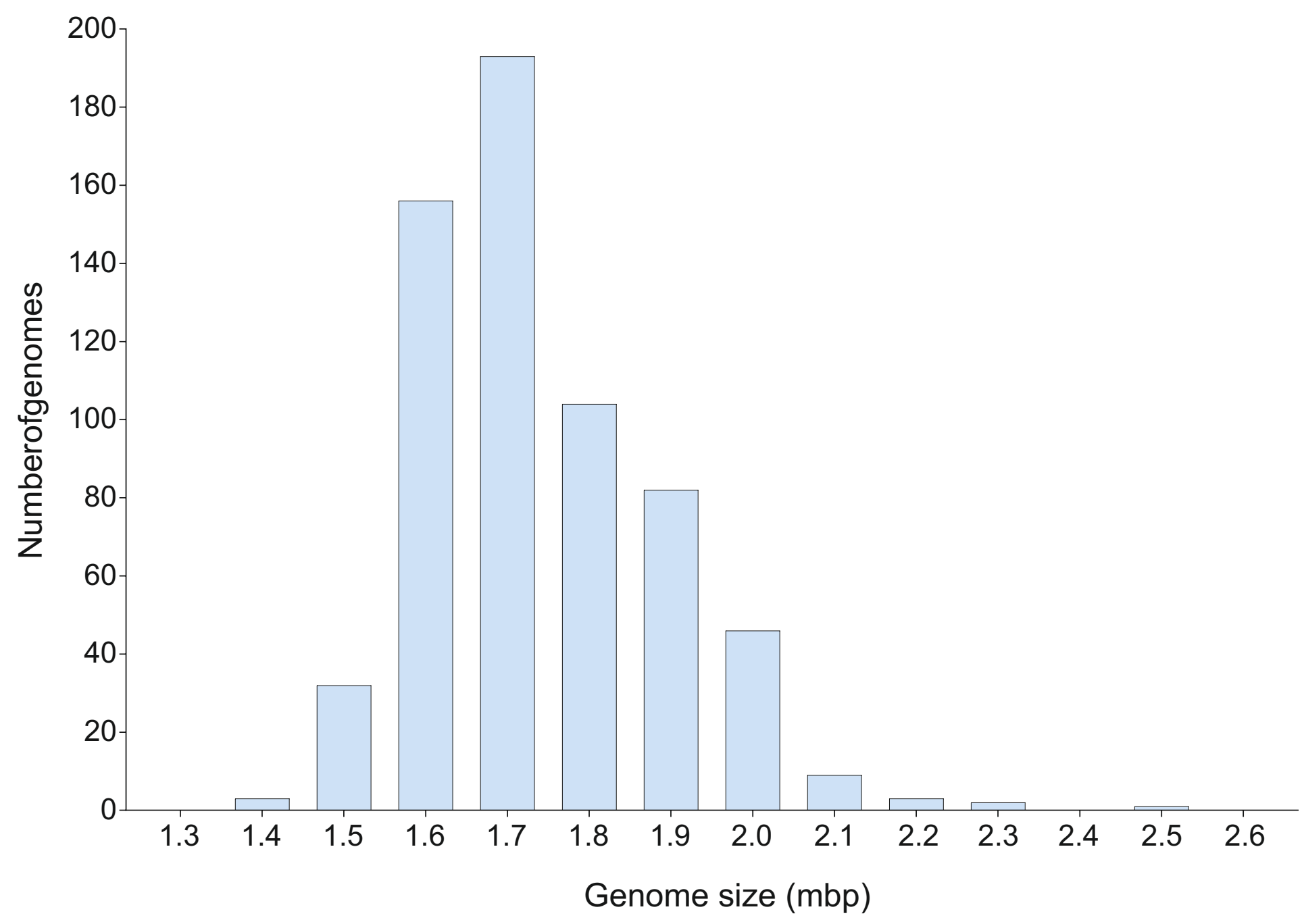




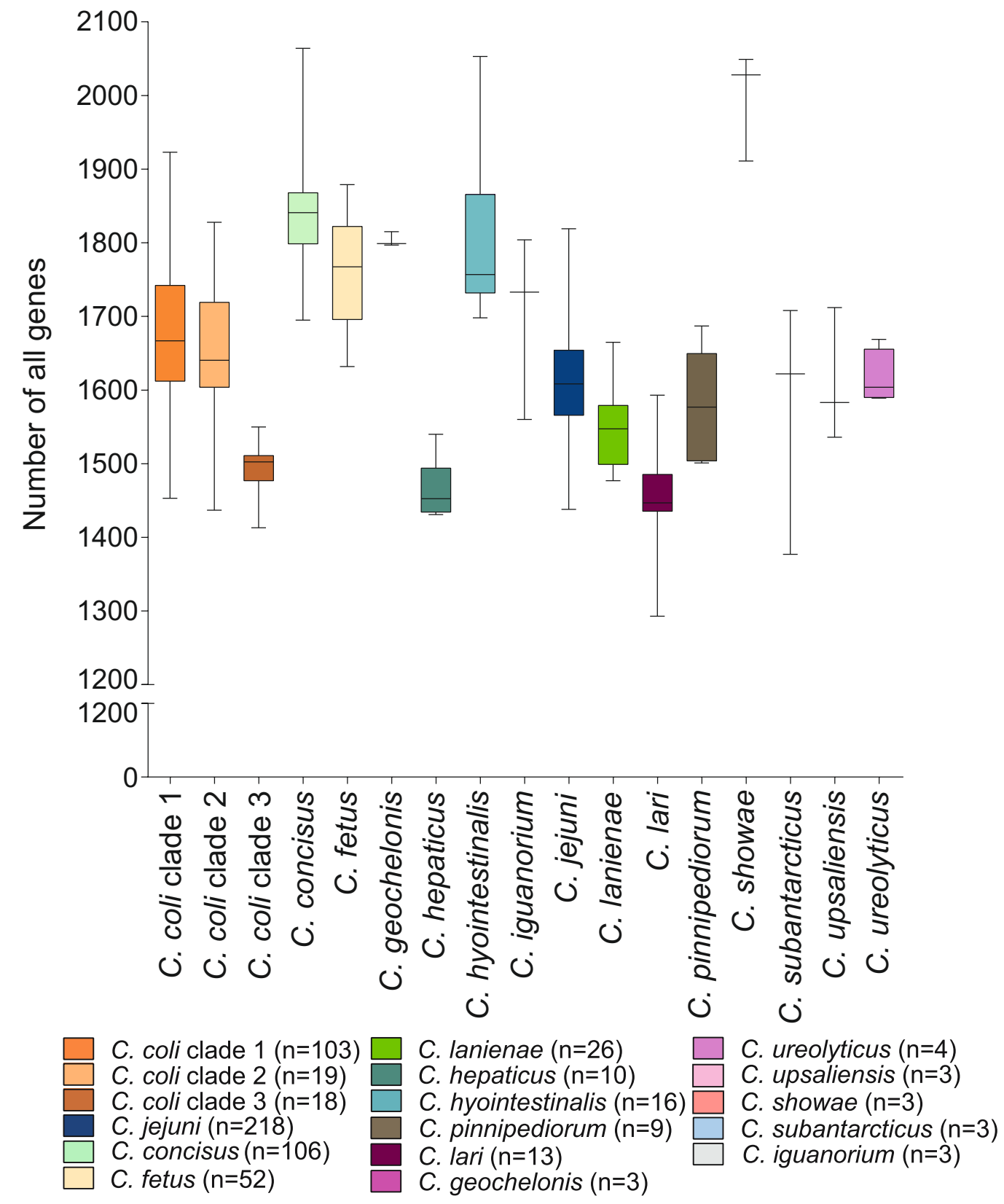




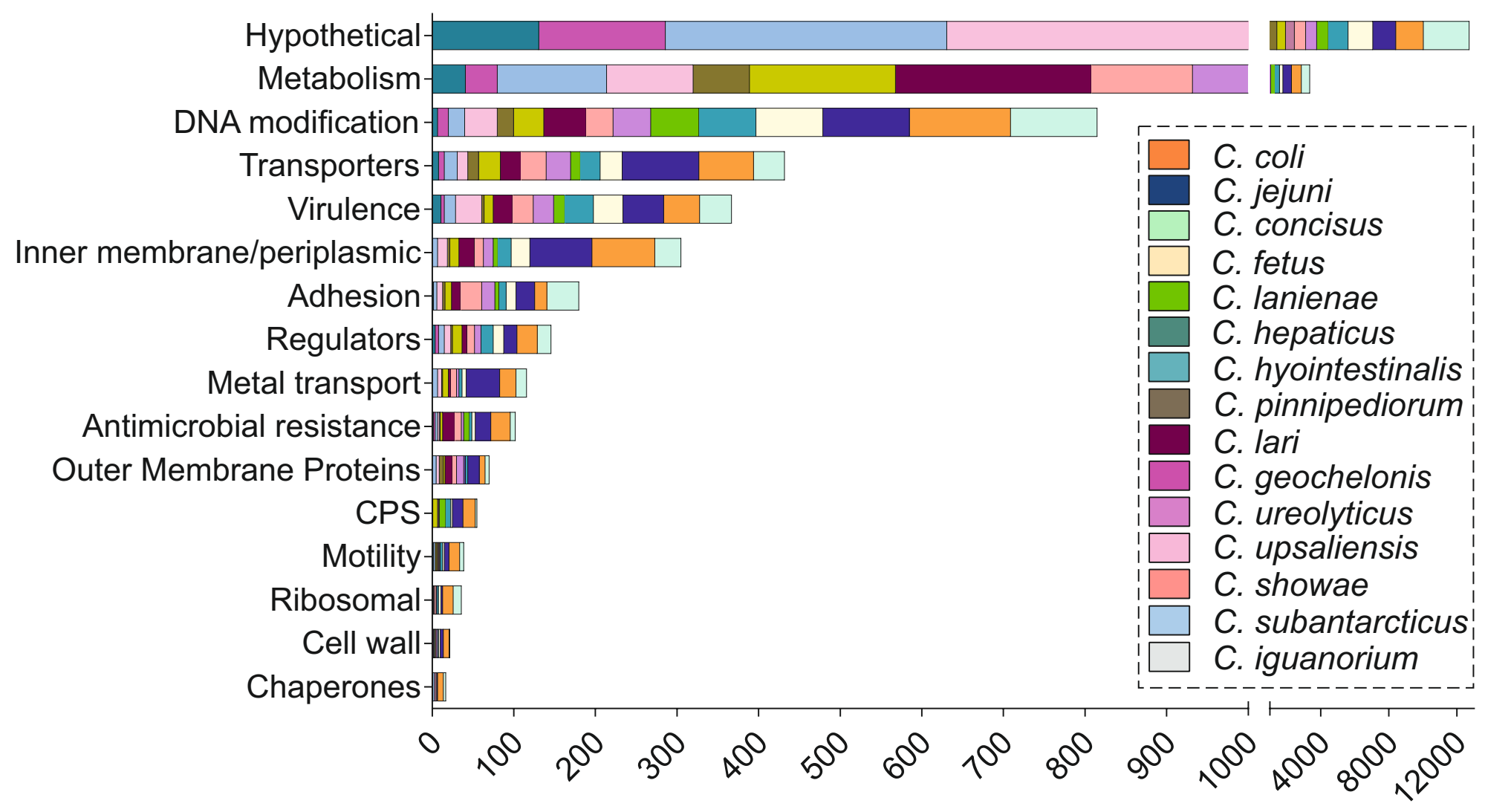

Accessory genes 
a

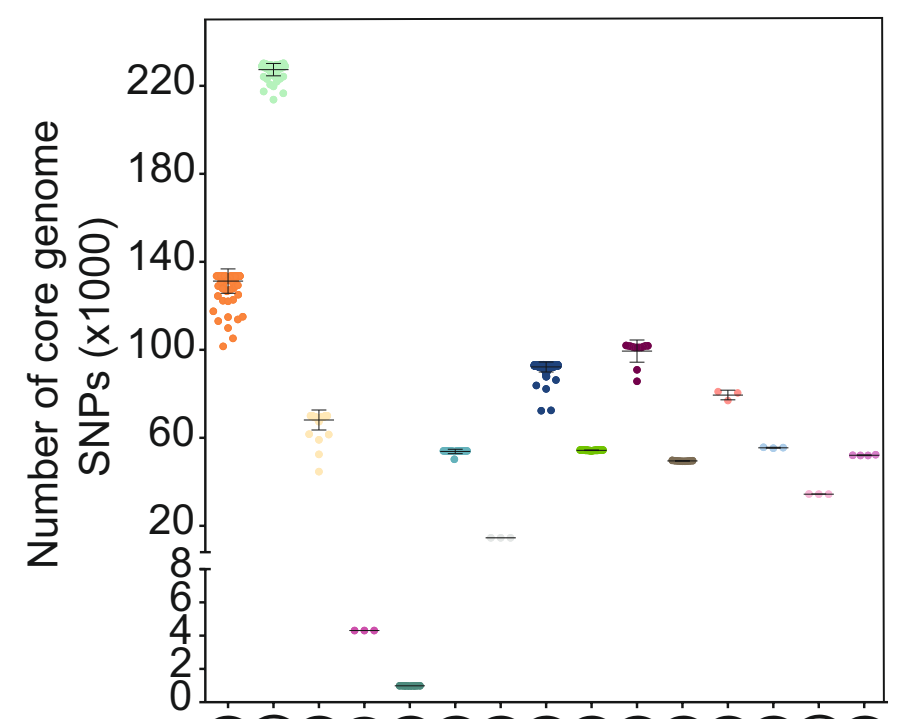

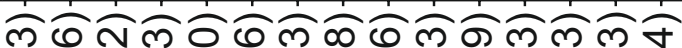

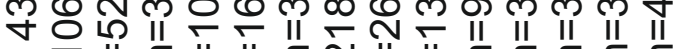
II II

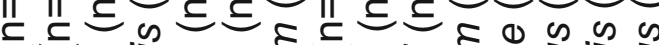

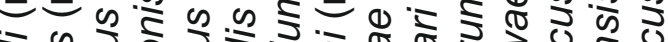

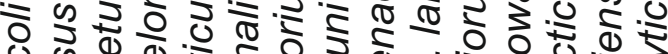
U.

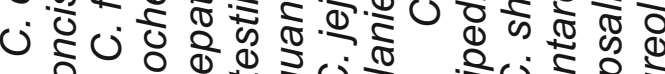

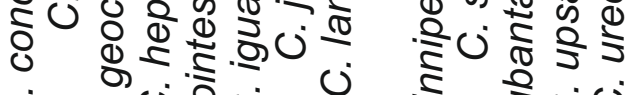

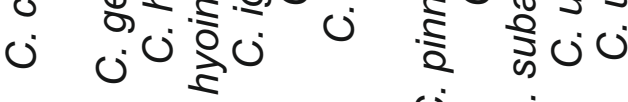
ن b

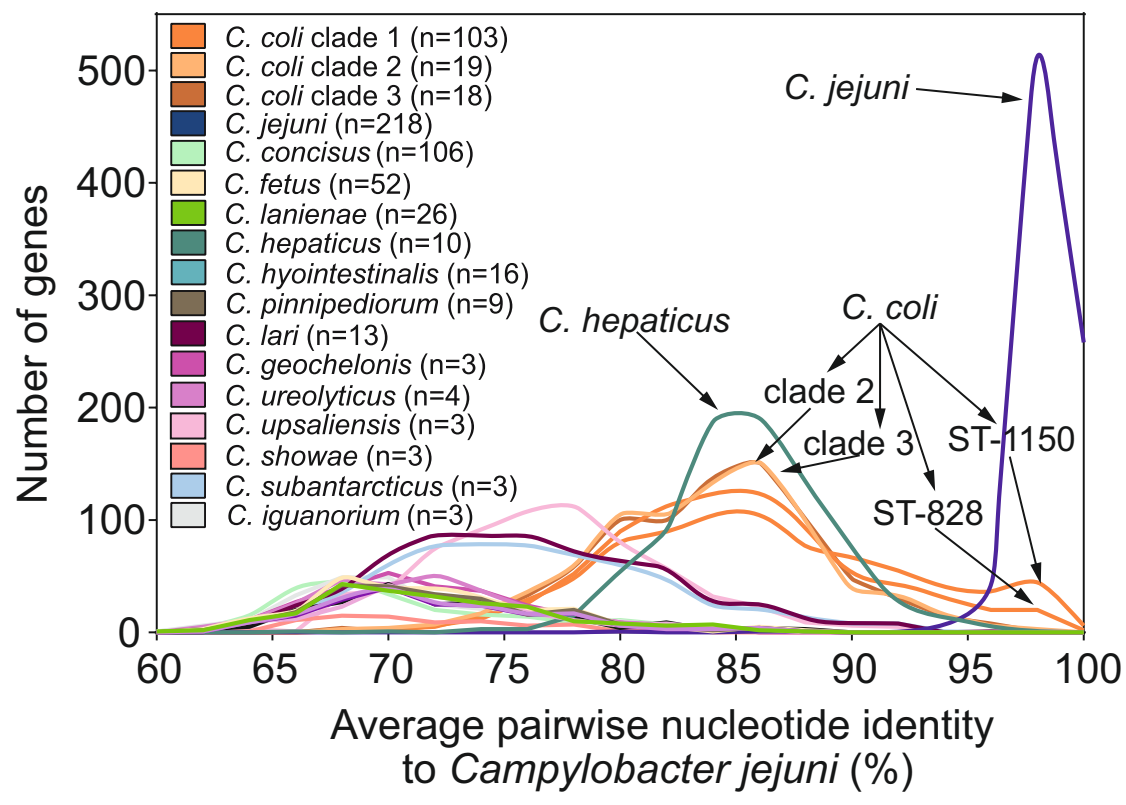




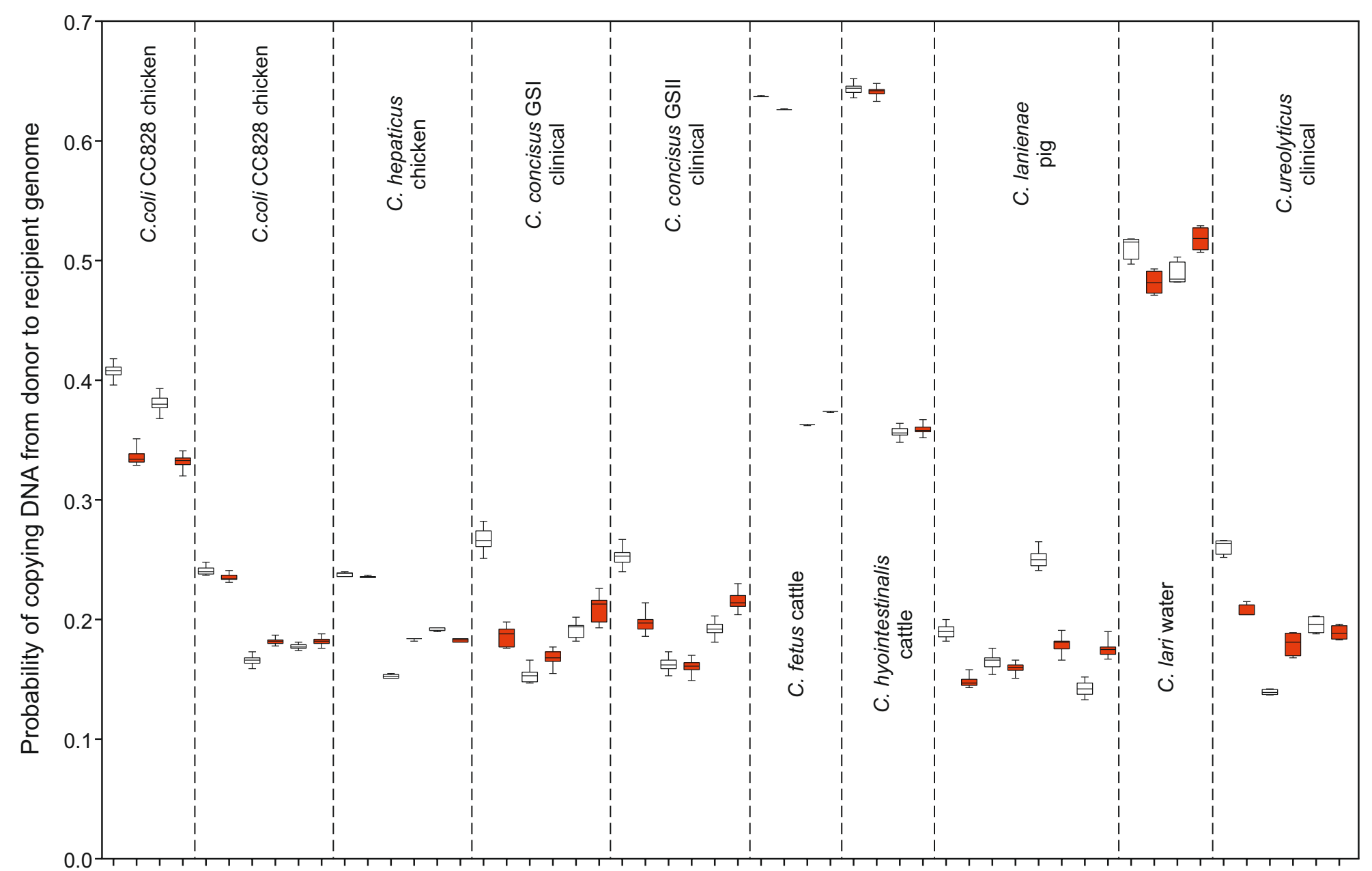

등 의 흫

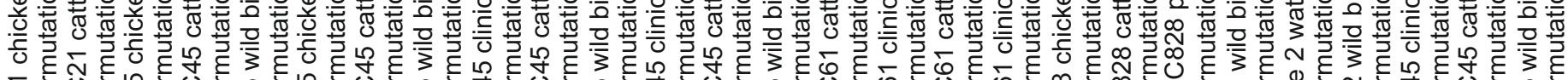

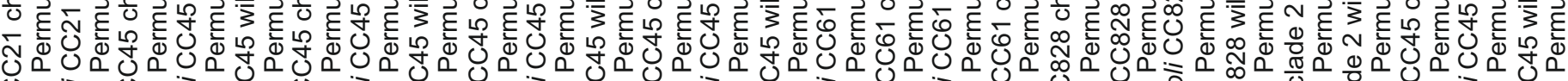

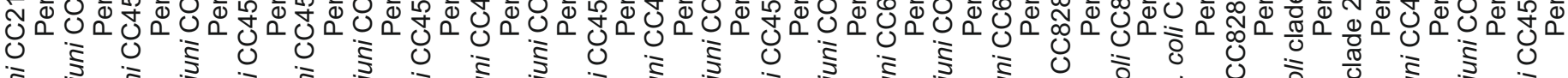

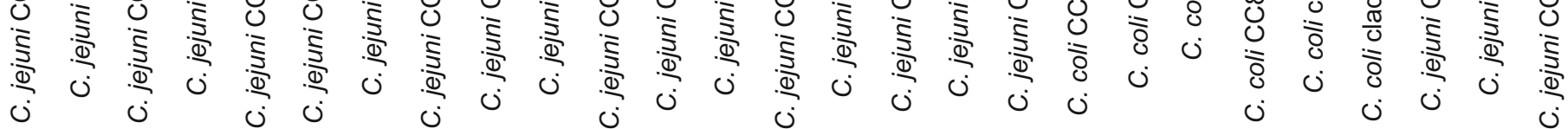




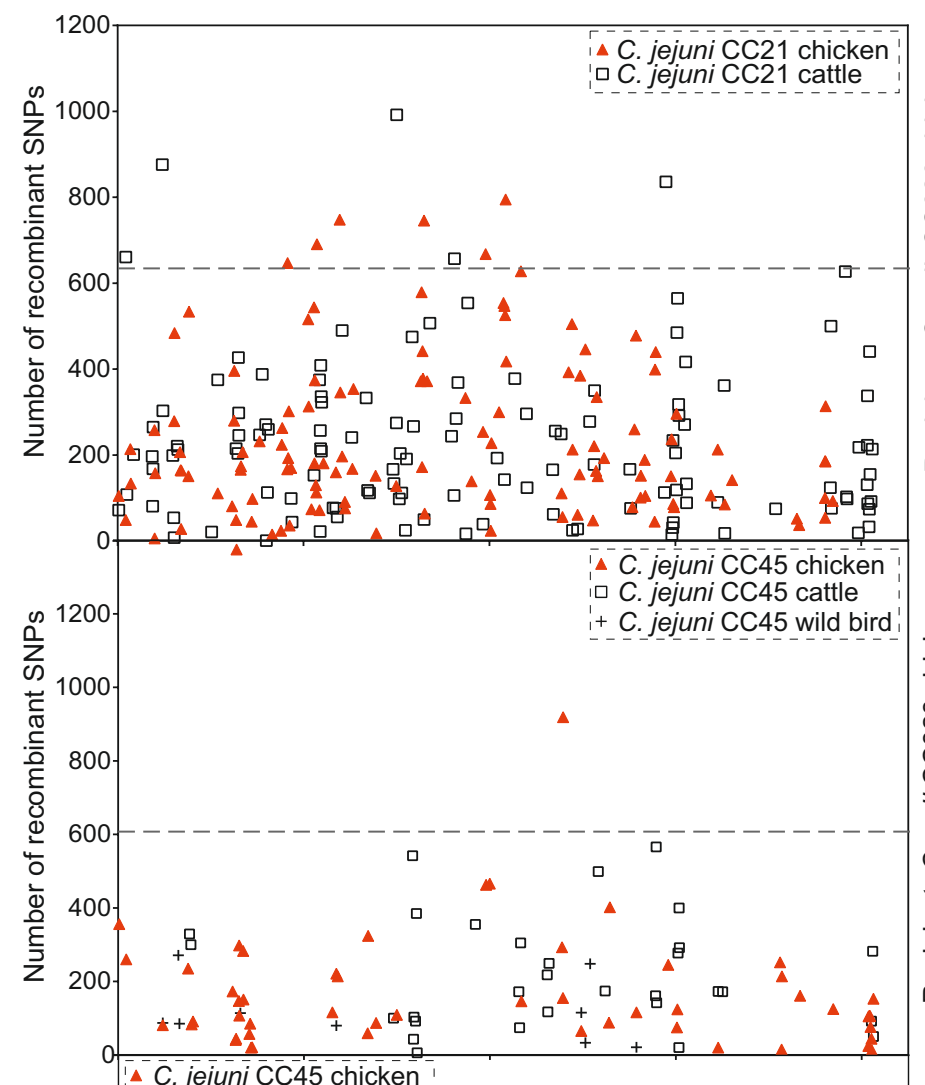

$700-1$, C. jejuni CC45 cattle

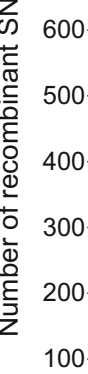

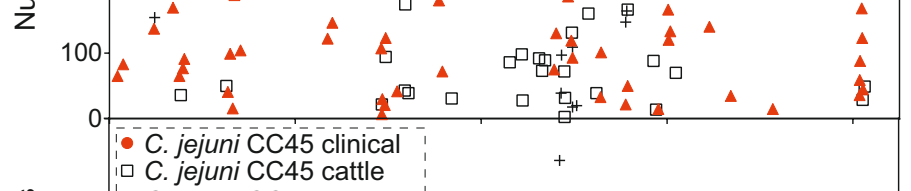

$\sum_{0}^{\infty} 500$ it C. jejuni CC45 wild bird

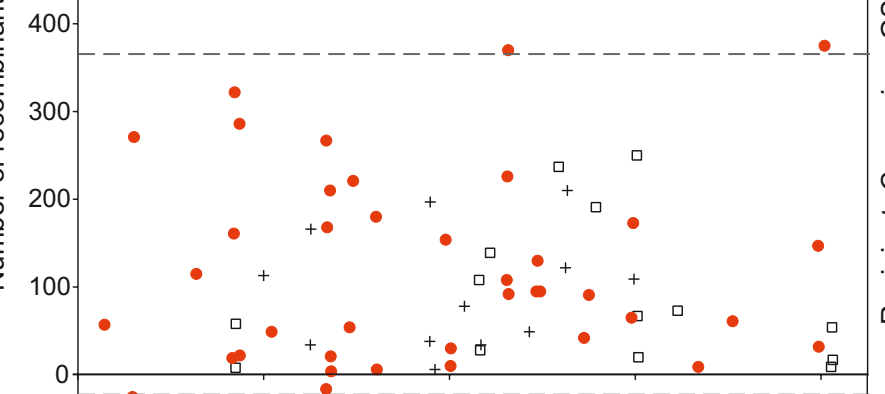

2

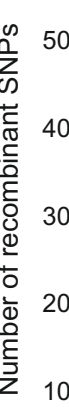

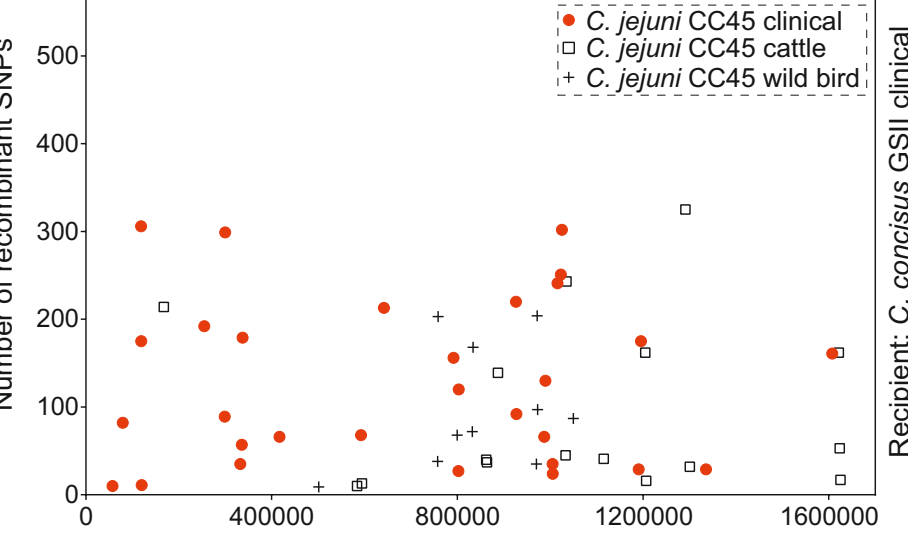

Genome position on 11168 reference genome

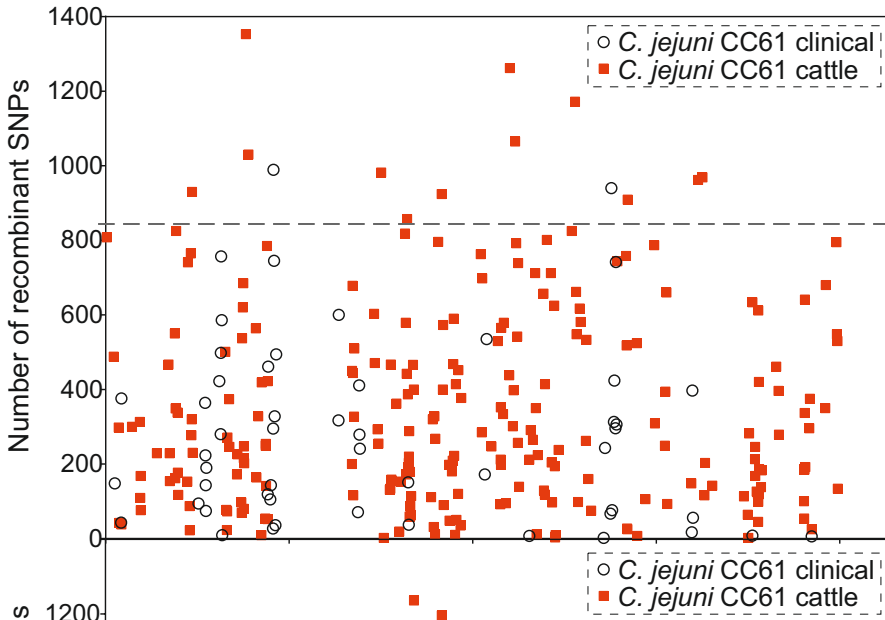

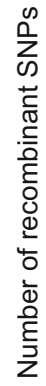
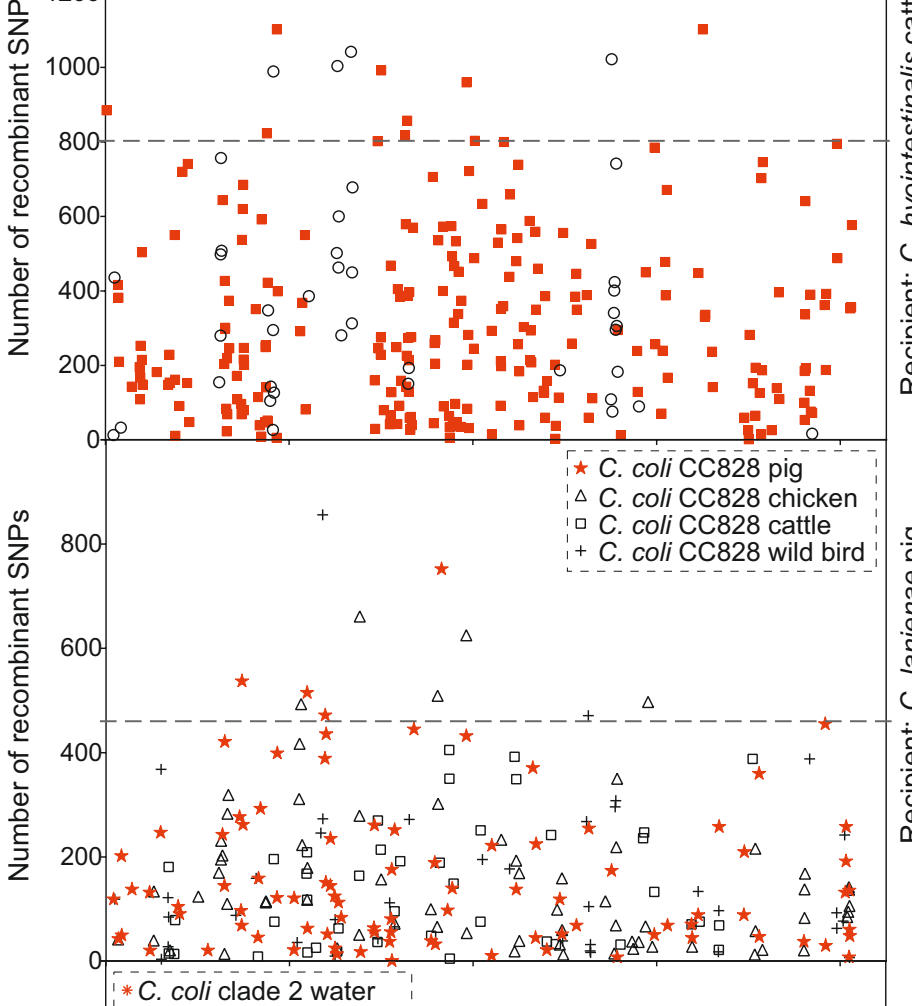

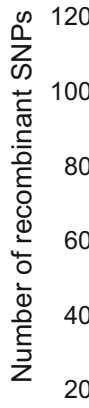
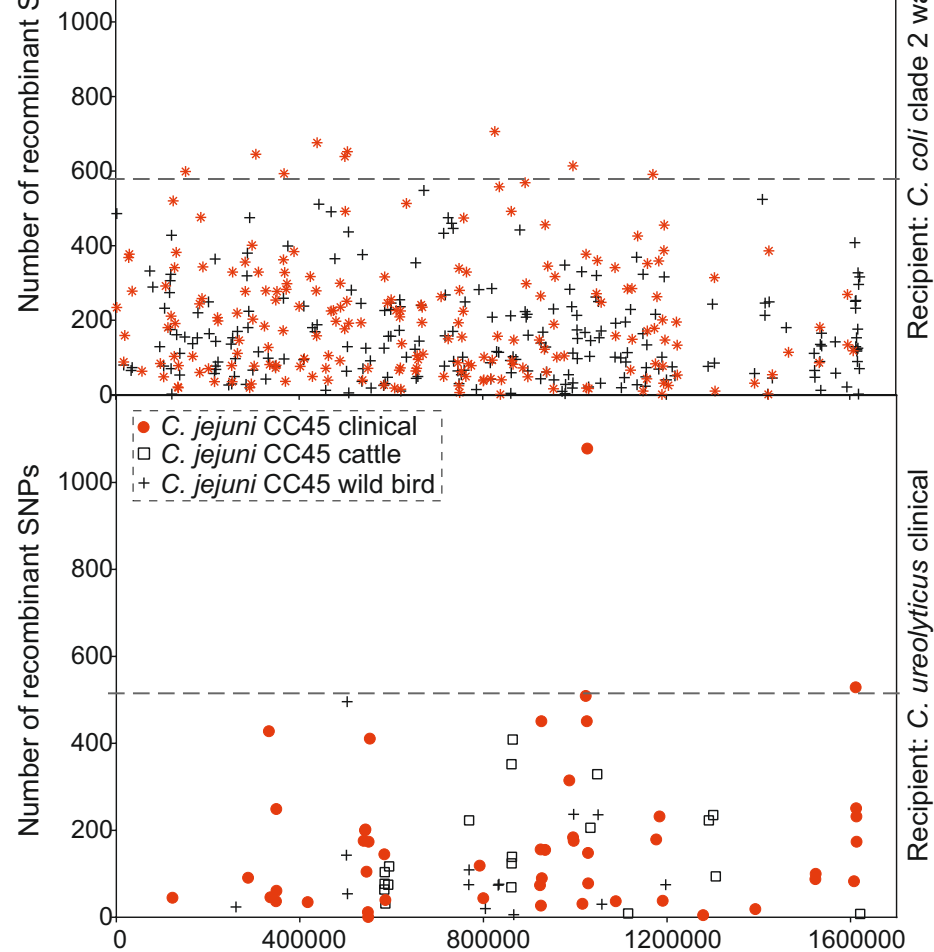

Genome position on 11168 reference genome 

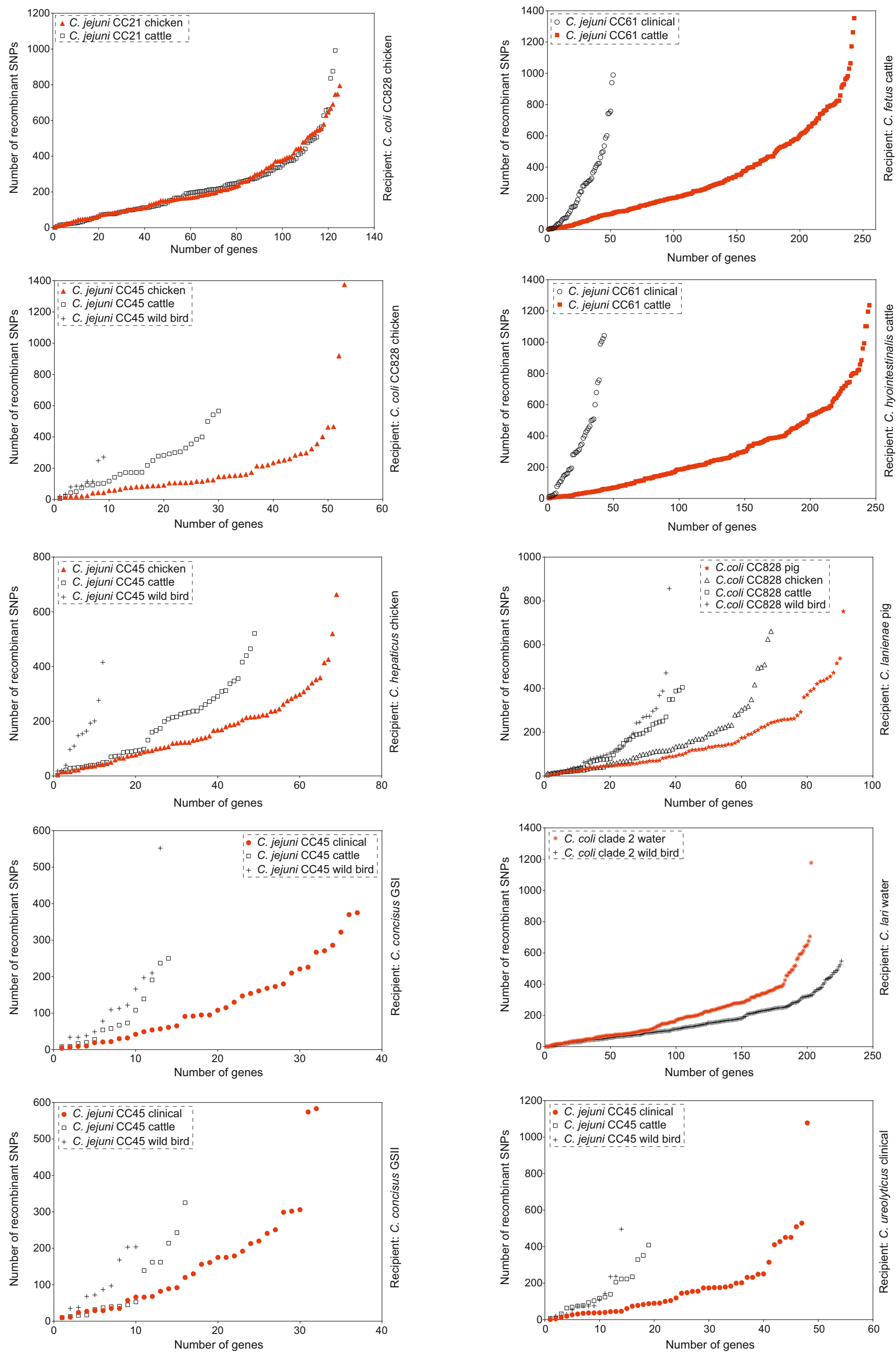


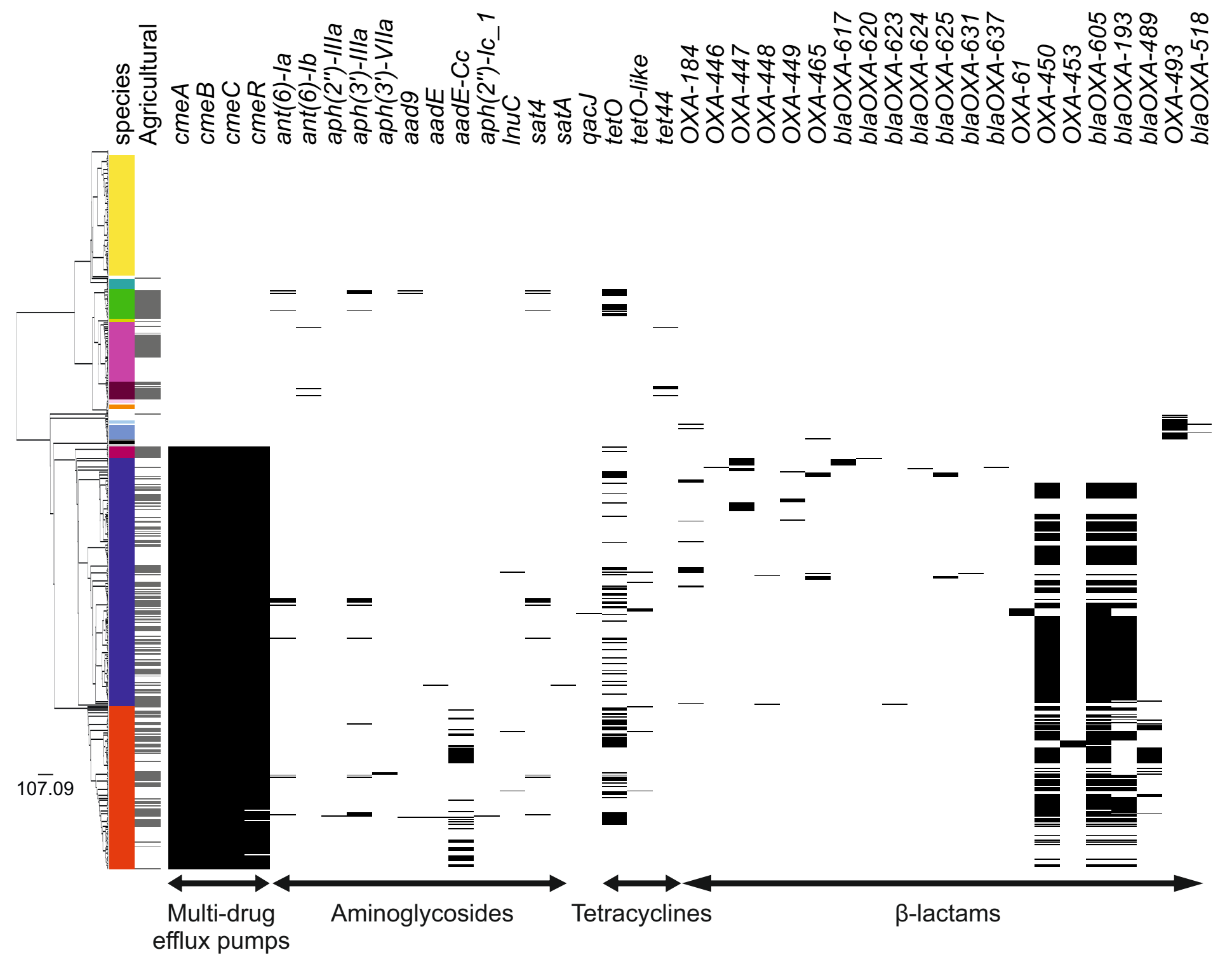




\section{C. jejuni}

Clinical (1)

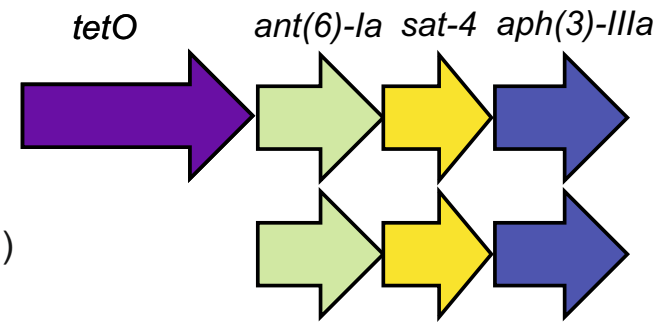

C. coli

Chicken (2) + Cattle (1)

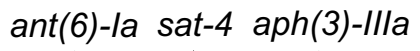

Water (1)

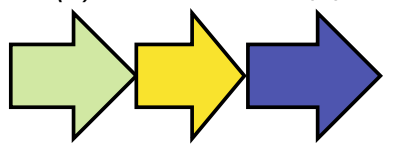

aad9 ant(6)-Ib tetO

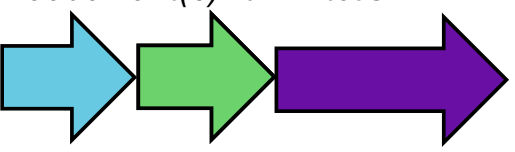

\section{C. lanienae}

Pig (2)

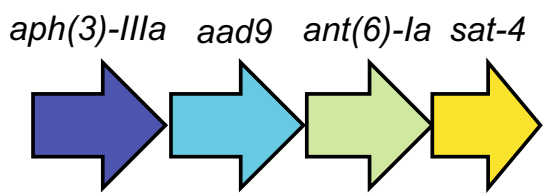

ant(6)-la sat-4 aph(3)-IIla

Pig (1)

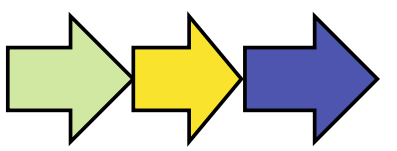

\section{C. hyointestinalis}

Cattle (1)

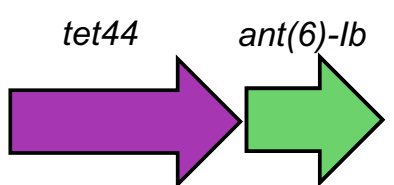

C. fetus subs fetus

Cattle (1)

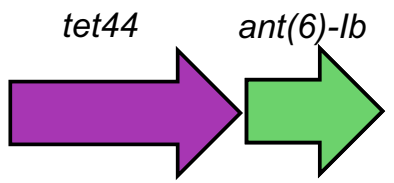

